\title{
Use of Four Predictive Screening Variables for Determination of Sacroiliac Joint Dysfunction in Adolescent Soccer Athletes
}

Brian Hanson

Follow this and additional works at: https://researchrepository.wvu.edu/etd

\section{Recommended Citation}

Hanson, Brian, "Use of Four Predictive Screening Variables for Determination of Sacroiliac Joint Dysfunction in Adolescent Soccer Athletes" (2018). Graduate Theses, Dissertations, and Problem Reports. 5759.

https://researchrepository.wvu.edu/etd/5759

This Thesis is protected by copyright and/or related rights. It has been brought to you by the The Research Repository @ WVU with permission from the rights-holder(s). You are free to use this Thesis in any way that is permitted by the copyright and related rights legislation that applies to your use. For other uses you must obtain permission from the rights-holder(s) directly, unless additional rights are indicated by a Creative Commons license in the record and/ or on the work itself. This Thesis has been accepted for inclusion in WVU Graduate Theses, Dissertations, and Problem Reports collection by an authorized administrator of The Research Repository @ WVU. For more information, please contact researchrepository@mail.wvu.edu. 
Use of Four Predictive Screening Variables for Determination of Sacroiliac Joint Dysfunction in Adolescent Soccer Athletes

\title{
Brian Hanson, ATC, CES
}

Thesis submitted to the College of Physical Activity and Sports Sciences

At West Virginia University

In partial fulfillment of the requirements for the degree of

Master of Science in

Athletic Training

\author{
Michelle A. Sandrey, PhD, ATC, Chair \\ Jean L. McCrory, PhD \\ Benjamin Moorehead, MD
}

Department of Sport Sciences

Morgantown, West Virginia

2018

Keywords: sacroiliac joint dysfunction, adolescent soccer athlete, functional movement screen, injury risk

Copyright 2018 Brian Hanson 


\begin{abstract}
Use of Four Predictive Screening Variables for Determination of Sacroiliac Joint Dysfunction in Adolescent Soccer Athletes
\end{abstract}

Brian Hanson, ATC, CES

Context: Chronic onset of sacroiliac joint dysfunction (SIJD) is increasing in adolescent athletic populations including soccer. However, there is currently no pre-season screening tool for SIJD in this population. There are variables that are currently associated with SIJD, however, it is unknown if these variables developed into a screening tool can accurately predict the risk of sustaining SIJD. Objective: The purpose of this study was to create an effective screening tool for SIJD in adolescent soccer athletes and establish predictive values for SIJD injury risk. Design: A retrospective exploratory study to screen for risk factors contributing to SIJD in the adolescent soccer athletes. Setting: The testing took place in an athletic training facility at a midAtlantic high school. Only one clinician administered the testing procedures. Patients or other participants: This study included members of the varsity and junior varsity boys' $(\mathrm{n}=6$, $16.33 \pm 1.37 \mathrm{yrs}, 176.50 \pm 6.98 \mathrm{~cm}, 72.12 \pm 9.92 \mathrm{~kg}$ ) and girls' $(\mathrm{n}=14,16.00 \pm 1.11 \mathrm{yrs}, 165.93 \pm 6.39$ $\mathrm{cm}, 61.11 \pm 6.92 \mathrm{~kg}$ ) soccer teams from one high school in north central West Virginia. All participants were members of these teams with a sports physical on file. Inclusion criteria included those subjects who are healthy, have no disorders affecting ability to perform any of the tests included in this study, no history of acute injury to the lower extremity or back in the past six months, and no history of surgeries to the core or back within the past year. Exclusion criteria included subjects who have a history of surgery to the core or back within the past year, and those who have a disorder affecting ability to perform any of the tests included in this study. Interventions: Each participant performed during one testing session the Functional Movement Screen (FMS), including all 7 functional movements and the 3 clearing tests, active knee extension test, Palpation Meter (PALM) measurement for pelvic angle, and goniometry assessment of active hip range of motion (flexion/extension/abduction/adduction /internal rotation/external rotation). Main outcome measures: The dependent variables that were measured are the final composite score of the FMS, angle measurement in degrees from the active knee extension test, pelvic tilt angle in degrees from the PALM, and angle measurement in degrees for active hip flexion, extension, abduction, adduction, internal rotation, and external rotation. Results: A significant correlation with large strength $(\mathrm{PCC}=0.545, \mathrm{p}=.013)$ was found between SIJ injury and active hip abduction. A significant correlation with large strength $(\mathrm{PCC}=0.732$, $\mathrm{p}<.01$ ) was found between the PALM and active hip extension. A significant correlation with medium strength $(\mathrm{PCC}=0.473, \mathrm{p}=.035)$ was found between the AKET and active hip flexion. One model in the binary logistic regression created a best fit with an odds ratio of $1.115\left(\mathrm{CI}_{95}=\right.$ $1.003,1.239, \mathrm{p}=.044)$ with the variables of SIJ injury and active hip abduction. Two nonsignificant models with moderate odds ratios were produced for the PALM (OR $=1.141$, $\left.\mathrm{CI}_{95}=.841,1.547, \mathrm{p}=.397\right)$ and years playing soccer $\left(\mathrm{OR}=1.319, \mathrm{CI}_{95}=.854,2.036, \mathrm{p}=.212\right)$. A stepwise binary logistic regression created a best fit model with an odds ratio of $1.168\left(\mathrm{CI}_{95}=\right.$ $1.004,1.359, \mathrm{p}=.045$ ) that included both active hip abduction and the FMS to detect and SIJ injury. Conclusion: The results from this study indicate that active hip abduction will significantly predict an SIJ injury. Years of playing soccer, the FMS, and pelvic positioning may also be clinically useful assessments to predict an SIJ injury. 


\section{ACKNOWLEDGEMENTS}

I would like to start by thanking my parents, Steve and Marilu. They have provided me with endless support and discipline throughout my entire academic career. If it weren't for them and the countless opportunities they provided me I would not be where I am today.

I would like to thank my two older sisters, Jackie and Stephanie. They have always been the perfect role models, not only as students, but by showing me what it takes to be a good person. The high level of success they have achieved in life continues to fuel my ambition to make myself a better person and for that I am forever grateful.

I would like to thank the rest of my family. It has been tough living away from all of you for the first time and in a new state for the past two years, but your support has been unwavering.

I would like to thank my friends, both the new ones made here, and the ones still back home. You all have kept me feeling sane while balancing the rigors of graduate school and work. Thanks to those who blew away any expectations and came to visit me in the mountains.

Thank you to my committee members, Dr. Benjamin Moorehead and Dr. Jean McCrory. I am very appreciative of the time and effort you have put into this process.

A giant thanks to my committee chair and graduate advisor, Dr. Michelle Sandrey. You certainly pushed me beyond my previous limits in the realm of research and writing. The amount of time spent reading my drafts, making suggestions, and meeting with me did not go unnoticed. Thank you for all the challenges provided both inside and outside the classroom.

To my clinical supervisor at HealthWorks, Mike Casselman, it has been the utmost pleasure to serve under you for the past two years. Your guidance and expertise has assisted me to improve as a clinician. Best of luck with your new job and all future endeavors.

To my athletic director, Jeff Bailey. Thanks for being the world's best AD, you have certainly made my job easy.

To my soccer coaches, Graham Peace, Kat Devlin, and Dustin Talton at University High School. You all have been a pleasure to work with and helped with my transition as a newly certified athletic trainer. I appreciate the trust you had in me from day one to always give the best care to our student athletes.

To my subjects/athletes. You all have kept me on my toes and kept me feeling young these past two seasons. Thank you for all the laughs and success on the field.

Lastly, I want to thank everyone else I did not mention that has helped me get to this point. I am incredibly appreciative of the impact everyone has made on my life. 


\section{TABLE OF CONTENTS}

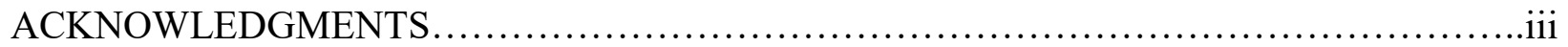

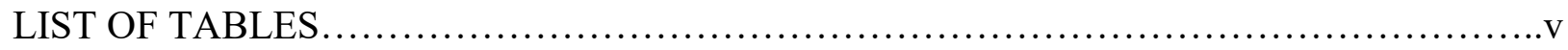

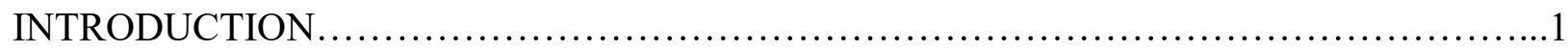

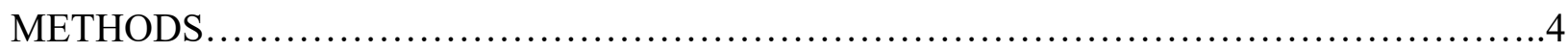

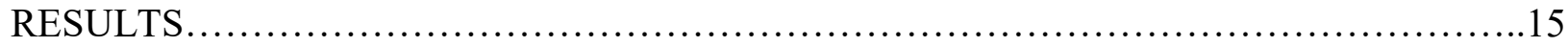

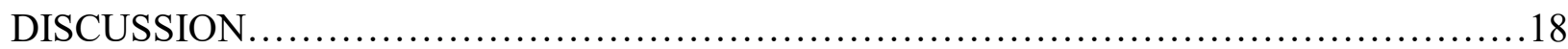

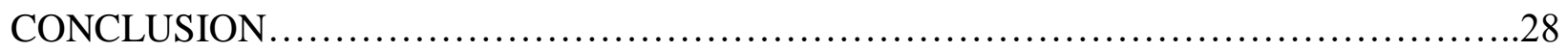

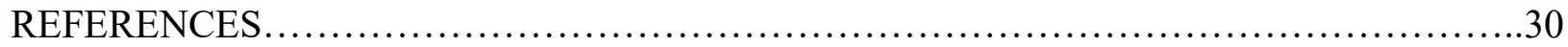

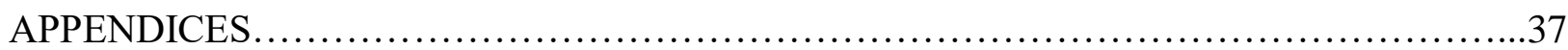

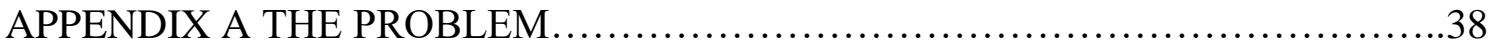

APPENDIX B LITERATURE REVIEW ....................................47

APPENDIX C ADDITIONAL METHODS .......................................72

APPENDIX D ADDITIONAL RESULTS ........................................106

APPENDIX E RECOMMENDATIONS FOR FUTURE RESEARCH...............110

ADDITIONAL REFERENCES...................................................... 111 


\section{LIST OF TABLES}

TABLE B1. Ligamentous/Fascia Support Structures of the Sacrum.........................49

TABLE B2. Muscle Origin/Insertion/Action/Innervation Surrounding the SIJ.................51

TABLE B3. Measurement Techniques for Hamstring Length/Extensibility ....................64

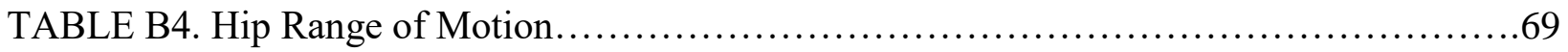

TABLE C1. Informed Parental or Guardian Consent..................................... 72

TABLE C2. Informed Assent........................................................... 78

TABLE C3. Informed Consent 18 Years or Older.......................................... 82

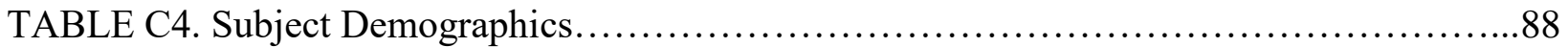

TABLE C5. Verbal Instructions for Functional Movement Screen.............................89

TABLE C6. Functional Movement Screen Scoring Procedures.................................93

TABLE C7. Active Knee Extension Test..................................................97

TABLE C8. Pelvic Positioning............................................................... 98

TABLE C9. Hip Range of Motion - Goniometer..................................... 100

TABLE C10. Functional Movement Screen Scoring Sheet................................. 104

TABLE C11. Data Collection Sheet........................................................ 105

TABLE D1. Descriptive Statistics (Means \pm SD) for Subject Demographics...................106

TABLE D2. Descriptive Statistics (Means \pm SD) for All Screening Variables.....................106

TABLE D3. Descriptive Statistics (Means \pm SD) for Subject Demographics and SIJ Injury....107

TABLE D4. Descriptive Statistics on Means and SD for Screening Variables and SIJ Injury...107

TABLE D5. Pearson Product Correlations of Demographic Data to SIJ Injury................107

TABLE D6. Pearson Product Correlations of Predictive Variables to SIJ Injury.................108

TABLE D7. Crosstab of Lower Extremity (DS, IL, HS) Movements from the FMS............108 


\section{LIST OF TABLES}

TABLE D8. Binary Logistic Regression Model for Screening Variables Associated with the

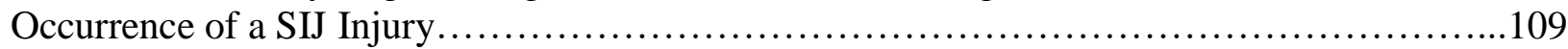

TABLE D9. Stepwise Binary Logistic Regression Model for Screening Variables Associated

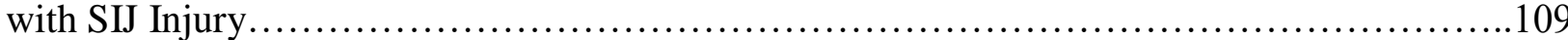




\section{INTRODUCTION}

Low back pain (LBP) has been shown to affect up to $80 \%$ of the general population at some point in their lifetime. ${ }^{1,2}$ Although LBP is a main symptom, sacroiliac joint dysfunction (SIJD) often clinically presents with LBP, thus leading to the conclusion that LBP can be caused by various injuries. Specifically, amongst the adolescent population, prevalence of LBP has reported to range from $30 \%$ to $74 \% .{ }^{3,4}$ Low back pain, which can be caused by SIJD, was found to increase with age amongst the adolescent population. Increases in LBP are evident starting with $1 \%$ at seven years of age, to $17 \%$ at twelve years of age, and climbs to $53 \%$ at 15 years of age. ${ }^{5}$ Further, prevalence amongst adolescents with SIJD pain has been reported to range from $13 \%$ to $30 \%$ of all injuries with LBP as a symptom. ${ }^{6,7}$

Historically SIJD has been seen in young athletes who have sustained some form of mild trauma, however, more athletes now are experiencing a chronic onset. ${ }^{8}$ SIJD is commonly seen in sports with unilateral and repetitive biomechanical forces, such as kicking in soccer. Although there is little research on specifically SIJD, there is an apparent link between LBP and SIJD resulting in play time loss for athletes, specifically soccer. In one study, ${ }^{9} \mathrm{LBP}$ was found to be the most prevalent previous overuse injury with an incidence of $28 \%$ among soccer players. At least $60.6 \%$ of soccer players $(\mathrm{n}=190)$ were found to have experienced LBP in their lifetime, and $56.9 \%$ felt it in the previous 12 months, resulting in $27.7 \%$ missing training from injury. ${ }^{10}$ Another study ${ }^{11}$ reported 54.4\% of futsal players experiencing LBP in their lifetime, and 25.7\% had absence from training sessions due to LBP.

The nature of soccer places high intensity forces on the lower extremities that are often unilaterally dominant. These forces are transferred superiorly to the trunk through the sacrum and SIJ acting as the gateway. The biomechanical demands of playing soccer, including bending 
and twisting of the trunk and variable lateral movement are a reason for SIJD to occur at such a high rate. ${ }^{11,12}$ With consideration of the biomechanics and prevalence of SIJ in soccer athletes, a screening tool should be created to evaluate potential risk factors. Four different components that have the potential to biomechanically evaluate SIJD prevalence are the Functional Movement Screen (FMS), pelvic positioning, hamstring length, and hip range of motion (ROM).

The FMS is a preexisting screening tool that investigates seven fundamental movement patterns (deep squat, hurdle step, active straight leg raise (ASLR), rotary stability, inline lunge, shoulder mobility, and trunk stability push up). Currently there is little research available on whether the FMS subtests correlate with predicting SIJD. Only one study ${ }^{13}$ was conducted comparing FMS with chronic LBP patients to healthy controls. The authors ${ }^{13}$ reported that the chronic LBP patients scored significantly lower on the deep squat, hurdle step, ASLR, and rotary stability compared to the healthy controls. The results of this study indicate that those four tests of the FMS could contribute to accurately predicting SIJD.

The movement of the innominates in both static and dynamic positions directly affects the movement of the sacrum, and potentially the motion that occurs at the SIJ. Malalignment of the innominates has the potential to negatively impact the SIJ. Pelvic asymmetry has been shown to contribute to altered lower extremity mechanics and contribute to SIJD in the frontal and sagittal planes. ${ }^{14}$ Athletes who participated in a sport with lateral movements, much like a goalkeeper or defender in soccer, would over time develop pelvic asymmetry problems leading to an increased incidence in back pain. ${ }^{15}$

Hamstring tightness in individuals with LBP could be a compensatory mechanism to weak gluteal muscles, which in turn decrease the compression stability mechanism of the SIJ. ${ }^{16-}$ ${ }^{19}$ Subjects with SIJD had significantly shorter hamstring muscle length in individuals with 
gluteal weakness compared to those who did not have gluteal weakness. ${ }^{20}$ In soccer players a natural hip adaptation may occur resulting in unilateral hip ROM deficits from a repetitive kicking motion. Hip ROM is well cited in the literature in contributing to SIJ motion. ${ }^{15,21,22}$ Hip rotation was a strong predictor for innominate angle, which in turn affects the motion occurring at the SIJ. ${ }^{23}$ The link between hip internal and external rotation and SIJD was also evaluated. Individuals with LBP including some with designated SIJ pain demonstrated a hip asymmetry of decreased internal rotation on the affected side compared bilaterally to the unaffected side with patients who had specific SIJ pain. ${ }^{21}$ Using a control group design, subjects with non-specific low back pain were compared to healthy controls to analyze hip rotation and extension. There was a difference in hip extension where the controls had greater hip extension then those with LBP. $^{22}$

There is a plethora of knowledge on the SIJ in terms of anatomy, biomechanics, treatment, and rehabilitation. There is also a great deal of research on SIJD and LBP in athletes in the adult population across a wide span of sports. Conversely, there is a lack of knowledge on SIJD in adolescent athletes. Pain caused by SIJD historically has been more prominent in the adult population, however it has become increasingly prevalent in the adolescent population for reasons that are not well understood. ${ }^{2}$ With the increase of SIJD incidence in the adolescent population, some type of screening tool must be developed to assess predictive factors of SIJD, especially in soccer athletes. Currently there is no constructed clinical screening tool to assess predictive factors for SIJD in the adolescent soccer athlete population. With no known screening tool available, four different biomechanical and functional components that should be considered are the Functional Movement Screen (FMS), pelvic positioning, hamstring length, and hip ROM. 
Thus, the purpose of this study was to create an effective screening tool for SIJD in adolescent soccer athletes and establish predictive values for SIJD injury risk.

\section{METHODS}

Design

This study was a retrospective exploratory screening study to determine SIJD risk in adolescent soccer athletes. The independent variable was whether the athlete sustained a SIJ injury over the course of the past season. The dependent variables were the composite score of the FMS, the angle taken from the active knee extension test, pelvic angle measurement of both innominates, and goniometric angle hip range of motion measurements (flexion, extension, abduction, adduction, internal rotation, external rotation). These dependent variables were evaluated to predict potential SIJD injury risk.

Subjects

This study included members of the varsity and junior varsity boys' and girls' soccer teams from a high school in north central West Virginia. Twenty subjects (14 females, 6 males, $16.10 \pm 1.17 \mathrm{yrs}, 169.1 \pm 8.09 \mathrm{~cm}, 64.41 \pm 9.25 \mathrm{~kg}$ ) were recruited and completed all procedures of this study. Inclusion criteria included those subjects who are healthy, have no disorders affecting ability to perform any of the tests included in this study, no history of acute injury, other than a SIJD, to the lower extremity or back in the past six months, and no history of surgeries to the core or back within the past year. The subject had a sport physical on file and were currently a member of either the boys' or girls' soccer team at one high school during this past sports season. Exclusion criteria included subjects who have a history of surgery to the core or back within the past year, and those who have a disorder affecting ability to perform any of the tests 
included in this study. This study was approved by the Institution's Office of Research Compliance.

Instruments

Functional Movement Screen (FMS): The FMS was developed by Cook in an effort to connect pre-participation medical screening and performance testing. ${ }^{24-28}$ This screening was created in attempt to detect deficiencies by incorporating the mobility of the kinetic chain and stability necessary for performance. Although inconclusive results on the validity of the FMS to screen or detect movement deficiencies was evident, the procedures reproduced with consistency was apparent. ${ }^{28-33}$ Intra-rater reliability has been reported to range from ICC $=0.74$ to $0.99 .{ }^{33}$ Thus, clinicians frequently use the FMS as a screening tool and despite not being the original intent of the FMS, professionals in the field of exercise, sport performance, and sport medicine use the FMS to analyze the movement capabilities of athletes and those who are at risk for injury. This interpretation of the FMS has been heavily investigated and the results show that athletes who score 14 or less points on the FMS are at an increased risk for injury. ${ }^{34-39}$ While a lot of research exists on collegiate aged athletes, there is little research that exists investigating the use of the FMS as an injury prediction tool on adolescent soccer athletes.

Active knee extension test: Hamstring length measures the dynamic lengthening ability of the hamstring muscle group as the origin rests in a fixed position while the distal portion is in movement. It has been determined that the active knee extension test provides the best objective measurement of hamstring length due to the ease of measurement and excellent reliability of the test. ${ }^{40-43}$ An average range of motion for this test in normal healthy adults was shown to have a deficit of full extension of $35.6+/-10.4^{\circ}$ for men, and $27.1+/-13.5^{\circ}$ for women. ${ }^{44}$ In 
comparison, elite track and field athletes $(n=127)$ established a normal value ranging between $72.3^{\circ}$ and $73.9^{\circ}$ with the active knee extension test. ${ }^{45}$

Palpation meter (PALM): The PALM is a device with a built in inclinometer that has been used to objectively measure pelvic angle. Despite little use in the adolescent population the PALM has shown to be both valid and reliable in measuring pelvic angles in the sagittal plane. ${ }^{46-}$ ${ }^{48}$ A neutral pelvis has been established at 0 degrees with positive degrees describing an anterior innominate tilt, and negative degrees describing a posterior innominate tilt. ${ }^{47}$ Normative values in an asymptomatic adult population have been reported to be $6.49^{\circ}$ in males and $6.78^{\circ}$ in females. ${ }^{47}$

Hip range of motion: The hip has six degrees of freedom allowing for flexion, extension, abduction, adduction, internal rotation, and external rotation. Measurement of these movements can be assessed using a goniometer providing an angle in degrees. Goniometer use for angle measurement has been shown to be both reliable and valid in healthy populations and those with chronic LBP. ${ }^{49-51}$ Average hip range of motion values in males and females aged 11 to 17 years of age have been established. Results for males and females, respectively are flexion $\left(113^{\circ}\right.$, $\left.120^{\circ}\right)$, extension $\left(15^{\circ}, 22^{\circ}\right)$, abduction $\left(34^{\circ}, 44^{\circ}\right)$, adduction $\left(14^{\circ}, 17^{\circ}\right)$, internal rotation $\left(35^{\circ}, 35^{\circ}\right)$, and external rotation $\left(40^{\circ}, 46^{\circ}\right) .^{52}$

Procedures

Before the screening tool procedures started, an informational meeting took place with the subjects and their parents. In this meeting, the informed parental consent form with HIPAA included (Table C1), informed assent form (Table C2), the informed consent form with HIPAA for subjects 18 and older (Table C3), and the demographic questionnaire (Table C4) were discussed. The informed consent forms with HIPAA and the demographic questionnaire were 
completed during this informational meeting. After subjects and parents completed the necessary paperwork, screening tool procedures were explained. Instructions for the testing procedures were explained to all subjects during the informational meeting and before performing the tests.

Those subjects who met all inclusion criteria were invited to participate in the study. Times were established for subjects to meet with the researcher once within a three-week period to complete all components of the screening tool; approximately one 30-minute session. The participants were permitted to engage in normal daily routines without limitations. Participants were allowed to wear self-selected athletic shoes and athletic clothes (shorts and a t-shirt) for the FMS, while shoes and socks were removed for the active knee extension test, pelvic positioning measurements, and hip range of motion measurements. All screening tool procedures were performed in the athletic training room and auxiliary space at one Mid-Atlantic high school to serve as an environmental control. Administration and supervision of all testing was completed by the primary researcher.

Functional Movement Screen (FMS): Standard FMS procedures (Table C5, Table C6) were used as previously defined by Cook. ${ }^{25} \mathrm{~A}$ script was read (Table C5) to ensure understanding of the tested movements. Participants were not "cued" of their movements. Each participant was instructed to perform the 7 fundamental movements and 3 clearing tests (Table C6). Individuals were limited to a maximum of three trials for each movement, and an extensive warm up was not included. A movement was given a score between 0 and 3. A score of 1 indicates the inability to complete the movement, 2 represents compensation while completing a movement, and 3 signifies a correct completion of the movement without compensation. The raw score was used to denote right and left side scoring. The final score denoted the overall score for 
the test. The lowest score for the raw score (each side) carried over to give a final score for the test.

The first movement in the FMS (Table C6) was a deep squat designed to assess bilateral, symmetrical, functional mobility of the hips, knees, and ankles. A dowel was held overhead to assess bilateral symmetrical mobility of the shoulders and thoracic spine. The participant assumed a shoulder width apart stance and grasped the dowel so that the arms formed a 90 degree angle at the head. The participant then pressed the dowel overhead with the elbows in full extension. The participant was instructed to descend as far as possible into a squat while keeping heels on the ground and maintaining an upright torso. A one second pause at the bottom of the squat was completed before returning to the start position. The participant had a maximum of three trials to complete the movement to the best of his/her ability.

The second movement in the FMS (Table C6) was the hurdle step. This movement is designed to assess mobility and stability of the hips, knees, and ankles. The height of the hurdle was set to the height of the participant's tibial tuberosity. The participant (while holding a dowel behind the head and across the shoulders) was instructed to step over the hurdle with one leg, touch the ground on the other side of the hurdle (without accepting weight), and then return the leg back over the hurdle. This test was completed bilaterally. The participant had a maximum of three trials to complete the movement to the best of his/her ability.

The third movement of the FMS (Table C6) was the in-line lunge. This movement is designed to assess quadriceps flexibility, hip mobility, and stability, and bilateral ankle and knee stability. The participant stood on a 2 × 6 board and held a dowel behind the back. The dowel maintained three points of contact (base of skull, thoracic spine, and sacrum) throughout the lunge. The opposite hand of the front foot was used to grasp the dowel at the head while the 
other hand was placed on the dowel in the lumbar spine. The height of the tibial tuberosity was used as the distance between the two feet. The back knee touched the board behind the front foot and the feet were kept in the sagittal plane during the lunge. This test was assessed bilaterally. The participant had a maximum of three trials to complete the movement to the best of his/her ability.

The fourth movement of the FMS (Table C6) was the shoulder mobility test. This movement is designed to assess shoulder range of motion. The tester measured (in inches) the length of the participant's hand from the crease of the wrist to the end of the third finger. The participant was then instructed to close the fist, and maximally adduct, extend, and internally rotate with one shoulder and maximally abduct, flex, and externally rotate the other. The flexed shoulder was the side that was scored. The tester then measured the distance between the two fists. The test was assessed bilaterally. The participant had a maximum of three trials to complete the movement to the best of his/her ability.

The shoulder clearing test (Tale C6) was performed at the end of the shoulder mobility test. This movement was not scored but was used to observe a pain response. This clearing test is necessary to detect impingement symptoms that can go undetected with the shoulder mobility test. The individual was instructed to place the hand on the opposite shoulder and attempt to point the elbow upward. If pain was produced, a score of zero was given for the test. The clearing test was performed bilaterally.

The fifth movement in the FMS (Table C6) was the active straight leg raise. This movement is designed to assess active flexibility of the hamstrings and gastroc-soleus complex while maintaining a stable pelvis and core. The participants were instructed to lie on the back with the 2 x 6 board under the knees with the leg straight. The leg that was not tested remained in 
contact with the floor with the foot in a dorsiflexed position. The tester then identified the midpoint between the ASIS and midpoint of the patella. A dowel was then placed perpendicular to the floor at the measured midpoint. While maintaining contact with the floor through the head and lower back, the participant was instructed to raise the test leg with a dorsiflexed ankle and extended knee as far as possible. If the malleolus did not pass the dowel, the dowel was moved in line with the malleolus of the test leg and scored per the criteria. This test was performed bilaterally. The participant had a maximum of three trials to complete the movement to the best of his/her ability.

The sixth movement in the FMS (Table C6) was the trunk stability push-up. This movement is designed to assess trunk stability while a closed-chain upper body motion is completed. The participant assumed a prone position with the hand spaced shoulder-width apart and the feet together. Females were instructed to place thumbs in line with the chin. Males were instructed to place thumbs in line with the forehead. The participant was then instructed to lift the body as a unit with the knees extended and ankles dorsiflexed to complete one push-up. If the participant was not able to complete the push-up the hand position was moved level with the chin for males, and moved level to the clavicle for females. The participant had a maximum of three trials to complete the movement to the best of his/her ability.

The spinal extension clearing test (Table C6) was performed after the trunk stability push-up. This movement was not scored but was used to observe a pain response. The clearing test is necessary to detect back pain that can go undetected with movement screening. The participant was instructed to perform a press-up in the push-up position. If pain was produced, a score of zero was given for the test. 
The seventh movement in the FMS (Table C6) was the rotary stability test. The participant was instructed to assume a quadruped position with both hands and both feet on the ground at relatively 90 degree angles (shoulders relative to the upper torso; hips/knees relative to the lower torso). The 2 x 6 board was placed between the knees and hands so that both the hands and knees are touching the board. The participant was then instructed to lift the arm and leg (flexes shoulder, extends hip) on the same side and attempt to touch the knee and elbow together. If the participant was unable to complete such a repetition, the pattern changed to a diagonal pattern (opposite arm and leg). This test was performed bilaterally. The participant had a maximum of three trials to complete the movement to the best of his/her ability.

The spinal flexion clearing test (Table C6) was performed at the end of the rotary stability test. This movement was not scored, but was used to observe a pain response. The purpose of this clearing test is necessary due to back pain going undetected by movement screening. Spinal flexion was cleared when a quadruped position was assumed, and then rocked back to touch the buttocks to the heels and chest to the thighs. Hands remained in front of the body, reaching out as far as possible. If pain was produced, a score of zero was given for the test.

Active knee extension test: The next measurement in the screening tool was hamstring length. Procedures that have been previously described were used for the active knee extension test and are outlined in Table. C7. ${ }^{42,53}$ The subject was supine on the table and was instructed to flex the testing extremity to 90 degrees and maintain that position. The investigator then secured the non-tested extremity to the table using a strap across the lower third of the thigh. The subject was then instructed to extend the knee as far as possible while keeping the foot in a relaxed position and held that position for approximately five seconds. The investigator then aligned the fulcrum of the goniometer to the midpoint of the lateral joint line, aligned the stationary arm to 
the greater trochanter of the femur, and aligned the movable arm to the lateral malleolus of the fibula. An angle measurement in degrees was taken from the goniometer. This test was performed bilaterally. The participant had two trials bilaterally, one after the other, and the average of both was taken.

Palpation meter (PALM): Procedures that have been previously described were used for assessment of pelvic angle and are outlined in Table $\mathrm{C} 8^{47,48}$ The investigator created markings on the floor that are $30 \mathrm{~cm}$ apart that the participant stood on. Participants adopted an erect posture and kept arms crossed over the chest. Participants were instructed to look at a fixed point ahead of them as to help control for postural sway. Palpation by the investigator was performed over the clothes. Palpation began by locating the ASIS bringing the thumbs inferior to superior and marked the most prominent protrusion with an adhesive felt pad. The investigator then located the PSIS by following the iliac crest with the thumbs first posteriorly, then superior and laterally from the sacrum and marked the most prominent protrusion with an adhesive felt pad. The subject held the pads in place as to limit movement of the pads over the athletic shorts. The calipers were placed over the marked ASIS and PSIS on the ipsilateral side and compressed to a firm resistance. The angle of inclination was read from the inclinometer built into the PALM device. Positive degrees were used to describe anterior innominate tilts, and negative degrees were used to describe posterior innominate tilts. The test was performed bilaterally. The participant performed two trials bilaterally, one after the other, and the average of both was taken.

Hip range of motion: Active hip range of motion was assessed by a goniometer for hip flexion, extension, abduction, adduction, internal rotation, and external rotation. These motions and the goniometer measurements for each are outlined in Table C9. The tests were performed 
bilaterally for all six motions. The participant performed two trials bilaterally, one after the other, and the average of both was taken.

Hip flexion measurements ${ }^{52}$ were taken with the participant lying in supine. The participant was then instructed to actively flex the hip as far as possible with the knee in a flexed position. The fulcrum of the goniometer was placed at the greater trochanter of the femur, the stationary arm was aligned parallel to the trunk of the participant, and the movement arm was aligned with the midpoint of the lateral joint line. Angle measurements were taken from the goniometer in degrees.

Hip extension measurements ${ }^{22,52}$ were taken with the participant lying prone with the extremity extended beyond the table. The participant was then instructed to actively extend the hip as far as possible. The fulcrum of the goniometer was placed at the greater trochanter of the femur, the stationary arm was aligned parallel to the trunk of the participant, and the movement arm was aligned with the midpoint of the lateral joint line. Angle measurements were taken from the goniometer in degrees.

Hip abduction measurements ${ }^{23,52}$ were taken with the participant in a side lying position. The participant was then instructed to actively abduct the hip as far as possible. The fulcrum of the goniometer was placed at the ASIS of the tested leg. The stationary arm was aligned with the contralateral ASIS, and the movement arm was aligned with the midpoint of the patella. Angle measurements were taken from the goniometer in degrees.

Hip adduction measurements ${ }^{52}$ were taken with the participant in a standing position. The participant was then instructed to actively adduct the hip as far as possible. The fulcrum of the goniometer was placed at the ASIS of the tested leg. The stationary arm was aligned with the 
contralateral ASIS, and the movement arm was aligned with the midpoint of the patella. Angle measurements were taken from the goniometer in degrees.

Hip internal rotation ${ }^{52}$ was taken with the participant in a short-seated position. The participant was then instructed to actively internally rotate the hip as far as possible. The fulcrum of the goniometer was placed at the center of the patella. The stationary arm was aligned horizontally with the table, and the movement arm was aligned with the shaft of the tibia. Angle measurements were taken from the goniometer in degrees.

Hip external rotation ${ }^{23,52}$ was taken with the participant in a short-seated position. The participant was then instructed to actively externally rotate the hip as far as possible. The fulcrum of the goniometer was placed at the center of the patella. The stationary arm was aligned horizontally with the table, and the movement arm was aligned with the shaft of the tibia. Angle measurements were taken from the goniometer in degrees.

All data from these measurements were recorded on the FMS scoring sheet (Table C10) and the data collection sheet (Table C11).

Statistical Analysis

Descriptive analysis consisted of means and standard deviations of all subjects for demographic information, FMS composite scores, active knee extension test, PALM, and hip range of motion measurements. To determine the strength of the relationship between all variables, Pearson's Correlation Coefficient was used. Relationship strengths are defined as small (.1-.29), medium (.3-.49), and large (.5-1.0). ${ }^{54}$ To determine predictors of injury other statistics including binary logistic regression, Cox \& Snell $\mathrm{R}^{2}$, Nagelkerke $\mathrm{R}^{2}$, and odds ratio were used with $95 \%$ Confidence Intervals. A binary logistic regression was used producing a Cox \& Snell pseudo $\mathrm{R}^{2}$, Nagelkerke pseudo $\mathrm{R}^{2}$, and odds ratio statistics. The higher the Cox \& 
Snell pseudo $\mathrm{R}^{2}$, and Nagelkerke pseudo $\mathrm{R}^{2}$ the better the model fits the data. The ability to predict outcomes or characteristics that may predispose an athlete to sustain a SIJD can be useful both clinically and in applied settings.

Eleven models were selected to indicate best fit. The first model compared FMS composite scores and SIJ injury history. The second model compared the average of both extremities' active knee extension test and SIJ injury history. The third model SIJ compared the average of both innominates' pelvic angle tilt measurement from the PALM and SIJ injury history. The fourth through ninth model compared the average angle for both extremities for active hip flexion, extension, abduction, adduction, internal rotation, and external rotation and SIJ injury history. The tenth model compared years of playing soccer and SIJ injury history. The eleventh model compared current athletic participation and SIJ injury history. A stepwise binary logistic regression was analyzed to investigate any interaction between the previous eleven variables. The $\mathrm{P}$ value was set at $\mathrm{P}=0.05$ for all analyses. IBM/SPSS software (IBM/SPSS, Inc., Chicago, IL) version 24.0 was used for all analyses.

\section{RESULTS}

\section{Demographic Data}

Fourteen females $(\mathrm{age}=16.00 \pm 1.11 \mathrm{yrs}$, height $=165.93 \pm 6.39 \mathrm{~cm}$, mass $=61.11 \pm 6.92$ $\mathrm{kg})$ and six males $(\mathrm{age}=16.33 \pm 1.37 \mathrm{yrs}$, height $=176.50 \pm 6.98 \mathrm{~cm}$, mass $=72.12 \pm 9.92 \mathrm{~kg})$ adolescent soccer athletes who participated on the varsity and/or junior varsity teams at one north central West Virginia High School volunteered for this study. Three (15\%) of the subjects were in the freshman class, three (15\%) of the subjects were in the sophomore class, ten $(50 \%)$ of the subjects were in the junior class, and four (20\%) of the subjects in the senior class. None of these subjects had an injury status that prevented them from any of the study measurements at the time 
of data collection. Five (25\%) of these athletes sustained a SIJ injury over the course of the previous soccer season. Other injuries that occurred over the course of the season were ankle injuries $(n=3,15 \%)$, knee injury $(n=1,5 \%)$, and hamstring injury $(n=1,5 \%)$. None of these players missed significant time from these injuries, and therefore were not excluded from the study. Position was divided into four categories, keeper $(n=1,5 \%)$, defense $(n=8,40 \%)$, midfield ( $\mathrm{n}=8,40 \%)$, and forwards $(\mathrm{n}=3,15 \%)$. Descriptive subject data including age, height, weight, years playing soccer, playing soccer year-round, and current athletic activity is presented in Table D1. Descriptive subject data on the means and standard deviations of the screening variables for male and female participants are presented in Table D2. Descriptive subject data on demographics and the means and standard deviations of the screening variables between those who have an SIJ injury and those who do not are presented in Tables D3-D4.

\section{Correlation Coefficients}

Pearson correlation coefficients were run for the relationships between demographic data and SIJ injury (Table D5) and the relationships between the predictive variables and SIJ injury (Table D6). No significant correlations were found between SIJ injury, years playing soccer, and current athletics participation. Small to large correlations were present among the predictive screening variables and SIJ injury. A significant correlation with large strength $(\mathrm{PCC}=0.545, \mathrm{p}$ $=.013$ ) was found between SIJ injury and active hip abduction. As hip abduction increased so did the occurrence of a SIJ injury. A significant correlation with medium strength (PCC $=0.473$, $\mathrm{p}=.035)$ was found between the AKET and active hip flexion. As hip flexion increased so did the AKET results. A significant correlation with large strength $(\mathrm{PCC}=0.732, \mathrm{p}<.01)$ was found between the PALM measurement and active hip extension. As the pelvis was tilted anteriorly active hip extension increased. 


\section{Cross Tabs of Lower Extremity FMS Movements}

A cross tabs of the three lower extremity based movements, deep squat, inline lunge, and hurdle step, from the FMS was run with SIJ injury occurrence set as the dependent variable. This information is presented in Table D7. The cross tabs revealed that those who did and did not have an SIJ injury scored similarly on the deep squat and hurdle step. The inline lunge, however, demonstrated that those without a SIJ injury performed well, whereas, the majority with a SIJ injury had decreased performance.

Logistic Regression and Odds Ratios

A binary logistic regression was run producing a Cox \& Snell pseudo $\mathrm{R}^{2}$ and Nagelkerke pseudo $\mathrm{R}^{2}$ statistics. The higher the Cox \& Snell pseudo $\mathrm{R}^{2}$ and Nagelkerke pseudo $\mathrm{R}^{2}$ statistics, the better the model fits the data. One model provided the best fit. The $2 \times 2$ contingency table using the variables SIJ injury and active hip abduction produced a Cox \& Snell $\mathrm{R}^{2}$ (.282), Nagelkerke $\mathrm{R}^{2}(.418)$, and an odds ratio of $1.115\left(\mathrm{CI}_{95}=1.003,1.239, \mathrm{p}=.044\right)$. This logistic model "moderately" fits the data and accounts for $28.2 \%-41.8 \%$ of the variance of hip abduction being able to predict SIJ injury or not. The odds ratio for hip abduction increased the risk of SIJ injury by $11.5 \%$. All other models did not produce statistically significant results and are presented in Table D8. Two nonsignificant models with moderate odds ratios were produced for the PALM $\left(\mathrm{OR}=1.141, \mathrm{CI}_{95}=.841,1.547, \mathrm{p}=.397\right)$ and years playing soccer $(\mathrm{OR}=1.319$, $\mathrm{CI}_{95}=.854,2.036, \mathrm{p}=.212$ ) The models using the variables 1$)$ SIJ injury and FMS composite scores; and 2) SIJ injury and years playing accurately predicted one subject with SIJ, however, did not produce statistically significant results for the entire model.

A step wise binary logistic regression was run producing a Cox \& Snell pseudo $\mathrm{R}^{2}$ and Nagelkerke pseudo $\mathrm{R}^{2}$ statistics to investigate interaction affects within and between the 
variables. Two models provided the best fit. The $2 \times 2$ contingency table using the variables SIJ injury and active hip abduction produced the same outcome listed above. The second model included three variables, SIJ injury history along with hip abduction and FMS composite scores. All other variables were not found to be included into the model equation. This model produced a Cox \& Snell $\mathrm{R}^{2}$ (.426), Nagelkerke $\mathrm{R}^{2}(.631)$, and an odds ratio of $1.168\left(\mathrm{CI}_{95}=1.004,1.359, \mathrm{p}\right.$ $=.045)$. This logistic model "moderately" fits the data and accounts for $42.6 \%-63.1 \%$ of the variance of hip abduction being able to predict SIJ injury or not. The odds ratio for hip abduction and FMS increased the risk of SIJ injury by $16.8 \%$. The interaction term was not significant (OR $\left.=1.003, \mathrm{CI}_{95}=.999,1.007, \mathrm{p}=.095\right)$ between active hip abduction and FMS composite scores. All stepwise binary logistic regression statistics are presented in Table D9.

\section{DISCUSSION}

The main purpose of this study was to determine screening variables that can effectively predict SIJD for adolescent soccer athletes. The results of this analysis showed that there were large statistically significant correlations between active hip abduction and SIJ injury occurrence, and PALM measurement and active hip extension. There was also a medium statistically significant correlation between the AKET and active hip flexion. One model, active hip abduction, of the binary logistic regression produced a statically significant finding. The model reflected the concept that those with the highest angle of active hip abduction had an increased risk of an SIJ injury by $11.5 \%$. All other models did not produce statistically significant results. A stepwise binary logistic regression produced another statistically significant model that included the FMS with active hip abduction. In this model, those with the highest angle of active hip abduction, and the lowest FMS composite scores had an increased risk of SIJ injury by 16.8\%. These findings suggest that ROM, especially hip abduction, and FMS scores may be an 
important consideration in deciding which variables to evaluate, as well as to consider for prevention and intervention strategies.

As this is the first study to evaluate potential predictor variables for SIJD in adolescent soccer players, the findings from the current study cannot be directly compared with the prior studies that evaluated risk factors and the effect on low back pain in adolescents ${ }^{55}$ or the FMS in relation to low back pain. ${ }^{13}$ However, the results from those studies provide a basis as to why certain variables should be considered.

Injury Demographics and SIJ Injury

Among the 20 subjects that volunteered for this study, five had an SIJ injury, all females, over the course of the past soccer season. The higher incidence of SIJ injury in females compared to male counterparts may partially be explained by anatomical differences between the two sexes. In males, the articular surface between the sacrum and ilium are shaped like an "inverted L", while in females they are generally smaller and more oblique shaping a "C" appearance. ${ }^{17,56}$ Females are also generally not able to produce as much force with muscle activation compared to males. This decreased muscle output could negatively impact the "force closure" mechanism. In this mechanism the latissimus dorsi works with the contralateral gluteus maximus to generate the force closure on the SIJ as co-activation occurs and force is transferred through the posterior layer of the thoracolumbar fascia. ${ }^{18,19,57}$ The decreased amount of stability at the SIJ could explain this observed difference in injury occurrence between sexes.

Position on the team also had an influence on SIJ injury. The five with an SIJ injury, two were backfield players, and three were midfielders. This is in agreement with current literature as midfielders have been reported to be at the highest rate of LBP potentially caused by an SIJ injury. ${ }^{10}$ This could be due in part that midfielders cover the most distance throughout the 
game. ${ }^{58}$ Upon movement, roles are switched between attacking and defending. This involves increased use of the hip adductors and abductors which may lead to an inflare or outflare of the innominates ${ }^{59}$ This may result in a compression of the SIJ and a decrease of mobility in the joint. An inflare or an outflare could be potential mechanisms for the creation of pain and dysfunction at the SIJ.

It has been postulated that the number of years playing soccer may have an influence on developing an SIJ injury. ${ }^{60}$ Of the five with an SIJ injury, four currently play soccer year-round and all five remain physically active. These five subjects have also been playing soccer for 8 , $11,11,14$, and 15 years, respectively. The average number of years playing soccer amongst all subjects was 9.70 years. Although no statistically significant correlations were found between years playing, current physical activity, and SIJ injury, the potential for an SIJ injury exists via a chronic/overuse mechanism. Although current research is limited on the relationship between early sports specialization and overuse injury, especially with the low back, initial findings indicate that playing a sport for 8 months or greater over the year leads to an increased risk of overuse lower extremity injuries. ${ }^{61-63}$ When injuries were reported by type, low back overuse injuries in sport specialized athletes were $13.7 \%$ in relation to all the overuse injuries reported. ${ }^{60}$ Although the research is limited, currently there is a modest relationship showing that playing a sport year-round may increase risk of an overuse injury such as SIJ.

\section{Correlation of Hip Abduction to SIJ Injury Occurrence}

Hip abduction is a component of multiple functional movements of soccer and this may be contributing to SIJ injury as the results from this study found a positive large correlation between the two. The fundamental skills of soccer are the kick and running involving lateral 
movement. Hip abduction occurs during the kicking motion and lateral movements, and contribute to the "force closure" mechanism. ${ }^{16,18,19}$

More specifically, during the backswing of the kicking motion, the hip is slowly abducted and externally rotated by a concentric contraction of the gluteus medius. ${ }^{64}$ The hip remains abducted and externally rotated during the initiation of forward motion through impact with the ball. ${ }^{64}$ Meanwhile the gluteus medius on the stance leg is activated to maintain hip stabilization during the kicking motion. The gluteus medius plays an important role in the kicking motion working both as a joint mover and as a stabilizer. With the repetitive kicking motions in soccer this muscle can be quick to fatigue. Soccer players also incorporate forward, backward, and lateral motions moving up and down the field. The sacral motions become increasingly complex during the gait cycle. In walking from heel strike to midfoot stance, and toe off the sacrum goes through rotational movement in both directions as well as side bending. ${ }^{65}$ These motions and the forces transferred through the SIJ are exacerbated during running. Stress at the SIJ is further increased from the lateral movements involved with cutting in soccer. Therefore, excessive and repetitive hip abduction may result in the gluteus medius decreasing the ability to maintain stabilization of the pelvis and the SIJ, altering the biomechanics and decreasing the effectiveness of the "force closure" mechanism. The decreased stability, created by excessive and repetitive hip abduction, at the SIJ will result in increased shear forces which leads to potential injury. ${ }^{17,65-}$ 68

\section{Correlations of HROM to AKET and PALM}

Hamstring flexibility influences both the performance of active hip flexion and the AKET. The positive medium strength correlation from this study supported that. All subjects were able to bilaterally score a three on the active straight leg test suggesting that each subject 
has good hamstring flexibility. This is further supported by the subjects exceeding the normative values for both active hip flexion and the AKET. The hamstrings muscles collectively are a twojoint muscle as they act upon both the knee and hip joint. ${ }^{17}$ During active hip flexion the proximal portion at the ischial tuberosity is put under increased strain, whereas, during the AKET the distal portion at the knee is put under increased strain. ${ }^{17,41,57}$ A subject with increased hamstring flexibility performed well in both screening variables.

Active hip extension and pelvic positioning produced a positive large correlation in this study. All of the subjects were recorded to have an anterior pelvic tilt that ranged from $2.25^{\circ}$ to $18.25^{\circ}$. This relationship may not be due to the strength of the gluteus maximus. Perhaps this relationship can be explained with soccer specific biomechanics. The hip flexors, such as the iliopsoas and the rectus femoris, undergo eccentric contraction in the back swing followed by a powerful concentric contraction for the remaining portions of the kicking motion. ${ }^{69,70}$ This load from the hip flexors pulls on the pelvic innominates anteriorly. Additionally, an overused iliopsoas muscle may increase lumbar lordosis and inhibit transverse abdominis activation. An increased lumbar lordosis in turn creates an increased anterior pelvic tilt. ${ }^{71,72}$ The anterior pelvic tilt, altered the biomechanical positioning of the subjects' pelvis. This altered positioning may have allowed compensation from other muscles, such as the hamstrings, to produce more force leading to increased performance in active hip extension..$^{18,20}$ Model of Predicting SIJ Injury

The best fit model for predicting SIJ injury was hip abduction. The odds ratio that was produced interpreted that those with the highest angle of hip abduction were at a $11.5 \%$ increased risk for SIJ injury. This contradicts current literature that has found that a decrease, rather than an increase in hip abduction is related to having an SIJ injury. ${ }^{22,23}$ It is also reported in the literature 
that decreases in hip extension, adduction, internal rotation, and external rotation are related to an SIJ injury. ${ }^{21,73}$ Although this information conflicts with current literature, the importance of hip range of motion should be addressed, especially if asymmetry is evident in the lumbopelvic region. ${ }^{74}$

Why an increase in hip abduction may be a concern is related to the biomechanical alteration that occurs at the sacrum during kicking, running, and lateral movements in soccer. The increase in hip abduction also may influence the "force closure" mechanism that is predominantly controlled by the latissimus dorsi, gluteus maximus, and thoracolumbar fascia. ${ }^{16-}$ ${ }^{19,57}$ If the sacrum cannot properly serve as the gateway between the lower extremities and the spinal column, then the forces will remain in the SIJ and result in injury. This adaptation of excessive and repetitive active hip abduction was most likely acquired over time by the subjects in this study based off the physical demands of soccer and the longevity and frequency that they have played and trained.

The other models that may have some relevancy for predicting an SIJ injury included the FMS, and years playing as screening variables. Each of these models were not statistically significant, however, each was able to accurately predict one case of a SIJ injury creating potential clinical relevancy. The FMS model produced an odds ratio interpreted as a higher composite score would decrease the risk of an SIJ injury by $50.5 \%$. This odds ratio supported the concept that clinicians frequently use the FMS as a screening tool for injury risk, despite not being the original intent of the FMS. This interpretation of the FMS has been heavily investigated and the results show that athletes who score 14 or less points on the FMS are at an increased risk for injury. ${ }^{34-39,75}$ Specifically it has been cited that a score of 14 or less on the FMS resulted in a 4-fold increase of lower extremity risk of injury over the course of a season. ${ }^{34}$ 
Observed from this binary logistic regression model it accurately predicted SIJ injury for the subject who had the lowest score, 15 , of all 20 subjects who volunteered. Conversely, the other four who sustained an SIJ injury performed well with scores of 18, 18, 19, and 19, respectively. Those scores align closer to the average FMS composite score for the non-injury group (18.6 \pm 0.83). Overall the group performed well with an average FMS composite score of $18.4 \pm 1.10$, suggesting that the athletes in this population were highly trained and capable of performing efficient athletic movements.

The model for years playing soccer produced an odds ratio, which was interpreted as those with the greatest amount of years played had an increased risk of SIJ injury by $31.9 \%$. The subjects in this group had a mean of $9.70 \pm 4.05$ years of soccer experience with a mean age of $16.10 \pm 1.17$ years. Half of these subjects' lives have been dedicated to playing soccer. Further, there is a clinical difference in years playing soccer between the SIJ injury and healthy group. The SIJ injury group had a mean of $11.80 \pm 2.77$ years of playing soccer, compared to $9.00 \pm$ 4.24 years in the healthy group. Among the five with the injury, all have been playing for 8,11 , 11,14 , and 15 years, respectively. The model accurately predicted the subject who had played for 15 years. Additionally, the subject who had 14 years of experience is the same subject with a composite score of 15 whom was accurately predicted in the FMS model. Despite limited research available on years playing on the risk of developing an overuse injury, initial findings may support the clinical relevancy of this model as there is a modest relationship between playing year-round and sustaining an overuse injury in the lower extremity. ${ }^{60-63}$

Upon investigation of a stepwise binary logistic regression, a statistically significant model including both hip abduction, and the FMS together was produced. The odds ratio when the FMS was included increased from $11.5 \%$ to a $16.8 \%$ risk of SIJ injury. This odds ratio may 
be low; however, it holds clinical significance. The increased risk of injury suggested that these two screening variables are related to each other. The seven fundamental movements of the FMS are primarily performed in the sagittal plane; however, the subject must be able to maintain stability to not deviate into the frontal or transverse plane. This stability is controlled partly by the gluteus medius, which is the main contributor to hip abduction. The need to activate the gluteus medius during certain functional movements may be why the model's ability to predict an SIJ injury improved with the inclusion of the FMS. The more applicable movements for soccer in the FMS are those performed in standing, including the deep squat, hurdle step, and inline lunge. Only one study has reported individual scores of the seven fundamental movements in those with chronic LBP. ${ }^{13}$ A decrease in performance for the deep squat and hurdle step were found in that study. ${ }^{13}$ Upon investigation of the individual scores from the subject who was accurately predicted by the model, the subject had decreased scores in the deep squat, hurdle step, inline lunge, trunk stability push up, and rotary stability. These decreased scores directly supported the findings of Ko et al. ${ }^{13}$ that the deep squat, hurdle step, and inline lunge are applicable to soccer. The other four subjects with SIJ injury also support the findings of Ko et al. ${ }^{13}$ The first subject had decreased performance on the deep squat and hurdle step, the second and third subjects had decreased performance on the inline lunge, and the fourth subject had decreased performance on the hurdle step. These four subjects also performed poorly on the rotary stability, however, performed well on the three remaining movements. When compared to the subjects without a SIJ injury they too produced mixed results with the deep squat and hurdle step, which may suggest an altered biomechanical pattern in soccer players exists. The subjects without a SIJ injury performed very well on the inline lunge, whereas the SIJ injury group had mixed results. This may suggest that those with an SIJ injury have poor hip stability which may 
explain their poor performance with the inline lunge. This model may be a link to predict an SIJ injury, along with excessive hip abduction that may be caused by a dysfunctional gluteus medius and may explain decreased performance in the FMS.

\section{Clinical Importance}

This is the first screening tool model created for predicting an SIJ injury within this athletic population. Clinicians may use the information created by these models to develop a preseason screening tool. Two models in this study indicated a good fit for prediction which may develop a potential clinical prediction rule for clinicians to utilize active hip range of motion and the FMS in preseason screening. The model that included active hip abduction produced an odds ratio that a clinician may interpret large hip abduction measurements increased the risk of SIJ injury by $11.5 \%$. Therefore, clinicians should be conscious of hip range of motion abnormalities in active athletic populations. In soccer, it is necessary for the hip to have six degrees of freedom to efficiently perform the running and kicking biomechanics of the sport. These motions at the hip interact in concert with motions occurring at the pelvis, sacrum, and SIJ. If one of the components has dysfunction this may transfer up the kinetic chain and create SIJD, therefore assessing hip range of motion is a necessary component to consider for a SIJD screening tool in soccer athletes. For this reason, all hip range of motion measurements, and not only hip abduction, should be included in a prediction model.

When the model included the FMS with hip abduction, the odds ratio improved and was interpreted that large active hip abduction angle measurements, with low FMS composite scores resulted in a $16.8 \%$ increased risk of SIJ injury. For clinicians this shows relevancy for incorporating multiple screening variables into the prediction model. The clinical use of the FMS has evolved over time. The FMS has transitioned from detecting deficient mobility and stability 
and is currently used in the literature to see if the test is able to determine an athlete's risk of injury $^{13,24,34,37,38,76}$ A score of 14 or less on the FMS has been supported in the literature to demonstrate an increase in injury. ${ }^{34,76}$ From this study the FMS was able to accurately predict one case of a SIJ injury with a score of 15 . After investigation of the individual scores, this subject had decreased performance on the deep squat, hurdle step, and inline lunge which are more relatable movements to soccer. As mentioned previously the inline lunge had mixed performances with the injury group, compared to all subjects without SIJ injury achieved perfect scores. The clinician may be better suited to utilizing those few soccer related movements, especially the inline lunge, from the FMS to screen for an SIJ injury. The clinician may also incorporate soccer specific movements to utilize alongside the FMS movements.

Clinically, the PALM also produced an odds ratio that demonstrated fair ability to predict a SIJ injury. The odds ratio produced was interpreted as a greater anterior rotated pelvis increased the risk of SIJ injury by $15.1 \%$. An anterior rotated pelvis for these subjects increased the model's ability to identify a SIJ injury. Muscle imbalances are most likely present in these individuals with an anterior pelvic tilt. This is supported by a positive Thomas test observed bilaterally on 12 subjects and unilaterally on 6 subjects, indicating an overactive iliopsoas.

The biomechanical stresses and deficits observed by clinicians from this screening variable will reveal what prevention interventions should take place. Currently there is no constructed clinical screening tool to assess predictive factors for SIJD in the adolescent soccer athlete population. With no known screening tool available, four different biomechanical and functional components that should be considered are the Functional Movement Screen (FMS), pelvic positioning, hamstring length, and hip ROM. This study, may suggest clinically relevant 
objective information on this adolescent athletic population, and which variables should be considered for determining SIJ injury.

Limitations

Limitations have been identified in this study. This first is the sample size used. A convenience sample of adolescent soccer athletes from one Mid-Atlantic high school were recruited. Therefore, the results cannot be generalizable to all adolescent soccer athletes. The overall number $(n=20)$ was low, reducing the power of the statistics in the study, as well as the low number with an SIJ injury $(n=5)$. Of the subjects with an SIJ injury all were female, making it difficult to draw comparisons between sexes as well as making the clinical prediction model applicable to adolescent male athletes. Increasing the sample size of male and female subjects potentially could improve the power to detect those predictor variables that did not reach statistical significance. Until then, only best clinical practice can be utilized to determine which preseason assessments can predict an SIJ injury. Procedures were created to control for extraneous variables. The procedures created consistent results from subject to subject, all measurements were recorded twice and averaged, and another clinician was present in the room to eliminate potential bias from the assessor. Evaluation and diagnosis of a SIJ injury is a challenging skill and may be viewed as a limitation to this study. Reliability for various tests, such as palpations, pain provocation, standing flexion, and other movement tests, has been shown to be poor. ${ }^{77-82}$ To address this limitation a thorough evaluation was performed on all athletes with LBP and suspected of a SIJ injury. An extensive history was taken, palpations of bony and soft tissue landmarks were taken to differentiate location of pain, movement based tests, and pain provocation tests were conducted to rule in and out various low back pathologies. CONCLUSION 
The results from this study indicate that active hip abduction may predict an SIJ injury. Years of playing soccer, the FMS, and pelvic positioning may also be clinically useful assessment measures to predict an SIJ injury. Because of the clinical implications these variables have to predict SIJ injury in adolescent soccer players, future studies are warranted. Since this study was the first to investigate a potential screening tool, future studies with an increased sample size may be able to reinforce the findings reported from this study. As studies like this evolve more subjects with greater diversity in demographics should be utilized to increase the power of these prediction models. This can lead to more evidence based prediction models, as well as evidence based preventative protocols. 


\section{REFERENCES}

1. Waddell G. A new clinical model for the treatment of low back pain. Spine. 1987; 12:632641.

2. Anderson GBJ. Epidemiological features of chronic low back pain. Lancet. 1999;354:581-5.

3. Shah T, Cloke DJ, Rushton S, Shirley MD, Deehan DJ. Lower back symptoms in adolescent soccer players: predictors of functional recovery. Orthop J Sports Med.

2014;2(4):2325967114529703.

4. Goshtigian GR, Swanson BT. Using the selective functional movement assessment and regional interdependence theory to guide treatment of an athlete with back pain: a case report. Int J Sports Phys Ther. 2016;11(4):575-95.

5. Hill JJ, Keating JL. A systematic review of the incidence and prevalence of low back pain in children. Phys Ther Rev. 2009;14:272-284.

6. Maigne JY, Aivaliklis A, Pfefer F. Results of sacroiliac joint double block and value of sacroiliac pain provocation tests in 54 patients with low back pain. Spine. 1996;21 : 1989-92.

7. O'Sullivan PB. Altered motor control strategies in subjects with sacroiliac joint pain during the active straight leg raise test. Spine. 2002;27(1):E1-8.

8. Stoev I, Powers AK, Puglisi JA, Munro R, Leonard JR. Sacroiliac joint pain in the pediatric population. J Neurosurg Pediatr. 2012;9(6):602-7.

9. Ristolainen L, Heinonen A, Turunen H, Mannstrom H, Waller B, Kettunen JA, Kujala UM. Type of sport is related to injury profile: a study on cross country skiers, swimmers, long distance runners, and soccer players. a retrospective 12-month study. Scand J Med Sci Sports. 2010;20(3):384-93.

10. Tunås $\mathrm{P}$, Nilstad A, Myklebust G. Low back pain in female elite football and handball players compared with an active control group. Knee Surg Sports Traumatol Arthrosc. 2015;23(9):2540-7.

11. Noormohammadpour P, Rostami M, Mansournia MA, Farahbakhsh F, Pourgharib shahi MH, Kordi R. Low back pain status of female university students in relation to different sport activities. Eur Spine J. 2016;25(4):1196-203.

12. Van Hilst J, Hilgersom NF, Kuilman MC, Kuijer PP, Frings-dresen MH. Low back pain in young elite field hockey players, football players and speed skaters: Prevalence and risk factors. J Back Musculoskelet Rehabil. 2015;28(1):67-73. 
13. Ko MJ, Noh KH, Kang MH, Oh JS. Differences in performance on the functional movement screen between chronic low back pain patients and healthy control subjects. J Phys Ther Sci. 2016;28(7):2094-6.

14. Riegger-Krugh C, Keysor JJ. Skeletal malalignments of the lower quarter: correlated and compensatory motions and postures. J Orthop Sports Phys Ther. 1996;23(2):164-70.

15. Bussey MD. Does the demand for asymmetric functional lower body postures in lateral sports relate to structural asymmetry of the pelvis. J Sci Med Sport. 2010;13(3):360-4.

16. Van Wingerden JP, Vleeming A, Snijders CJ, Stoeckart R. A functional-anatomical approach to the spine-pelvis mechanism: interaction between the biceps femoris muscle and the sacrotuberous ligament. Eur Spine J. 1993;2(3):140-4.

17. Harrison DE, Harrison DD, Troyanovich SJ. The sacroiliac joint: a review of anatomy and biomechanics with clinical implications. J Manip Physiol Ther. 1997;20(9): 607-17.

18. Franke BA. Formative dynamics: the pelvic girdle. J Man Manip Ther. 2003;11(1):12-40.

19. Van Wingerden JP, Vleeming A, Buyruk HM, Raissadat K. Stabilization of the sacroiliac joint in vivo: verification of muscular contribution to force closure of the pelvis. Eur Spine J. 2004;13(3):199-205.

20. Arab AM, Nourbakhsh MR, Mohammadifar A. The relationship between hamstring length and gluteal muscle strength in individuals with sacroiliac joint dysfunction. J Man Manip Ther. 2011;19(1):5-10.

21. Cibulka MT, Sinacore DR, Cromer GS, Delitto A. Unilateral hip rotation range of motion asymmetry in patients with sacroiliac joint regional pain. Spine. 1998;23(9):1009-15.

22. Roach SM, San juan JG, Suprak DN, Lyda M, Bies AJ, Boydston CR. Passive hip range of motion is reduced in active subjects with chronic low back pain compared to controls. Int $J$ Sports Phys Ther. 2015;10(1):13-20.

23. Bussey MD, Bell ML, Milosavljevic S. The influence of hip abduction and external rotation on sacroiliac motion. Man Ther. 2009;14(5):520-5.

24. Cook EG, Burton L, Hoogenboom BJ. Pre-participation screening: The use of fundamental movements as an assessment of function-Part 1. N AM J Sports Phys Ther. 2006;1(2):62-72.

25. Cook G. Movement: Functional Movement Systems, Screening - AssessmentCorrective Strategies. Lotus Publishing; 2011;6:88-104.

26. Cook EG, Burton L, Hoogenboom BJ. Functional movement screeing: The use of fundamental movements as an assessment of function-Part 1. Int J Sports Phys Ther. 2014;9(3):396-409. 
27. Kraus K, Schütz E, Taylor WR, Doyscher R. Efficacy of the functional movement screen: a review. J Strength Cond Res. 2014;28(12):3571-84.

28. Moran RW, Schneiders AG, Major KM, Sullivan SJ. How reliable are Functional Movement Screening scores? a systematic review of rater reliability. Br J Sports Med. 2016;50(9):52736.

29. Clifton DR, Harrison BC, Hertel J, Hart JM. Relationship between functional assessments and exercise-related changes during static balance. J Strength Cond Res. 2013;27(4):966972.

30. Shultz R, Anderson SC, Matheson GO, Marcello B, Besier T. Test-retest and interrater reliability of the functional movement screen. J Athl Train. 2013;48(3):331-6.

31. Beach TA, Frost DM, Callaghan JP. FMS scores and low back loading during lifting: whole body movement screening as an ergonomic tool? Appl Ergon. 2014;45(3):482-489.

32. Whiteside D, Deneweth JM, Pohorence MA, et al. Grading the functional movement screen: a comparison of manual (real-time) and objective methods. J Strength Cond Res. 2015;29(1):254-261.

33. Bonazza NA, Smuin D, Onks CA, Silvis ML, Dhawan A. Reliability, validity, and injury predictive value of the functional movement screen a systematic review and meta-analysis. Am J Sports Med. 2017;45(3):725-732.

34. Chorba RS, Chorba DJ, Bouillon LE, Overmyer CA, Landis JA. Use of a functional movement screening tool to determine injury risk in female collegiate athletes. $N$ Am J Sports Phys Ther. 2010;5(2):47-54.

35. Dossa K, Cashman G, Howitt S, West B, Murray N. Can injury in major junior hockey players be predicted by a pre-season functional movement screen: a prospective cohort study. J Can Chiropr Assoc. 2014;58(4):421-427.

36. Kiesel KB, Butler RJ, Plisky PJ. Prediction of injury by limited and asymmetrical fundamental movement patterns in American football players. $J$ Sport Rehabil. 2014;23(2):88-94.

37. Bardenett SM, Micca JJ, Denoyelles JT, Miller SD, Jenk DT, Brooks GS. Functional Movement Screen normative values and validity in high school athletes: can the FMS ${ }^{\text {TM }}$ be used as a predictor of injury. Int J Sports Phys Ther. 2015;10(3):303-8.

38. Dorrel BS, Long T, Shaffer S, Myer GD. Evaluation of the Functional Movement Screen as an injury prediction tool among active adult populations: a systematic review and metaanalysis. Sports Health. 2015;7(6):532-7. 
39. Garrison M, Westrick R, Johnson MR, Benenson J. Association between the functional movement screen and injury development in college athletes. Int J Sports Phys Ther. 2015;10(1):21-28.

40. Shultz SJ, Nguyen AD, Windley TC, Kulas AS, Botic TL, Beynnon BD. Intratester and intertester reliability of clinical measures of lower extremity anatomic characteristics: implications for multicenter studies. Clin J Sport Med. 2006;16(2):155-61.

41. Davis DS, Quinn RO, Whiteman CT, Williams JD, Young CR. Concurrent validity of four clinical tests used to measure hamstring flexibility. J Strength Cond Res. 2008;22(2):583-8.

42. Hamid MS, Ali MR, Yusof A. Interrater and intrarater reliability of the active knee extension (AKE) test among healthy adults. J Phys Ther Sci. 2013;25(8):957-61.

43. Neto T, Jacobsohn L, Carita AI, Oliveira R. Reliability of the Active-knee-extension and straight-leg-raise tests in subjects with flexibility deficits. J Sport Rehabil. 2015;17:20140220.

44. Schulze A, Böhme D, Weiss C, Schmittner MD. Active muscle extension testing of the hamstrings: reference values and impacting factors. Sportverletz Sportschaden. 2013;27(3):156-61.

45. Malliaropoulos N, Kakoura L, Tsitas K, et al. Active knee range of motion assessment in elite track and field athletes: normative values. Muscles Ligaments Tendons J. 2015;5(3):203-7.

46. Petrone MR, Guinn J, Reddin A, Sutlive TG, Flynn TW, Garber MP. The accuracy of the Palpation Meter (PALM) for measuring pelvic crest height difference and leg length discrepancy. J Orthop Sports Phys Ther. 2003;33(6):319-25.

47. Herrington L. Assessment of the degree of pelvic tilt within a normal asymptomatic population. Man Ther. 2011;16(6):646-8.

48. Azevedo DC, Santos H, Carneiro RL, Andrade GT. Reliability of sagittal pelvic position assessments in standing, sitting and during hip flexion using palpation meter. $J$ Bodyw Mov Ther. 2014;18(2):210-4.

49. Nussbaumer S, Leunig M, Glatthorn JF, Stauffacher S, Gerber H, Maffiuletti NA. Validity and test-retest reliability of manual goniometers for measuring passive hip range of motion in femoroacetabular impingement patients. BMC Musculoskelet Disord. 2010;11:194.

50. Roach S, San juan JG, Suprak DN, Lyda M. Concurrent validity of digital inclinometer and universal goniometer in assessing passive hip mobility in healthy subjects. Int J Sports Phys Ther. 2013;8(5):680-8. 
51. Kim SG, Kim EK. Test-retest reliability of an active range of motion test for the shoulder and hip joints by unskilled examiners using a manual goniometer. $J$ Phys Ther Sci. 2016;28(3):722-4.

52. Sankar WN, Laird CT, Baldwin KD. Hip range of motion in children: what is the norm. $J$ Pediatr Orthop. 2012;32(4):399-405.

53. Rakos DM, Shaw KA, Fedor RL, Lamanna M, Yocum CC, Lawrence KJ. Interrater reliability of the active-knee-extension test for hamstring length in school-aged children. Pediatr Phys Ther. 2001;13(1):37-41.

54. Wuensch, K. East Carolina Univeristy. Pearson correlation coefficient. Cohen's Conventions for Small, Medium and Large Effects.

55. Feldman DE. Risk factors for the development of low back pain in adolescents, McGill University; 1998.

56. Vleeming A, Schuenke MD, Masi AT, Carreiro JE, Danneels L, Willard FH. The sacroiliac joint: an overview of its anatomy, function and potential clinical implications. $J$ Anat. 2012;221(6):537-67.

57. Vleeming A, Pool-Goudzwaard AL, Stoeckart R, Van Wingerden JP, Snijders CJ. The posterior layer of the thoracolumbar fascia: its function in load transfer from spine to legs. Spine. 1995;20(7):753-8.

58. Mara JK, Thompson KG, Pumpa KL, Morgan S. Quantifying the high-speed running and sprinting profiles of elite female soccer players during competitive matches using an optical player tracking system. J Strength Cond Res. 2017;31(6):1500-1508.

59. Cuppett M, Paladino J. The anatomy and pathomechanics of the sacroiliac joint. Athl Ther Today. 2001;6(4):6-14.

60. Jayanthi NA, Labella CR, Fischer D, Pasulka J, Dugas LR. Sports-specialized intensive training and the risk of injury in young athletes: a clinical case-control study. Am J Sports Med. 2015;43(4):794-801.

61. Post EG, Trigsted SM, Riekena JW, et al. The association of sport specialization and training volume with injury history in youth athletes. Am J Sports Med. 2017;45(6):1405-1412.

62. Bell DR, Post EG, Trigsted SM, Hetzel S, Mcguine TA, Brooks MA. Prevalence of sport specialization in high school athletics: a 1-year observational study. Am J Sports Med. 2016;44(6):1469-74.

63. Fabricant PD, Lakomkin N, Sugimoto D, Tepolt FA, Stracciolini A, Kocher MS. Youth sports specialization and musculoskeletal injury: a systematic review of the literature. Phys Sportsmed. 2016;44(3):257-62. 
64. Levanon J, Dapena J. Comparison of the kinematics of the full-instep and pass kicks in soccer. Med Sci Sports Exerc. 1998;30:917-927.

65. Alderink GJ. The sacroiliac joint: a review of anatomy, mechanics, and function. J Orthop Sport Phys Ther. 1991;13:71-84.

66. Foley BS, Buschbacher RM. Sacroiliac joint pain: anatomy, biomechanics, diagnosis, and treatment. Am J Phys Med Rehabil. 2006;85(12):997-1006.

67. Brolinson PG, Kozar AJ, Cibor G. Sacroiliac joint dysfunction in athletes. Curr Sports Med Rep. 2003;2(1):47-56.

68. Geraci MC, Brown W. Evidence-based treatment of hip and pelvic injuries in runners. Phys Med Rehabil Clin N Am. 2005;16(3):711-47.

69. Barfield WR. The biomechanics of kicking in soccer. Clin Sports Med. 1998;17(4):711-28.

70. Lees A, Asai T, Andersen TB, Nunome H, Sterzing T. The biomechanics of kicking in soccer: a review. J Sports Sci. 2010;28(8):805-17.

71. Adhia DB, Milosavljevic S, Tumilty S, Bussey MD. Innominate movement patterns, rotation trends and range of motion in individuals with low back pain of sacroiliac joint origin. Man Ther. 2016;21:100-8.

72. Forst SL, Wheeler MT, Fortin JD, Vilensky JA. The sacroiliac joint: anatomy, physiology and clinical significance. Pain Phys. 2006;9(1):61-7.

73. Chesworth BM, Padfield BJ, Helewa A, et al. A comparison of hip mobility in patients with low back pain and matched healthy subjects. Physiother Can. 1994;46:267-74.

74. Van Dillen LR, Bloom NJ, Gombatto SP, Susco TM. Hip rotation range of motion in people with and without low back pain who participate in rotation-related sport. Phys Ther Sport. 2008;9:72-81.

75. Warren M, Smith CA, Chimera NJ. Association of the functional movement screen with injuries in Division I athletes. J Sport Rehabil. 2015;24(2):163-170.

76. Clay H, Mansell J, Tierney R. Association between rowing injuries and the functional movement screen ${ }^{\mathrm{TM}}$ in female collegiate division I rowers. Int J Sports Phys Ther. 2016;11(3):345-9.

77. Laslett M. Evidence-based diagnosis and treatment of the painful sacroiliac joint. $J$ Man Manip Ther. 2008;16(3):142-52. 
78. Robinson HS, Brox JI, Robinson R, Bjelland E, Solem S, Telje T. The reliability of selected motion and pain provocation tests for the sacroiliac joint. Man Ther. 2007;12:72-79.

79. Van der Wurff P, Hagmeijer RH, Meyne W. Clinical tests of the sacroiliac joint: a systematic methodological review. part 1: reliability. Man Ther. 2000;5:30-36.

80. Vincent-Smith B, Gibbons P. Inter-examiner and intra-examiner reliability of the standing flexion test. Man Ther. 1999;4:87-93.

81. Carmichael JP. Inter- and intra-examiner reliability of palpation for sacroiliac joint dysfunction. J Manipulative Physiol Ther. 1987;10:164-171.

82. Potter NA, Rothstein JM. Intertester reliability for selected clinical tests of the sacroiliac joint. Phys Ther. 1985;65:1671-1675. 


\section{APPENDICES}




\section{APPENDIX A}

\section{THE PROBLEM}

\section{Research Question}

Low back pain (LBP) has been shown to affect up to $80 \%$ of the general population at some point in their lifetime. ${ }^{1,2}$ Although LBP is a main symptom, sacroiliac joint dysfunction (SIJD) often clinically presents with LBP, thus leading to the conclusion that LBP can be caused by various injuries. Specifically, amongst the adolescent population prevalence of LBP has reported to range from $30 \%$ to $74 \% .{ }^{3,4}$ Low back pain, which can be caused by SIJD, was found to increase with age amongst the adolescent population. Increases in LBP are evident starting with $1 \%$ at seven years of age, to $17 \%$ at twelve years of age, and climbs to $53 \%$ at 15 years of age. ${ }^{5}$ Further, prevalence amongst adolescents with SIJD pain has been reported to range from $13 \%$ to $30 \%$ of all injuries with LBP as a symptom. ${ }^{6,7}$

Sacroiliac joint dysfunction is prevalent perhaps due to an increase in LBP in the adolescent population. Historically SIJD has been seen in young athletes who have sustained some form of mild trauma, however, more athletes now are experiencing a chronic onset. ${ }^{8}$ SIJD is commonly seen in sports with unilateral and repetitive biomechanical forces, such as kicking in soccer. In one study ${ }^{9}$ LBP was found to be the most prevalent previous overuse injury with an incidence of $28 \%$ among soccer players. At least $60.6 \%$ of soccer players $(n=190)$ were found to have experienced LBP in their lifetime, and $56.9 \%$ felt it in the previous 12 months, resulting in $27.7 \%$ missing training from injury. ${ }^{10}$ Another study ${ }^{11}$ reported $54.4 \%$ of futsal players experiencing LBP in their lifetime, and $25.7 \%$ had absence from training sessions due to LBP. Although there is little research on specifically SIJD there is an apparent link between LBP and SIJD resulting in time loss for athletes, specifically soccer. 
The sacroiliac joint (SIJ) has been described as a diarthrodial joint. The sacrum articulates with the right and left ilium of the pelvic bones. ${ }^{66}$ There are several ligaments that support the sacrum and the SIJ. These ligaments include the anterior sacroiliac, dorsal sacral, the interosseous SI, sacrospinous, iliolumbar, and most importantly the sacrotuberous. ${ }^{17,65}$ The sacrotuberous ligament connects the ischial tuberosity to the sacrum preventing sacral flexion and rotation, and acts at the bridge for the hamstrings to the sacrum. ${ }^{17}$ In soccer athletes, the hamstrings are constantly activated, which in turn increases the stress demand on the SIJ. This mechanism occurs during kicking as the hamstring is elongated, which increases the tension on the sacrotuberous ligament.

There are also several muscles that interact with the sacrum that provide dynamic stabilization. The gluteus maximus, erector spinae, and piriformis muscles all have attachments to the sacrum. ${ }^{65,67}$ With the gluteus maximus' origination over the lateral border of the sacrum, this muscle acts as an important stabilizer of the SIJ in multiple planes of movement. In soccer where the hip flexors are dominant, reciprocal inhibition may lead to weak gluteal muscles. A weak gluteus maximus could lead to poor gait mechanics and kicking patterns increasing the instability and risk of injury to the SIJ.

The sacrum in literature is described as the gateway for transmitting force from the lower extremities to the spinal column. ${ }^{17,65-68}$ The motions that occur through the SIJ have been described as complex, existing in several different oblique planes. ${ }^{66,67}$ Furthermore, the SIJ has no single axis of motion, rather it has been described to have 6 degrees of freedom. ${ }^{83}$ In soccer motions occurring throughout the kinetic chain vary tremendously between dribbling, passing, and longballs. The diagonal force and follow through motion of kicking can contribute to additional stress at the SIJ and increase risk of injury. 
The prevalence of LBP and SIJD amongst soccer athletes is high. The nature of soccer places high intensity forces on the lower extremities that are often unilaterally dominant. These forces are transferred superiorly to the trunk through the sacrum and SIJ acting as the gateway. The biomechanical demand of playing soccer, with bending and twisting of the trunk are a reason for SIJD to occur at such a high rate. ${ }^{11,12}$ Further into the research, it is found that goalkeepers and midfielders had the highest rate of LBP potentially caused by SIJ. One study reported playing midfield $\left(\mathrm{R}^{2}=.92, \mathrm{p}=.03\right)$ and goalkeeper $\left(\mathrm{R}^{2}=1.11, \mathrm{p}=.05\right)$ were both found to be at a greater risk for LBP during the previous 12 months. ${ }^{10}$ When investigating the physical demands of both of these positions, the risk for developing SIJD become apparent. Goal keepers often are diving into uneven landings and using quick reflexive actions to make attempts at incoming players and balls. Midfielders must complete an array of skills on the field as they serve for both offensive and defensive purposes. They are also most prone to fatigue as they typically travel the most in game experiences. ${ }^{58}$ Together these traits combine to potentially explain why these two positions are at an elevated risk.

With consideration to the anatomy of the SIJ, the biomechanics of the SIJ, and the prevalence of SIJ in soccer athletes, a screening tool should be created looking at different risk factors. Four different components that should be considered are the Functional Movement Screen (FMS), hamstring length, pelvic positioning, and hip range of motion (ROM).

The FMS is a preexisting screening tool that investigates seven fundamental movement patterns (deep squat, hurdle step, active straight leg raise (ASLR), rotary stability, inline lunge, shoulder mobility, and trunk stability push up) that are each scored on a scale of 0 to 3 . A total score is combined, with scores of 14 or below indicating those who are at a predisposed risk for injury. Currently there is little research available on whether the FMS subtests correlate with 
predicting SIJD. Only one study was conducted comparing FMS with chronic LBP patients to healthy controls. The authors ${ }^{13}$ reported that the chronic LBP patients scored significantly lower on the deep squat $(\mathrm{p}=.002)$, hurdle step $(\mathrm{p}=.002)$, ASLR $(\mathrm{p}=.005)$, and rotary stability ( $p<.001)$ compared to the healthy controls. The results of this study indicate that those four tests of the FMS could contribute to accurately predicting SIJD. A low score on these tests potentially indicate weakness in muscles that are responsible for stabilizing the SIJ.

The hamstrings play a vital role in SIJ stability through the proximal origination at the ischial tuberosity in the posterior ilium and attachment to the sacrotuberous ligament. Hamstring tightness in individuals with LBP could be a compensatory mechanism for weak gluteal muscles, which in turn decrease the compression stability mechanism of the SIJ. ${ }^{16,19}$ Further, a link between SIJD and hamstring muscle strains may exist, as treatment of hamstring strains that included a corrective SIJ manipulation created an increase in hamstring length and resolution of symptoms. ${ }^{84}$ Subjects with SIJD had significantly shorter hamstring muscle length in individuals with gluteal weakness compared to those who did not have gluteal weakness. ${ }^{20}$ Soccer players during the kicking motion increase the eccentric load placed on the hamstring muscle group which may contribute to muscle tightness making hamstring length shorter.

Pelvic positioning is another potential predictive factor for SIJD. The movement of the innominates in both static and dynamic positions directly affects the motion of the sacrum, therefore the motion that occurs at the SIJ. Malalignment of the innominates and other irregular pelvic positioning has the potential to negatively impact the SIJ. Pelvic asymmetry has been shown to contribute to altered lower extremity mechanics and contribute to SIJD in the frontal and sagittal planes. ${ }^{14}$ Athletes who participate in a sport with lateral movements, much like a goalkeeper or defender in soccer, would affect pelvic posture. Those who played in a lateral 
dominant sport had more incidence of back pain compared to non-athletes, and athletes who participated in sports without a lateral component. ${ }^{15}$ Specific pelvic asymmetry such as, left anterior interior chain (AIC) pattern, has been described as the tendency to shift the center of gravity (COG) to the right with the pelvis and lumbar vertebrae rotated right and upper thoracic vertebrae and pubic symphysis rotated left. ${ }^{85}$ This pattern could be apparent in soccer players as more time is spent on one extremity, especially with the planting leg during the kicking motion.

Hip ROM is well cited in the literature in contributing to SIJ motion. ${ }^{15,21,23}$ Similar to SIJ motion with six degrees of freedom in the unique oblique axis, all planes of hip ROM impact SIJ motion. Hip rotation was a strong predictor for innominate angle, which in turn affects the motion occurring at the SIJ. ${ }^{23}$ The link between hip internal and external rotation and SIJD was also evaluated. Individuals with LBP including some with designated SIJ pain demonstrated a hip asymmetry of decreased internal rotation on the affected side compared bilaterally to the unaffected side. ${ }^{21}$ Using a control group design, subjects with non-specific low back pain were compared to healthy controls to analyze hip rotation and extension. The control group had greater hip extension then those with LBP. ${ }^{22}$ It was discussed that the decrease of hip extension during gait could have led to altered muscle activation in the lumbo-pelvic region and resulted in an adapted posture resulting in LBP. ${ }^{22}$ In soccer athletes a similar hip adaptation may occur resulting in unilateral hip ROM deficits from a repetitive kicking motion.

There is a plethora of knowledge on the SIJ in terms of anatomy, biomechanics, treatment, and rehabilitation. There is also a great deal of research on SIJD and LBP in athletes in the adult population across a wide span of sports. Conversely, there is a lack of knowledge on SIJD in adolescent athletes. Pain caused by SIJD historically has been more prominent in the adult population, however it has become increasingly prevalent in the adolescent population for 
reasons that are not well understood. ${ }^{2}$ With the increase of SIJD incidence in the adolescent population, some type of screening tool must be developed to assess predictive factors of SIJD, especially in soccer athletes. Currently there is no constructed clinical screening tool to assess predictive factors for SIJD in the adolescent soccer athlete population. Thus, the following questions were asked:

Research Questions

1. Can the composite score of the FMS accurately predict the risk of an SIJD injury in adolescent soccer athletes?

2. Can pelvic positioning, such as an anterior pelvic tilt, accurately predict the risk of SIJD in adolescent soccer athletes.

3. Can functional hamstring length accurately predict the risk of SIJD in adolescent soccer athletes?

4. Can hip active ROM, compared bilaterally accurately predict the risk of SIJD in adolescent soccer athletes?

Experimental Hypothesis

1. The composite score of the FMS will be less than or equal to 14 in those who sustained a SIJD injury.

2. An increased anterior pelvic tilt will be observed in those who sustained a SIJD injury.

3. Functional hamstring length will be decreased in those who sustained a SIJD injury.

4. Deficits in active hip IR/ER, ABD and/or Ext will be observed in those who sustained a SIJD injury.

Assumptions

1. All subjects will meet the inclusion criteria for the research study.

2. The instruments and techniques used will be valid and reliable.

3. Evaluation tests will be performed identically on subjects.

4. The documentation of each subjects' evaluation will be accurate. 
5. All SIJD injuries are reported and documented accurately in the subject population.

\section{Delimitations}

1. Subject population will be limited to only male and female soccer athletes from one high school in north central West Virginia.

2. Subjects will be between the ages of 15 and 18 and will potentially be participating in travel soccer and/or winter season sports at the time of data collection.

Operational Definitions

1. AIC pattern - Anterior Interior Chain pattern; An inherent pattern of asymmetry involving the trunk, ribs, spine, pelvis, and hip joints where the COG is shifted to the leg that is predominantly used in standing. ${ }^{85}$

2. Acute Injury - An injury that occurred in practice or competition with an acute mechanism that resulted in medical exclusion of a minimum two consecutive weeks of practice or competition.

3. FMS - Functional Movement Screen; A comprehensive examination that assesses seven different fundamental movements previously identified as foundation for more advanced dynamic movements. Each movement is graded 0 to 3 with a cumulative score ranging from 0 to 21 . Scores of 14 or lower are associated with increased risk of injury. ${ }^{13}$

4. Hip ROM IR - Hip range of motion internal rotation; Angle measurements using a goniometer for the motion. IR is motion occurring in the transverse plane as the hip rotates in toward the midline of the body. ${ }^{21,22,52,73}$

5. Hip ROM ER - Hip range of motion external rotation; Angle measurements using a goniometer for the motion. ER is motion occurring in the transverse plane as the hip rotates out away from the body. ${ }^{21-23,52,73}$

6. Hip ROM ABD - Hip range of motion abduction; Angle measurements using a goniometer for the motion. $\mathrm{ABD}$ is motion occurring in the frontal plane as the leg is moved away from the body. ${ }^{21-23,52,73}$

7. Hip ROM ADD - Hip range of motion adduction; Angle measurements using a goniometer for the motion. ADD is motion occurring in the frontal plane as the leg is moved toward the midline of the body. ${ }^{21,22,52,73}$

8. Hip ROM Flex - Hip range of motion flexion; Angle measurements using a goniometer for the motion. Flexion is motion occurring in the sagittal plane as the leg is moved forward. ${ }^{21,22,52,73}$ 
9. Hip ROM Ext - Hip range of motion extension; Angle measurements using a goniometer for the motion. Extension is motion occurring in the sagittal plane as the leg is moved backward. ${ }^{21,22,52,73}$

10. LBP - Low back pain; Pain in the lumbo-pelvic region that can be caused by an array of different problems including SIJD ${ }^{1,2,6,7}$

11. Level Belt Pro Application - Also referred to as an iPod-based tilt sensor; which measures pelvic positioning, such as anterior/posterior/lateral pelvic tilt to help determine neutral pelvic tilt. ${ }^{86}$

12. PALM - Palpation Meter; A device with two adjustable calipers and an inclinometer that can be used to measure pelvic positioning. ${ }^{47}$

13. Pelvic Positioning - Measurement of the pelvic innominates in a resting position compared to a neutral position.

14. SIJ- Sacroiliac Joint; A diarthrodial joint, that consists of the sacrum articulating with the right and left ilium of the pelvic bones. ${ }^{66}$

15. SIJD - Sacroiliac joint dysfunction; An injury noted by pain that occurs at the SIJ due to mechanical stress ${ }^{66,67}$

16. Six degrees of freedom - Motion of the sacrum defined as moving along an $\mathrm{X}, \mathrm{Y}$, and $\mathrm{Z}$ axis including sacral extension, flexion, left rotation, right rotation, and lateral flexion. ${ }^{55}$

Limitations

1. Participants can drop out at any time.

2. The study may not be generalizable to other adolescent athletes in different populations.

3. No SIJD specific screening tool exists as to what should be included.

4. Subjects may not give $100 \%$ while performing evaluation tests.

5. Limited research on predictive factors of SIJD with adolescent soccer athletes.

6. The investigator performing all testing measurements on the subjects was the main clinician for the diagnosis of an SIJD injury.

Significance of the Study

Sacroiliac joint dysfunction prevalence in the adolescent athletic population has been on the rise and reasoning behind this is not understood. Research should be conducted on how well 
potential predictive variables for SIJD in adolescent athletes so the mechanism and risk factors behind this injury can be better understood. A reliable and valid screening tool can also be created to identify at risk athletes early in the off season or preseason. At that time, a preventative program intervention can take place to reduce the athletes risk of injury and overall reduce time lost in training and competition. Benefits from this study may reveal what some of those accurate predictive factors are, such as the FMS, pelvic positioning, hamstring length, hip ROM, and potentially others. From that a base screening tool may be developed for SIJD in adolescent soccer athletes. Future researchers should be able to apply the results to conduct additional studies on other adolescent and college aged athletes in a variety of sports to evaluate the usefulness of the screening tool.

At the completion of this study, dissemination of information will occur. This information will have a direct affect on the athletes to better understand movement patterns, risk of injury, and how to decrease that risk. The information will also be beneficial to clinicians who choose to incorporate these components into a screening tool to evaluate deficits prior to the start of the season. Both the athletes and coaches will benefit from this study as the athlete's potential for injury can be decreased with preventative rehabilitation programs, ultimately decreasing the amount of time lost in training and competition directly contributing to the success of the team. To further benefit the athletes, clinicians, and coaches this information can be presented at symposiums, workshops, or conventions. 


\section{APPENDIX B \\ LITERATURE REVIEW}

Introduction

Sacroiliac joint dysfunction has been reported to affect $13 \%$ to $30 \%$ of all individuals with non-specific LBP. ${ }^{71,87}$ SIJD has traditionally been thought to only exist in an older population, however, the prevalence among adolescents is increasing. ${ }^{2}$ Among adolescents, SIJD has been reported to range from $13 \%$ to $30 \%$ of all LBP injuries. ${ }^{6,7}$ In the athletic population, SIJD injuries were only thought to occur in acute instances to adolescents. From a clinical perspective, SIJD in the adolescent population is starting to become a chronic problem. ${ }^{8}$ The complex motion at the SIJ that exists in different oblique planes contributes to the onset of the injury. ${ }^{66,67}$ The motion at the SIJ has also been described as having six degrees of freedom. ${ }^{83}$ The SIJ acts as the gateway to transmitting forces from the lower extremities to the trunk. ${ }^{17,65-68}$ In sports with repetitive motion, such as soccer, these forces intensify these motions of the joint and may lead to a chronic onset of injury.

As the problem of SIJD continues to increase in the adolescent athlete the need for a screening tool becomes apparent. With the use of screening tool, deficiencies may be detected, and appropriate preventative interventions may be implemented. The FMS, hamstring length, pelvic positioning, and hip ROM should be considered as components to a screening tool. The FMS has been shown to reliably assess risk of injury in an athletic population. ${ }^{34,76}$ Considering biomechanics of the SIJ and biomechanics of soccer, hamstring length, pelvic positioning, and hip ROM should be included as a component of the screening tool. In this literature review the following topics will be discussed: the anatomy of the SIJ, the biomechanics of the SIJ, the 
biomechanics of soccer, epidemiology of soccer, and the FMS, hamstring length, pelvic positioning, and hip ROM as the four different components to a potential screening tool. Anatomy of the Sacroiliac Joint

The SIJ is a true diarthrodial joint, the sacrum articulates with the right and left ilium of the pelvic bones. ${ }^{66,72}$ The joint space between the sacrum and the ilia contains synovial fluid, and the space is encased by a fibrous capsule similar to many other articular joints in the body. ${ }^{72}$ Typically, the articulating surfaces of the SIJ are formed within the first three sacral segments, $\mathrm{S} 1, \mathrm{~S} 2$, and S3, although in females it is not common to see inclusion of the complete S3 segment. ${ }^{56}$ The S1 segment therefore creates the largest portion of the articulating surface, whereas the S3 segment contributes the smallest. The articular surfaces of the SIJ at the sacral base are wider posteriorly than anteriorly, whereas at the lower portion the anterior aspect is wider than the posterior. ${ }^{17}$ The shape of these articular surfaces have been shown to differ between sexes, due most in part to the S3 segment. In males, the articular surface between the sacrum and ilium are shaped like an "inverted L", while in females they are generally smaller and more oblique shaping a "C" appearance. ${ }^{17,56}$ Considering development of the SIJ and sacral segments, ossification of the first two sacral segments begins in utero ${ }^{56,88}$ After birth and into late adolescence the development of the sacrum and the SIJ is variable between individuals. Apophyses surrounding the SIJ will fuse between the ages of 16 and $20{ }^{89}$ This variability of development with the addition of stress induced by repetitive motion in soccer may contribute to the increase in prevalence of SIJD in adolescents.

In addition to the stability provided by the bony anatomy of the SIJ, there are several ligaments that provide static and dynamic support to the SIJ. Some of these ligaments due to their anatomical positions interact with the thoracolumbar fascia (TLF) to provide dynamic 
support. Descriptions of these ligaments and the TLF are discussed in Table B1. Of these ligaments the anterior SI ligament, the dorsal sacral ligament, interosseous SI ligament, and sacrospinous ligament directly create static stabilization of the SIJ due to anatomical proximity to the joint. ${ }^{17,65}$ Conversely the sacrotuberous and iliolumbar ligaments provide dynamic stabilization of the joint as forces are transmitted from the lower extremities to the spinal column. ${ }^{17,56,65}$ As injury to the SIJ occurs in soccer with the repetitive motion, sequelae to these ligaments can be expected. The TLF spans from the thoracic region to the sacrum, serving as a primary attachment site for the main movers and stabilizers of the spine. The TLF is comprised of three different layers, the lumbar posterior layer, the middle lumbar posterior layer, and the lumbar anterior layer. ${ }^{17,67}$ Each of these layers work as a system to coordinate all the various anatomical structures in concert. ${ }^{17}$

Table B1. Ligamentous/Fascia Support Structures of the Sacrum ${ }^{17,56,59,65,90}$

\begin{tabular}{|c|c|c|c|}
\hline Structure & Sacrum Attachment & Other Attachment & Stability \\
\hline Anterior SI Ligament & $\begin{array}{l}\text { Anterior superior (S1-S3) } \\
\text { portion of lateral border of } \\
\text { sacrum }\end{array}$ & $\begin{array}{l}\text { Articulating SIJ } \\
\text { surfaces of the ilia }\end{array}$ & $\begin{array}{l}\text { Opposes translation of the } \\
\text { sacrum superior/inferior } \\
\text { and separation of the } \\
\text { articulating surfaces of the } \\
\text { SIJ }\end{array}$ \\
\hline Dorsal Sacral Ligament & $\begin{array}{l}\text { Posterior (S3-S5) portion } \\
\text { of lateral border of sacrum }\end{array}$ & $\begin{array}{l}\text { Long - Posterior } \\
\text { superior iliac spine }\end{array}$ & $\begin{array}{l}\text { Opposes anterior rotation } \\
\text { of sacrum on the ilia }\end{array}$ \\
\hline Interosseous SI Ligament & $\begin{array}{l}\text { Posterior portion of lateral } \\
\text { border of Sacrum }\end{array}$ & $\begin{array}{l}\text { Articulating SIJ } \\
\text { surfaces of the ilia }\end{array}$ & Opposes distraction of SIJ \\
\hline Sacrospinous Ligament & $\begin{array}{l}\text { Lateral border (S3-S5) of } \\
\text { the sacrum }\end{array}$ & $\begin{array}{l}\text { Lateral border of } \\
\text { coccyx } \\
\text { Ischial tuberosity via } \\
\text { the sacrotuberous } \\
\text { ligament }\end{array}$ & $\begin{array}{l}\text { Opposes sacral rotation on } \\
\text { the ilia }\end{array}$ \\
\hline Sacrotuberous Ligament & $\begin{array}{l}\text { Lateral border (S3-S5) of } \\
\text { the sacrum }\end{array}$ & $\begin{array}{l}\text { Lateral border of the } \\
\text { coccyx } \\
\text { Ischial tuberosity }\end{array}$ & $\begin{array}{l}\text { Dynamic stability as force } \\
\text { transfers from the } \\
\text { hamstrings to the sacrum }\end{array}$ \\
\hline Iliolumbar Ligament & None & $\begin{array}{l}\text { Transverse process of } \\
\text { L5 } \\
\text { Posterior portion of } \\
\text { the inner lip of the } \\
\text { iliac crest } \\
\text { Thoracolumbar } \\
\text { Fascia }\end{array}$ & $\begin{array}{l}\text { Assists in stabilization of } \\
\text { the lumbosacral junction }\end{array}$ \\
\hline
\end{tabular}


Thoracolumbar Fascia
SIJ, and indirectly through the multifidis and erector spinae groups
Quadratus lumborum, latissimus dorsi, and erector spinae group muscles. Iliolumbar ligament, lumbar vertebrae, lower thoracic vertebrae, and iliac crest

There are also several muscles that interact with the sacrum that provide dynamic stabilization. The gluteus maximus, erector spinae, multifidus, and piriformis muscles all have attachments to the sacrum. ${ }^{65,67}$ These muscles however do not serve to attach the sacrum directly to the ilium, but rather from the sacrum to various other bony structures. This makes the SIJ unique as there is no muscle acting directly over it. The activation of these muscles directly impacts the stability and mobility of the sacrum and SIJ. Upon activation of these muscles, the "force closure" mechanism is put into effect. The "force closure" mechanism is the active compression of the SIJ produced by muscle activation, body weight, and ligamentous force. ${ }^{16,18,19}$ The stability this creates has been described as a complex self-bracing mechanism. ${ }^{17}$ The strength and endurance of these muscles becomes increasingly important to provide stability at the SIJ during functional activities of daily living, and more forceful activities such as lateral and rotational movements in soccer. Other muscles involved that do not have an attachment to the sacrum include gluteus medius, latissimus dorsi, quadratus lumborum, biceps femoris, psoas major, and transverse abdominis, and diaphragm. Even though they do not have an attachment directly on the sacrum, the latissimus dorsi, and biceps femoris have been shown to be important contributors to the "force closure" mechanism. ${ }^{18,57}$ The latissimus dorsi works with the contralateral gluteus maximus to generate the force closure on the SIJ as co-activation occurs and force is transferred through the posterior layer of the thoracolumbar fascia. ${ }^{18,19,57}$ The biceps femoris has two roles in the dynamic stability of the SIJ. Force is transferred superiorly to the SIJ 
through the sacrotuberous ligament, and the biceps femoris also may act as a hip extensor contracting with the gluteus maximus to aid in the "force closure" mechanism. ${ }^{18,59}$ Every muscle along with the origin, insertion, action, and innervation are listed in Table B2. Beyond these few main contributors all the other muscles mentioned in Table B2 allow for further stabilization of the SIJ in multiple planes of movement.

The muscles of the lumbo-pelvic region have also been categorized into outer and inner units to describe the stability that they provide. The inner unit is described as involving the multifidus, transverse abdominis, diaphragm, and the pelvic floor, while the outer unit involves the latissimus dorsi, gluteus maximus, gluteus medius, erector spinae, biceps femoris, and the obliques. ${ }^{18,65,91}$ The inner unit has direct influence on the SIJ or the innominates creating stability in posture, respiration, and movement. ${ }^{18,91}$ The outer unit consists of larger muscles with greater force production that becomes essential with functional movements. For example, the gluteus maximus and latissimus dorsi, coupled with the thoracolumbar fascia, create a stabilizing force perpendicular to the SIJ while dynamic movements occur. ${ }^{19}$ These two units of muscle must work together to provide the stabilization needed during sports specific movements. If there is a deficit or dysfunction in a portion of a unit it may lead to increased stress at the SIJ and result in injury. ${ }^{17,18,67}$

Table B2. Muscle Origin/Insertion/Action/Innervation Surrounding the SI ${ }^{17,56,59,65,72,92,93}$

\begin{tabular}{|c|c|c|c|c|}
\hline Muscle & Origin & Insertion & Action & Innervation \\
\hline Gluteus Maximus & $\begin{array}{l}\text { Posterior surface of } \\
\text { lower part of } \\
\text { sacrum, posterior } \\
\text { gluteal line, side of } \\
\text { coccyx, TLF, } \\
\text { sacrotuberous } \\
\text { ligament and gluteal } \\
\text { aponeurosis }\end{array}$ & $\begin{array}{l}\text { ITB, gluteal } \\
\text { tuberosity of femur }\end{array}$ & $\begin{array}{l}\text { Extension and } \\
\text { lateral rotation of } \\
\text { hip; adduction of } \\
\text { hip; stabilize knee } \\
\text { in extension through } \\
\text { ITB }\end{array}$ & $\begin{array}{l}\text { Inferior gluteal } \\
\text { nerve }\end{array}$ \\
\hline $\begin{array}{l}\text { Erector Spinae } \\
\text { (Spinalis, }\end{array}$ & $\begin{array}{l}\text { Common } \\
\text { tendon(TLF) that } \\
\text { attaches to the }\end{array}$ & $\begin{array}{l}\text { Various attachments } \\
\text { at the posterior ribs, } \\
\text { spinous and }\end{array}$ & $\begin{array}{l}\text { Laterally flex } \\
\text { vertebral column to } \\
\text { the same side; }\end{array}$ & Spinal \\
\hline
\end{tabular}




\begin{tabular}{|c|c|c|c|c|}
\hline $\begin{array}{l}\text { Longissimus, } \\
\text { Iliocostalis) }\end{array}$ & $\begin{array}{l}\text { posterior surface of } \\
\text { sacrum, iliac crest, } \\
\text { spinous processes of } \\
\text { the lumbar and last } \\
\text { two thoracic } \\
\text { vertebrae }\end{array}$ & $\begin{array}{l}\text { transverse processes } \\
\text { of thoracic and } \\
\text { cervical vertebrae } \\
\text { and mastoid process } \\
\text { of temporal bone }\end{array}$ & $\begin{array}{l}\text { extend vertebral } \\
\text { column }\end{array}$ & \\
\hline Multifidus & $\begin{array}{l}\text { Sacral Region: } \\
\text { Posterior sacrum, } \\
\text { medial posterior } \\
\text { iliac spine, dorsal } \\
\text { sacral ligaments } \\
\text { Transverse process } \\
\text { of C4-L5 }\end{array}$ & Spinous Process & $\begin{array}{l}\text { Extension of } \\
\text { vertebral column } \\
\text { and rotation to } \\
\text { opposite side }\end{array}$ & $\begin{array}{l}\text { Posterior primary } \\
\text { divisions of the } \\
\text { spinal nerves }\end{array}$ \\
\hline Piriformis & $\begin{array}{l}\text { Anterior surface of } \\
\text { the Sacrum }\end{array}$ & $\begin{array}{l}\text { Superior aspect of } \\
\text { greater trochanter }\end{array}$ & $\begin{array}{l}\text { Laterally rotate the } \\
\text { hip, and abduct the } \\
\text { hip when hip is } \\
\text { flexed }\end{array}$ & Sacral Plexus \\
\hline Gluteus Medius & $\begin{array}{l}\text { External surface of } \\
\text { ilium, between iliac } \\
\text { crest and posterior } \\
\text { gluteal line dorsally } \\
\text { and anterior gluteal } \\
\text { line ventrally, } \\
\text { gluteal aponeurosis }\end{array}$ & $\begin{array}{l}\text { Oblique ridge on the } \\
\text { lateral surface of the } \\
\text { greater trochanter }\end{array}$ & $\begin{array}{l}\text { Abducts hip, } \\
\text { medially rotate and } \\
\text { flex hip, laterally } \\
\text { rotate and extend } \\
\text { hip }\end{array}$ & $\begin{array}{l}\text { Superior gluteal } \\
\text { nerve }\end{array}$ \\
\hline Latissimus Dorsi & $\begin{array}{l}\text { Inferior angle of } \\
\text { scapula, spinous } \\
\text { processes of last six } \\
\text { thoracic vertebrae, } \\
\text { last three or four } \\
\text { ribs, TLF, and } \\
\text { posterior iliac crest }\end{array}$ & $\begin{array}{l}\text { Intertubercular } \\
\text { groove of the } \\
\text { humerus }\end{array}$ & $\begin{array}{l}\text { Extend, adduct, and } \\
\text { medially rotate the } \\
\text { shoulder }\end{array}$ & Thoracodorsal nerve \\
\hline $\begin{array}{l}\text { Quadratus } \\
\text { Lumborum }\end{array}$ & $\begin{array}{l}\text { Iliolumbar ligament, } \\
\text { iliac crest }\end{array}$ & $\begin{array}{l}\text { Inferior border of } \\
\text { the last rib and } \\
\text { transverse process } \\
\text { of L1-L4 vertebrae }\end{array}$ & $\begin{array}{l}\text { Extension, lateral } \\
\text { flexes lumbar } \\
\text { vertebral column, } \\
\text { depresses last rib, } \\
\text { fixes last } 2 \text { ribs } \\
\text { during respiration }\end{array}$ & Lumbar plexus \\
\hline Biceps Femoris & $\begin{array}{l}\text { Long Head: Ischial } \\
\text { tuberosity } \\
\text { Short Head: Lateral } \\
\text { lip of linea aspera }\end{array}$ & Head of the fibula & $\begin{array}{l}\text { Flex the knee, } \\
\text { laterally rotate the } \\
\text { flexed knee, extend } \\
\text { the hip, and tilt the } \\
\text { pelvis posteriorly }\end{array}$ & $\begin{array}{l}\text { Sciatic Nerve from } \\
\text { the tibial and } \\
\text { peroneal branches }\end{array}$ \\
\hline Psoas Major & $\begin{array}{l}\text { Ventral surface of } \\
\text { transverse process } \\
\text { of all lumbar } \\
\text { vertebrae, sides of } \\
\text { bodies, and } \\
\text { corresponding } \\
\text { intervertebral discs } \\
\text { of T12-L5. } \\
\text { Membranous arches } \\
\text { that extend over } \\
\text { sides of bodies of } \\
\text { lumbar vertebrae }\end{array}$ & $\begin{array}{l}\text { Lesser trochanter of } \\
\text { femur }\end{array}$ & Hip flexion & Lumbar plexus \\
\hline
\end{tabular}




\begin{tabular}{|c|c|c|c|c|}
\hline $\begin{array}{l}\text { Transverse } \\
\text { Abdominis }\end{array}$ & $\begin{array}{l}\text { Lower } 6 \text { ribs, lateral } \\
1 / 3 \text { inguinal } \\
\text { ligament, lip of iliac } \\
\text { crest }\end{array}$ & $\begin{array}{l}\text { Linea alba, pubic } \\
\text { crest }\end{array}$ & $\begin{array}{l}\text { Stabilization, holds } \\
\text { internal organs in }\end{array}$ & $\begin{array}{l}\text { Thoracoabdominal } \\
\text { nerves, } 1^{\text {st }} \text { lumbar } \\
\text { nerve, Posterior } \\
\text { primary divisions of } \\
\text { spinal nerves }\end{array}$ \\
\hline Diaphragm & $\begin{array}{l}\text { Inner surface of } \\
\text { lower six ribs } \\
\text { Upper two or three } \\
\text { lumbar vertebrae } \\
\text { Inner part of } \\
\text { xiphoid process }\end{array}$ & Central tendon & $\begin{array}{l}\text { Draw down the } \\
\text { central tendon of the } \\
\text { diaphragm } \\
\text { Increase the volume } \\
\text { of the thoracic } \\
\text { cavity during } \\
\text { inhalation }\end{array}$ & Phrenic nerve \\
\hline
\end{tabular}

Biomechanics of the Sacroiliac Joint

The sacrum in literature is described as the gateway for transmitting force from the lower extremities to the spinal column. ${ }^{17,65-68}$ The motions that occur through the SIJ exists in several different oblique planes. ${ }^{66,67}$ Furthermore, the SIJ has no single axis of motion, rather it has been described to have 6 degrees of freedom. ${ }^{83}$ Since the SIJ is not a simple synovial joint motion is necessary at the SIJ even though it is not a significant amount of motion. The SIJ has been described as having only two to three degrees of motion. ${ }^{17,65,66}$ Further, sacroiliac motion was reported to average 2.5 degrees with a range of $0.8-3.9$ degrees. ${ }^{94,95}$ Translation of the sacrum has been reported to range from $0.1 \mathrm{~mm}$ to $1.6 \mathrm{~mm}$ with an average of $0.7 \mathrm{~mm} .{ }^{94,95}$

Sacral motion is dependent upon the rest of the kinetic chain, and the current physical demands placed upon the person. Simply, when in a static stance and the lumbar spine extends, the sacrum is moved into flexion with the sacral base moving anteriorly. This motion of the sacral bases moving anteroinferior is known as nutation. ${ }^{72}$ Nutation of the SIJ is necessary for the "force closure mechanism" to take place. When the sacral bases are in an anteriorly flexed position, the tension is increased on specifically the interosseous and short dorsal ligaments. ${ }^{18}$ The increased tension on these ligaments decreases the space between the innominates resulting in increased stability at the SIJ. Conversely when the lumbar spine flexes the sacrum is moved 
into extension with the sacral base moving posteriorly. This motion of the sacral bases moving posterosuperior is known as counter nutation. ${ }^{72}$ Counter nutation can be described as the unlocked position for the SIJ leaving it more susceptible to mobility. This unlocked position can also be achieved with anterior rotation of the innominates, and it is possible that over time this can lead to hypermobility of the SIJ resulting in injury. ${ }^{18}$ With respiration, upon inhalation the sacrum extends, and then moves into flexion upon exhalation. ${ }^{59}$ Torsional motion also occurs at the sacrum and is named for the motion around the oblique axis. ${ }^{59}$ For example, a left rotated sacrum on a left oblique axis or a right rotated sacrum on a right oblique axis.

During the walking gait cycle, sacral motion becomes increasingly complex. During heel strike of the right foot, the anterior surface of the sacrum rotates to the left and the superior surface is level. At midstance, the sacrum is rotated right and side bent left. Lastly, at heel strike of the left foot the opposite sequence of sacral motion occurs and the cycle continues to repeat. ${ }^{67}$ Pathological motion has not been objectified at this time in the literature, however, anything beyond the average end ranges of motion at the SIJ could be considered hypo/hypermobile. It is theorized that both hypo and hypermobility are attributed to the pathology of SIJD. ${ }^{67}$ Potential reasoning for the increase in prevalence within the adolescent population continues to be more apparent. The underdevelopment of the SIJ can produce hypermobility and exacerbated by the biomechanical demands of soccer this repetitive motion could lead to SIJD.

\section{Biomechanics of Soccer}

The kicking action is the premier motion for the sport of soccer, whether it is an instep kick, punt, or side foot kick. Kicking is more involved than just the leg performing the kicking motion. The technique behind kicking involves the approach, the support leg and pelvis, the kicking leg, and the spinal column. The approach for the soccer instep kick is usually from a 
differing angle than the intended flight path of the ball. This approach angle increases the rotational demands of kicking in the transverse plane. This approach to kicking is characterized by multiple segmental joint rotations occurring in multiple planes ${ }^{69,96}$ During the approach there is usually a small number of steps taken with the last stride length varying depending on the desired distance of ball flight. It has been reported that a longer last stride is correlated with a long-range kick compared to a medium range kick..$^{70}$

Specifically, during the backswing of the kicking motion, the hip may extend up to $29^{\circ}$ and is slowly abducted and externally rotated. ${ }^{64}$ Further down the chain the knee flexes and internally rotates while the ankle is plantar flexed up to $10^{\circ}$, abducted up to $20^{\circ}$, and slightly pronated. ${ }^{64,97}$ Muscle activity surrounding the kick has been investigated utilizing electromyography(EMG). Iliopsoas activity ranges from $60-80 \%$, and the gluteus maximus is highly variable reporting between $5-70 \%$ across studies. ${ }^{96,98}$ The intensity of the kick or desired length of ball travel could help to explain this reported wide range. Forward motion is then initiated by rotating the pelvis around the supporting leg while the knee remains in a flexed position. ${ }^{96}$ The hip then starts to flex while remaining externally rotated, and the ankle is adducted and plantarflexed. Upon impact the knee is now in extension while the hip is flexed, abducted, and externally rotated. ${ }^{64}$ During this forward motion the iliopsoas EMG activity ranges from $65.1 \%-100 \%$, and the gluteus maximus ranges from 2.1 to $32.1 \%{ }^{96,98}$

During these phases of kicking, the stance leg is also undergoing biomechanical stress. The support leg before impact is optimally flexed to $26^{\circ}$, and remains flexed throughout the duration of the kick. ${ }^{70}$ The spinal column is also inclined backward and laterally to the stance leg at ball contact. The pelvis on the stance leg is also rotated anteriorly up to $17^{\circ}$ during the swing phase, and then tilts posteriorly up to $10^{\circ}$ as contact with the ball is made.${ }^{64}$ The kicking motion 
affects the entire kinetic chain, and it becomes apparent that soccer puts stress upon the pelvis and the SIJ. With the repetitive nature of kicking fatigue will set in, and the potential breakdown of structures leading to injury of the SIJ may take place.

Aside from the kicking motion, the other dominant movement in soccer is running incorporating forward, backward, and lateral motions as the players move up and down the field. As previously mentioned the sacral motions become increasingly complex during the gait cycle. With the addition of lateral movements in soccer this increases the amount of stress induced at the SIJ. The lateral motions can result in an increase in hip adductors and internal rotators which may lead to an inflare or outflare of the innominates. ${ }^{59}$ With an inflare, the ASIS may present more near the midline and more anteriorly compared bilaterally. This inflare may result in an increased tension of the sacral ligaments putting the SIJ under stress. Conversely, an outflare presents with an ASIS that is further from the midline and more posterior. This may result in a compression of the SIJ and a decrease of mobility in the joint. An inflare or an outflare could be potential mechanisms for the creation of pain and dysfunction at the SIJ.

The physical demands of specific positions in soccer is variable. Midfielders cover the most distance throughout the game. ${ }^{58}$ They must also change roles of either attacking or defending multiple times throughout the game as the ball is put into play up and down the field. Midfielders may be the most susceptible to a chronic onset of injury at the SIJ as positioning requires the ability to kick long clearing balls, and to move laterally while defending and advancing the ball around opposing players. Goal keepers also have a unique set of movement patterns compared to other positions. Goal keepers must make lateral dives while attempting to make a save. During this motion the goal keeper will often land directly on the lateral aspect of the pelvis which may result in shear forces occurring at the SIJ. Goal keepers are similar to 
midfielders as there are attempts for several long clearing kicks throughout a game. This unilaterally dominant skill required by this position may lead to a chronic onset of injury at the SIJ.

Epidemiology of SIJD in Adolescents and Soccer Athletes

Currently there is not much research on SIJD or SIJ pain in soccer athletes compared to the wealth of research available on nonspecific LBP. In the general population, sacroiliac joint pain is reported to range between $15-30 \%$ in those with low back injuries. ${ }^{6,87,71}$ Within the general population, SIJ injury was thought to only occur in adults, however, there has been an increasing occurrence in adolescent athletes. Part of this may be due to the large increase in training hours put in by the adolescent athlete year-round. The prevalence of LBP and SIJD amongst soccer athletes is high. In one study LBP was found to be the most prevalent previous overuse injury with an incidence of $28 \%$ among soccer players. ${ }^{9}$ When looking at soccer athletes aged from 12 to 17 years of age low back injuries ranged from $11.1 \%$ to $19.4 \%$ of all injuries sustained.${ }^{99}$ Considering the number of lower extremity injuries that may occur in soccer, 1 to 2 out of every 10 injuries occurring to the low back is alarming. Sixty and six tenths percent of soccer players $(n=190)$ were found to have experienced LBP in their lifetime, and $56.9 \%$ felt it in the previous 12 months, resulting in $27.7 \%$ missing training from injury. ${ }^{10}$ In relation to position, goalkeepers and midfielders had the highest rate of LBP potentially caused by SIJ. In fact, playing midfield $\left(\mathrm{R}^{2}=.92, \mathrm{p}=.03\right)$ and goalkeepers $\left(\mathrm{R}^{2}=1.11, \mathrm{p}=.05\right)$ placed those individuals at a greater risk of LBP during the previous 12 months. ${ }^{10}$ In other sports, $54.4 \%$ of futsal players experiencing LBP in their lifetime, and $25.7 \%$ had absence from training sessions due to LBP. ${ }^{11}$

Further research needs to be conducted on soccer athletes evaluating SIJD and SIJ pain. Considering the anatomy and biomechanics of the SIJ, and soccer having physically demanding 
and repetitive biomechanics creates a lot of physical stress at the SIJ. Further studies may reveal that a portion of this nonspecific LBP is stemming from a SIJ deficiency and the excessive stress put upon the joint in soccer.

Predictive Screening Tool for Sacroiliac Joint Dysfunction

After extensive review of the anatomy of the SIJ, the biomechanics of the SIJ, and the biomechanics of soccer it was noted that each of these pieces are contributing to the creation of SIJD. Therefore, it is imperative to create a screening tool that would assess those who are at risk for developing SIJD. Incidence of SIJD within the adolescent soccer athlete population would decline with the proper implementation of preventative measures. For a thorough preseason assessment, the FMS, hamstring length, pelvic positioning, and hip ROM should be included in this screening tool. Each of these four components, methods of measurement, and reliability of each are discussed in this literature review.

Functional Movement Screen

The FMS was developed by Cook in an effort to connect pre-participation medical screening and performance testing. ${ }^{24-28}$ This screening tool attempted to detect deficiencies by challenging the interactions of kinetic chain mobility and stability necessary for performance. ${ }^{100,101}$ Inefficient movement can reinforce poor movement patterns and lead to injury. Once any deficiencies have been detected, it is possible for the clinician to address them and improve the fundamental movement of the athletes and decrease the risk of injury. Although inconclusive results on the validity of the FMS to screen or detect movement deficiencies are evident, the procedures to be reproduced with consistency is apparent. ${ }^{28-33}$ Thus, clinicians frequently use the FMS as a screening tool and despite not being the original intent of the FMS, professionals in the field of exercise, sport performance, and sport medicine use the FMS to 
analyze the movement capabilities of athletes and those who are at risk for injury. This interpretation of the FMS has been heavily investigated and the results show that athletes who score 14 or less points on the FMS are at an increased risk for injury. ${ }^{35-39,75}$ While a lot of research exists on collegiate aged athletes, there is little research that exists investigating the use of the FMS as an injury prediction tool for adolescent soccer athletes.

The FMS consists of a series of seven fundamental movement patterns and three clearing tests that are performed by the athlete and scored by a certified professional. ${ }^{24-28,102,103}$

Deep squat movement: This movement is a closed kinetic chain movement requiring proper mobility and stability to perform correctly. The deep squat is a bilateral movement and requires the athlete to perform symmetrical movement on both sides of the body in order to be performed. The athlete must show dorsiflexion in the ankles, knee flexion, and hip flexion while sitting into the squat. Keeping the arms from reaching over the toes requires thoracic spine extension and shoulder external rotation to occur. ${ }^{24,26}$ This movement measures the mobility of the ankles and thoracic spine during this basic functional movement. The squat movement is required for soccer in various save opportunities for the goal keeper and heading the ball.

Hurdle step movement: This movement is a unilateral movement which requires the athlete to stabilize the body on a single leg while moving the opposite leg. The hurdle step is a similar movement to walking or running and is designed to challenge proper stride biomechanics. ${ }^{26}$ One side of the body experiences hip flexion, knee flexion, and open-chain dorsiflexion of the ankle while at the same time the other leg requires stability. The hip, knee, and ankle on the opposite side of the movement are all stabilizing to maintain the position. As each leg performs opposing actions the subject must have control of asymmetrical movement at the hip. ${ }^{24}$ Deficiencies in stability can be detected while this basic functional movement is 
performed. In soccer asymmetrical hip movements are a fundamental part of the game considering the act of kicking a ball with two legs performing differing actions.

In-line lunge movement: This movement is another unilateral movement which requires the subject to maintain balance throughout the motion. The in-line lunge requires hip mobility in flexion and extension, knee flexion and extension, and closed-chain dorsiflexion of the ankles. This movement will also challenge hip stability in abduction in order to stay balanced in a lunge position. The lunge motion focuses on the stresses simulated during rotational, decelerating, and lateral movements. ${ }^{26}$ This movement may detect deficiencies in ankle mobility and core stability during performance of this basic functional movement. As soccer players move up and down the field during training and competition, these movements are all frequently encountered.

Shoulder mobility movement: This movement requires mobility of the shoulder joint, shoulder girdle, and thoracic spine. Shoulder internal rotation and adduction occur on one side while the opposite side is in shoulder external rotation and abduction. The movement requirements for the shoulder mobility movement are asymmetrical although it is a bilateral movement. ${ }^{24,26}$ This movement can detect deficiencies in shoulder mobility. The shoulder mobility clearing test is also noted here if there is pain. For a goal keeper to make a diving or jumping save, this requires both mobility and stability of the glenohumeral and thoracic joints.

Active straight leg raise movement: This movement requires the subject to move a single leg into hip flexion while lying supine. This requires hamstring flexibility and gastrocnemius/soleus flexibility of the leg. The opposite leg will stay on the ground during the movement and must be in a neutral position. This movement can detect deficiencies in hamstring mobility during performance of this basic functional movement. For soccer players to complete 
the kicking motion, this requires hamstring flexibility to efficiently complete the biomechanics of the motion.

Trunk stability push up movement: This movement is designed to test the ability of the athlete to stabilize the core and spine in a closed chain movement. ${ }^{102}$ The movement requires the muscles of the core to stabilize the trunk in all three planes of motion while a push up is performed. This movement is symmetrical; therefore, it requires stability in the shoulder. ${ }^{103}$ This movement can detect deficiencies in stability in the trunk and pelvis as this basic functional movement is performed. The extension clearing test is also noted here if there is pain with thoracic extension during a prone press up. In soccer, the core muscles must continue to stabilize the trunk throughout all the dynamic motions of kicking, cutting, and running.

Rotary stability movement: This movement challenges the body's ability to stabilize during a combined upper and lower extremity motion. ${ }^{103}$ Rotary stability is an asymmetrical movement and requires different movements to occur on each side of the body while stabilizing the trunk in the transverse plane. This movement can detect deficiencies in trunk and pelvic stability as this basic functional movement is performed. The flexion clearing test is also noted here if there is any pain during quadruped flexion. Almost every fundamental skill of soccer involves movement and stability in the transverse plane. If the athlete is not able to remain stable in this plane, it may lead to injury.

Reliability and Validity of the Functional Movement Screen

Reliability of the FMS has been reported to be as acceptable for live scoring. ${ }^{28}$ The interrater reliability among novice raters has been reported to be moderate to good (ICC $=0.74$ $0.98)^{28,104}$ The comparison of scores between novice and expert users of the FMS have also shown good interrater reliability $(\mathrm{ICC}=.88 \text { and } .98)^{105,106}$ Agreement between scores ranged 
from moderate to excellent $(\mathrm{K}=0.29-0.82) .{ }^{104}$ Test-retest reliability has also been found to be good $(\mathrm{ICC}=0.60)^{30}$ Comparing the results of these studies demonstrates that one may not need experience to appropriately administer this screening tool. Conversely, when looking at the validity of the FMS the results are mixed on whether or not the screening tool appropriately detects movement deficiencies in mobility and stability. There is little research on the validity of the FMS when utilized in adolescent athletes. Two studies ${ }^{100,101}$ found that the FMS is valid in detecting the deficiencies the screen intends to measure. Conversely, a few studies ${ }^{29,32,107}$ reported that the FMS may not be valid in detecting deficiencies. Clifton et al. ${ }^{29}$ demonstrated a weak internal validity of the FMS in a general population when postural fatigue after exercise did not alter FMS scores. Whiteside et al. ${ }^{32}$ investigated NCAA division one basketball players and reported that manual grading is not sensitive enough to detect deficiencies in joint angles compromising external validity. Finally, Smith et al. ${ }^{107}$ analyzed adolescent athletes FMS scores in comparison with BESS and Y-balance stability tests and demonstrated that the FMS may not be able to accurately assess deficiencies in stability.

Considering the FMS can be used to observe inefficiencies in movement patterns it is possible that the FMS could determine an athlete's risk for injury. ${ }^{13,24,34,37,38,76}$ As the use of the FMS has progressed and changed over time, several studies have been conducted investigating the use of this screening tool as a predictor of injury risk. The FMS was used to investigate the risk of injury in collegiate female athletes. A linear regression analysis established a predictive relationship between the FMS score and risk for injury in subjects who had not undergone an anterior cruciate ligament reconstruction. A score of 14 or less on the FMS resulted in a 4-fold increase of lower extremity risk of injury over the course of a season. ${ }^{34}$ The FMS has also been used on collegiate female rowing athletes to asses if risk of injuries with LBP can be accurately 
predicted. Those who were put in the high risk group with a FMS score below 14 were significantly more likely to experience LBP during the season $(\mathrm{p}=.036) \cdot{ }^{76}$ Currently, there is little to no research on the use of the FMS within the adolescent population, and specifically looking at risk of SIJD. One study ${ }^{37}$ used the FMS on high school athletes across multiple sports and reported that the FMS may be useful in recognizing deficiency in movement, however, it should not be the only tool utilized to predict injury. One study ${ }^{13}$ was found that investigated FMS performance on individuals with chronic LBP and compared them to healthy controls. The LBP group scored lower on the deep squat, hurdle step, ASLR, and the rotary stability movements. Since SIJD can be the cause of LBP it is postulated that some of the basic movements in the FMS could predict those who may develop SIJD. Hamstring Length

The hamstrings are a heavily utilized portion of the posterior kinetic chain in soccer athletes. With the kicking motion incorporating both hip flexion and knee extension, a large eccentric load is placed upon the hamstrings before ball contact. With the common attachment of the ischial tuberosity, the hamstrings place strain upon the sacrotuberous ligament which helps to dynamically stabilize the sacrum. With all this physical repeated stress induced by the demands of soccer, the hamstrings over time may habituate to a different resting length. This habituation may be a piece contributing to SIJD, making hamstring length a necessary portion of the SIJD screening tool. ${ }^{20}$

There are several widely researched means of assessing hamstring length. All of the various measurements for hamstring length, the reliability, and validity of each are discussed in Table B3. Among all these measurement tests the active knee extension is the most commonly used test and produces excellent intra and intertester reliability. ${ }^{40-43,53}$ Across studies the straight 
leg test reported similar reliability $(\mathrm{ICC}=0.93-0.97, .92)^{41,43}$ to the active knee extension test $(\mathrm{ICC}=0.87-0.94,0.94) .{ }^{41,43}$ However, the validity of these two tests to produce similar results were reported as fair $(\mathrm{r}=0.63) .{ }^{41}$ Similar findings on validity were reported when comparing these two tests with sacral angle measurement $(r=0.50,0.45)$ and the sit and reach test $(r=0.65$, 0.57). ${ }^{41}$ This shows that these tests cannot be interchangeable within a study as each test could produce different results. These four tests do all share similar benefits such as, not requiring any cumbersome equipment to perform each test. The sit and reach test is the only test that requires the use of a specific measuring device. Active knee extension, SLR, and sacral angle only require the use of a goniometer or inclinometer. Both of these devices are easy to use and become familiarized with. All of these tests would allow for easily reproduced results as there are simple instructions used and do not place a great deal of strain on the subjects.

Table B3. Measurement Techniques for Hamstring Length/Extensibility ${ }^{40-43,53}$

\begin{tabular}{|c|c|c|c|}
\hline Author & Purpose & Measurement & Results \\
\hline Neto et $\mathrm{al}^{43}$ & $\begin{array}{l}\text { To determine the } \\
\text { intrarater reliability of the } \\
\text { active-knee-extension test } \\
\text { and straight-leg-raise test } \\
\text { in subjects with flexibility } \\
\text { deficits. }\end{array}$ & $\begin{array}{l}\text { Active-knee-extension } \\
\text { test performed with the } \\
\text { subject in supine and the } \\
\text { hip in a fixed flexed } \\
\text { position. Followed by } \\
\text { active extension of the } \\
\text { knee. } \\
\text { Straight-leg-test was } \\
\text { performed passively with } \\
\text { the subject lying supine. } \\
\text { Both measurements } \\
\text { involved a goniometric } \\
\text { angle and were tested } \\
\text { twice. }\end{array}$ & $\begin{array}{l}\text { Active knee extension } \\
\text { was found to have } \\
\text { excellent intrarater } \\
\text { reliability. (ICC }=0.87 \text { - } \\
0.94, \text { SEM }=2.6-2.9^{\circ} \text { ) } \\
\text { Straight-leg-raise was } \\
\text { found to have excellent } \\
\text { intrarater reliability. (ICC } \\
=0.93-0.97, \text { SEM }=2.2- \\
\left.2.6^{\circ}\right)\end{array}$ \\
\hline Hamid et al. ${ }^{42}$ & $\begin{array}{l}\text { To determine the } \\
\text { reliability of the active } \\
\text { knee extension test among } \\
\text { healthy adults. }\end{array}$ & $\begin{array}{l}\text { Active-knee-extension } \\
\text { test performed with the } \\
\text { patient lying supine and } \\
\text { the hip flexed at a fixed } \\
120^{\circ} . \text { Followed by active } \\
\text { extension of the knee. } \\
\text { Goniometric } \\
\text { measurements were taken }\end{array}$ & $\begin{array}{l}\text { Interrater reliability for } \\
\text { the dominant and the non- } \\
\text { dominant knee were } \\
\text { reported as ICC }=0.87 \text {, } \\
0.81 \text {, respectively. } \\
\text { Intrarater reliability were } \\
\text { reported for tester } 1 \text { and } \\
\text { tester } 2 \text { as ICC }=0.78 \text { - }\end{array}$ \\
\hline
\end{tabular}


Davis et al. ${ }^{41}$

Shultz et al. ${ }^{40}$
To determine the intratester reliability of 4 hamstring length measurements: knee extension angle, straight leg raise, sacral angle, and sit and reach. twice by two

professionals and repeated again a week later.

The knee extension angle was performed with the patient lying supine. The ipsilateral hip is flexed to $90^{\circ}$ and is maintained while contralateral leg is fixed to the table. The knee is then actively extended.

The SLR test was performed with the patient lying supine. The SLR was performed passively by the examiner.

The sacral angle was performed with the subject sitting and in full knee extension, hips in neutral rotation, and full adduction. The subject was then instructed to reach forward toward their toes until a pull was felt. An inclinometer was used to measure an angle from the sacrum on the horizontal surface.

The sit and reach test was performed using a sit and reach device.

Measurement was taken in centimeters of how far the subject could reach forward.

Active knee extension was performed with the subject supine and the hip flexed and maintained at $120^{\circ}$. The subject then did five practice trials of actively extending the knee, then goniometric measurement was taken.
0.97, 0.75-0.84

respectively.

The intrarater reliability for each test was reported as follows: Knee extension angle ICC $=$ 0.94, SLR ICC = 0.92, Sacral angle ICC $=0.95$, sit and reach $\mathrm{ICC}=0.94$.

Correlation coefficients for concurrent validity of the combinations of the tests revealed poor to fair correlation. SLR and knee extension angle $r=0.63$. SLR and sacral angle $r=$ 0.50. SLR and sit and reach $r=0.65$. Knee extension angle and sacral angle $r=0.45$. Knee extension angle and sit and reach $r=0.57$. Sit and reach and sacral angle $r=$ 0.65 .

Intratester reliability was found to be excellent and was reported to range from $\mathrm{ICC}=0.91-0.98$ among the four testers.

Intertester reliability was found to be excellent and was reported to range from ICC $=0.89-0.97$. 


$\begin{array}{llll}\text { Rakos et al }^{53} & \begin{array}{l}\text { To determine the } \\ \text { interrater reliability of the } \\ \text { active knee extension test } \\ \text { to measure hamstring } \\ \text { length in a school aged } \\ \text { children population }\end{array} & \begin{array}{l}\text { Active knee extension } \\ \text { was performed with the } \\ \text { subject supine and the hip } \\ \text { flexed to } 90^{\circ} \text {. The subject } \\ \text { then actively extended the }\end{array} & \begin{array}{l}\text { Intertester reliability was } \\ \text { found to be good ICC }=\end{array} \\ & \begin{array}{l}\text { knee and a goniometric } \\ \text { measurement was taken. }\end{array}\end{array}$

\section{Pelvic Positioning}

The defining motion of soccer athletes is the kicking motion of striking a ball. This motion as previously mentioned creates a large eccentric load on the hamstrings. ${ }^{69,70}$ This eccentric load pulls on the pelvic innominates posteriorly. Conversely, the hip flexors, such as the iliopsoas and the rectus femoris undergo eccentric contraction in the back swing followed by a powerful concentric contraction for the remaining portions of the kicking motion. ${ }^{69,70}$ This load from the hip flexors pulls on the pelvic innominates anteriorly. Additionally, an overused iliopsoas muscle may increase lumbar lordosis with the transverse processes of the lumbar spine as the origin (Table B2.) An increased lumbar lordosis may also create an increased anterior pelvic tilt. ${ }^{72}$ Through both of these mechanisms the pelvis is pulled out of a neutral alignment and may create additional stress upon the sacrum and SIJ leading to a chronic onset of SIJD. ${ }^{59,66,72}$ Pelvic positioning then becomes a necessary component to consider for a SIJD screening tool in soccer athletes. Currently in the literature there are multiple ways to assess pelvic positioning.

Pelvic angle was measured with an inclinometer in the Schultz study. ${ }^{40}$ The subject was standing and an angle was taken between the horizontal plane and a line from the anterior superior iliac spine(ASIS) to the posterior superior iliac spine(PSIS). An inclinometer was then utilized to measure the degree of this angle to the nearest degree. This study reported acceptable to excellent intratester reliability ( $\mathrm{ICC}=0.64-0.98)$ among the four testers, and reported moderate intertester reliability $(\mathrm{ICC}=0.48-0.68) .{ }^{40}$ However, the validity of using an 
inclinometer to assess pelvic angle has been reported as poor. In one study ${ }^{108}$ pelvic angle measurements compared to radiographs resulted in invalid measurements (measurement error $\left.8.26^{\circ}, \mathrm{r}=0.28\right)$

The Level Belt Pro application was developed by Chaudhari and McKenzie. ${ }^{86}$ This application was created to find several parameters of pelvic positioning such as anterior, posterior, and lateral pelvic tilt. It also can determine an individual's neutral pelvic tilt. The Level Belt Pro application has been utilized in conjunction with the single leg raise test for pelvic tilt measurements. The single raise test is performed by placing the CoreX belt with iPod-based sensor (Level Belt Pro application) level on the hips in line with the ASIS and PSIS. ${ }^{109}$ The athlete then stands shoulder width feet apart and slowly raises and lowers one leg three inches off the ground. ${ }^{95}$ This test was compared with $3 \mathrm{D}$ motion analysis for validation showing high sensitivity, specificity, and accuracy. ${ }^{109}$ Inter-rater and intra-rater reliability of the Level Belt Pro application with the single leg raise test for pelvic tilt measurements was investigated. ${ }^{110}$ The intra-rater reliability was reported as excellent, however, the inter-rater reliability was reported as poor. $^{110}$

The palpation meter (PALM) has also been shown in research to be effective for pelvic positioning measurements. The PALM instrument has two calipers that can be placed between the ASIS and PSIS. An angle measurement then can be assessed with the built-in inclinometer. One study investigated the use of the PALM instrument for pelvic positioning in multiple positions. The intra-rater reliability for standing, sitting, hip flexion $45^{\circ}$, and hip flexion $90^{\circ}$ was reported as ICC $=0.92,0.90,0.89$, and 0.96 , respectively. ${ }^{48}$ Based on the good reliability scores, the PALM instrument can reliably measure pelvic positioning in multiple positions. Innominate angles in the sagittal plane from the PSIS to the ASIS in standing were investigated by 
Herrington. ${ }^{47}$ The intratester reliability reported was excellent $(\mathrm{ICC}=0.87)$, demonstrating great reliability for innominate angle measurements. Finally, the PALM's accuracy for measuring pelvic crest height was investigated. ${ }^{46}$ The calipers were placed at the most superior portion of both pelvic crests and an angle measurement between the two was recorded. Intra-rater and interrater reliability was found to be excellent reported as ICC $=0.97-0.98$, and ICC $=0.88$ respectively. ${ }^{46}$ Radiographs were taken as the reference criterion and validity of the PALM's ability to measure pelvic height difference was reported as ICC $=0.90-0.92 .{ }^{46}$ Compared to the inclinometer the PALM shows far greater validity when measuring pelvic angle compared to radiographs. The PALM provides an accurate measurement of pelvic angle whereas an inclinometer by itself does not.

Hip Range of Motion

The true hip joint consists of the femoral head and the acetabula of the innominates creating a ball and socket joint. Due to the anatomy of these joint the motion can be described as having six degrees of freedom. These motions and the possible influence on the SIJ are described in Table B4. It has been indicated that deficiencies in certain hip ranges of motion may be contributing to the problem of SIJD and LBP. ${ }^{21-23,73}$ Two studies ${ }^{22,23}$ are in agreement that a decrease in hip external rotation may contribute to low back pathology. Roach et al. ${ }^{22}$ also reported that hip extension may also contribute to LBP, whereas Bussey et al. ${ }^{23}$ reported that hip abduction may also have influence on SI motion. Conversely, two studies ${ }^{21,73}$ are in agreement that a decrease in hip internal rotation may contribute to SIJD and LBP. Currently, in the literature there is no reported link between hip flexion, and adduction with SIJD. Further research needs to be conducted in the adolescent population to establish a relationship between the other existing ranges of motion and SIJD occurrence. In soccer, it is necessary for the hip to 
have these six degrees of freedom to efficiently perform the running and kicking biomechanics

of the sport. These motions at the hip interact in concert with motions occurring at the pelvis, sacrum, and SIJ. If one of the components has dysfunction this may transfer up the kinetic chain and create SIJD, therefore assessing hip range of motion is a necessary component to consider for a SIJD screening tool in soccer athletes.

$\underline{\text { Table B4. Hip Range of Motion }}$ 21-23,52,73

\begin{tabular}{|c|c|c|c|}
\hline Motion & Description & Average Angle Values & Interaction with SIJ \\
\hline Flexion & $\begin{array}{l}\text { Decreasing angle between } \\
\text { femur and pelvic } \\
\text { innominates }\end{array}$ & $\begin{array}{l}\text { Males }=113^{\circ} \\
\text { Females }=120^{\circ}\end{array}$ & $\begin{array}{l}\text { Repetitive hip flexion may } \\
\text { increase the length of the } \\
\text { hip extensor muscles } \\
\text { creating a posterior tensile } \\
\text { stress of the sacrum. }\end{array}$ \\
\hline Extension & $\begin{array}{l}\text { Increasing angle between } \\
\text { femur and pelvic } \\
\text { innominates }\end{array}$ & $\begin{array}{l}\text { Males }=15^{\circ} \\
\text { Females }=22^{\circ}\end{array}$ & $\begin{array}{l}\text { A decrease in hip extension } \\
\text { has been shown in those } \\
\text { with LBP compared to } \\
\text { healthy controls. }^{22}\end{array}$ \\
\hline Abduction & $\begin{array}{l}\text { Moving the femur laterally } \\
\text { away from the midline of } \\
\text { the body }\end{array}$ & $\begin{array}{l}\text { Males }=34^{\circ} \\
\text { Females }=44^{\circ}\end{array}$ & $\begin{array}{l}\text { Has been strongly } \\
\text { associated with predicting } \\
\text { innominate angle } \\
\text { There is a lateral tensile } \\
\text { stress placed upon the SIJ } \\
\text { with activation of the hip } \\
\text { abductors. }\end{array}$ \\
\hline Adduction & $\begin{array}{l}\text { Moving the femur } \\
\text { medially toward the } \\
\text { midline of the body }\end{array}$ & $\begin{array}{l}\text { Males }=14^{\circ} \\
\text { Females }=17^{\circ}\end{array}$ & $\begin{array}{l}\text { The adductor muscle group } \\
\text { creates a shear force on the } \\
\text { innominates when activated } \\
\text { which indirectly may } \\
\text { transfer force to the SIJ. }\end{array}$ \\
\hline Internal Rotation & $\begin{array}{l}\text { Rotation of the femur } \\
\text { medially toward the } \\
\text { midline of the body }\end{array}$ & $\begin{array}{l}\text { Males }=35^{\circ} \\
\text { Females }=35^{\circ}\end{array}$ & $\begin{array}{l}\text { Has been strongly } \\
\text { associated with predicting } \\
\text { innominate angle } \\
\text { A decrease in internal } \\
\text { rotation compared } \\
\text { bilaterally has been } \\
\text { associated with } \text { SIJD }^{21} \text { and } \\
\text { LBP }^{73}\end{array}$ \\
\hline External Rotation & $\begin{array}{l}\text { Rotation of the femur } \\
\text { laterally away from the } \\
\text { midline of the body }\end{array}$ & $\begin{array}{l}\text { Males }=40^{\circ} \\
\text { Females }=46^{\circ}\end{array}$ & $\begin{array}{l}\text { Has been strongly } \\
\text { associated with predicting } \\
\text { innominate angle }\end{array}$ \\
\hline
\end{tabular}

Motion at the femoral acetabular hip joint is easily achieved using a manual goniometer. The research shows that goniometric hip measurements are both reliable and valid. ${ }^{49,51} \mathrm{Kim}$ and 
$\mathrm{Kim}^{51}$ investigated the test-retest reliability of both hip flexion and extension and reported excellent reliability for both (ICC $=0.946$, and 0.955 , respectively). Nussbaumer et al. ${ }^{49}$ investigated the concurrent validity and the test-retest reliability of hip flexion, abduction, adduction, internal rotation, and external rotation. The concurrent validity was reported at flexion $(\mathrm{ICC}=0.440)$, abduction $(\mathrm{ICC}=0.937)$, adduction $(\mathrm{ICC}=0.533)$, internal rotation $(\mathrm{ICC}=$ $0.875)$, and external rotation $(\mathrm{ICC}=0.542) .{ }^{49}$ The test-retest reliability for all five range of motions was reported as excellent at $(\mathrm{ICC}=0.916,0.924,0.842,0.950,0.914)$ for flexion/abduction/adduction/internal rotation/ external rotation, respectively. ${ }^{49}$ Comparatively motion at the femoral acetabular hip joint may also be achieved using a bubble inclinometer. Bubble inclinometer measurements are both reliable and valid. ${ }^{111}$ Intra tester reliability was reported to range from $\mathrm{ICC}=0.61-0.90$ for the various hip range of motions, whereas the concurrent validity of the bubble inclinometer against a three dimensional motion analysis system was excellent for all ranges of motion tested $(\mathrm{ICC}=0.87-0.98) .{ }^{111}$ Goniometric and inclinometer measurements for hip range of motion compared against one another revealed a statistically significant difference between hip extension, internal rotation, and external rotation. ${ }^{50}$ This provides caution that these two instruments should not be used interchangeably to measure the same subject for hip range of motion measurements.

Summary

Among the adolescent population SIJD is starting to become a chronic problem, especially in sports with repetitive motions, such as soccer. ${ }^{8}$ The immature musculoskeletal anatomy of the SIJ and surrounding structures in the adolescent population contributes to this rise. The biomechanics of the joint acting as the gateway to transmit forces from the lower extremities to the spinal column increases the stress place upon the SIJ. Additionally, the 
biomechanics of soccer places too great of a physical stress on the natural anatomy of the surrounding structures and the movements that occur to achieve the running and kicking motions of the sport. Further studies show that goal keepers and midfielders are affected most by these biomechanical stresses. ${ }^{10}$ From these considerations a screening tool should be devised and include the FMS, hamstring length, pelvic positioning, and hip range of motion measurements. The FMS will detect deficiencies in the stability and mobility of seven fundamental movements which can be related to soccer. The hamstring muscles have an indirect interaction with the SIJ via the sacrotuberous ligament and are heavily involved in kicking biomechanics. Pelvic positioning is greatly affected by the kicking biomechanics seen in soccer and directly influence all the soft tissues structures that interact with the pelvic innominates. Lastly, deficiencies in hip range of motion can affect the biomechanics of the kinetic chain including the SIJ. 


\section{APPENDIX C}

\section{ADDITIONAL METHODS}

Table C1. Informed Parental or Guardian Consent

\section{Only Minimal Risk \\ Parental or Guardian Consent and HIPAA Form}

Principal Investigator Dr. Michelle A. Sandrey

Department College of Physical Activity and Sport Sciences

Protocol Number 1712880468

Study Title Use of Four Predictive Variables for Determination of Sacroiliac Joint Dysfunction in Adolescent Soccer Athletes

Co-Investigator(s) Brian Hanson, ATC, CES

\section{Contact Persons}

In the event your child experiences any side effects or injury related to this research, you should contact Dr. Michelle A. Sandrey at (304) 293-0870. If you have any questions, concerns, or complaints about this research, you can contact Brian Hanson, ATC, CES at (262) 501-3739 or Dr. Michelle A. Sandrey at (304) 293-0870.

For information regarding your child's rights as a research subject, to discuss problems, concerns, or suggestions related to the research, to obtain information or offer input about the research, contact the Office of Research Integrity and Compliance (304) 293-7073.

In addition if you would like to discuss problems, concerns, have suggestions related to research, or would like to offer input about the research, contact the Office of Research Integrity and Compliance at 304-293-7073.

\section{Introduction}

Your child, , has been asked to participate in this research study, which has been explained to you and your child by This study is being conducted by Dr. Michelle A. Sandrey and Brian Hanson, ATC, CES at West Virginia University. This research is being conducted to fulfill the requirements for a masters thesis in Athletic Training in the Department of Sport Sciences at West Virginia University, under the supervision of Dr. Michelle A. Sandrey.

\section{Purpose(s) of the Study}

The purpose of this study is to create an effective screening tool for sacroiliac joint dysfunction (injury to the joint where the tailbone meets the pelvis) in adolescent soccer athletes.

\section{Description of Procedures}

Before the commencement of the study, an orientation meeting will provide you the purpose and methods of this study. At this meeting, risk, discomforts, and confidentiality issues will be explained to your child and your child will be asked to fill out a questionnaire regarding 
demographic information. Following this orientation, measurements will commence. This will take approximately 30 minutes to complete.

Your child does not have to answer all the questions. You will have the opportunity to see the questionnaire before signing this consent form. The study will be performed at University High School. Approximately 30 subjects are expected to participate in this study.

This study involves performing four clinical tests that will measure fundamental movements, hamstring length, pelvic positioning, and hip range of motion. All tests will be completed during scheduled times at University High School unless asked otherwise.

The four clinical tests are the functional movement screen, the active knee extension test, pelvic positioning with a palpation meter (PALM), and hip flexion (moving leg forward), extension (moving leg backward), abduction (moving leg out to side), adduction (moving leg toward the body), internal rotation (rotating the hip joint in), and external rotation(rotating the hip out) with a goniometer. A goniometer has a center circle with degrees revolving $360^{\circ}$, similar to a protractor, and has two arms that extend out to line up with different parts of the body.

Functional Movement Screening

Functional Movement Screening is an assessment of functional movement completed over seven different fundamental movements. For this screening your child will have a demonstration period and a testing period for each section. Your child will complete each section for a maximum of three trials. There will be approximately ten to twenty seconds of rest between trials. The seven movements your child will complete are the Deep Squat, Hurdle Step, Incline Lunge, Shoulder Mobility, Active Straight Leg Raise, Trunk Stability Push Up, and Rotary Stability.

Your child will perform the deep squat by holding a dowel overhead and attempting to squat parallel while keeping heels on the ground.

Your child will perform the hurdle step by holding a dowel behind the head resting on the shoulders. Your child will then step over the hurdle touching the heel to the ground and then return the heel to the start position.

Your child will perform the inline lunge by holding the dowel in line with the spine. While maintaining contact in an upright position your child will lunge forward, touching the knee to the ground.

Your child will perform shoulder mobility by putting one hand overhead and touching the opposite hand that will be touching the back.

Your child will perform the shoulder clearing test by touching the right hand to the left shoulder without pain and touching the left hand to the right shoulder without pain.

Your child will perform the active straight leg raise in a supine position (on back). While raising the leg, the opposite leg and back must remain in contact with the ground. 
Your child will perform the trunk stability push-up by lying prone with the hands in line with the chin or forehead, then pushing up.

Your child will perform the spinal extension clearing test in a prone position (on stomach). Your child will place hands under the shoulders and then press the chest off the ground surface trying to extend the elbows.

Your child will perform the rotary stability test in the quadruped position (hands and knees). The arm and same leg will be extended. Without touching the ground the elbow must touch the knee before returning to the start position.

Your child will perform the spinal flexion clearing test by starting in the quadruped position and then sitting back on the heels while extending the arms out as far as possible.

\section{Active Knee Extension Test}

The test will be performed on both legs. Your child will lay supine with the testing leg bent at $90^{\circ}$. The non-testing leg will be held to the table with a strap. The outside knee joint will be marked and a line will be drawn from the hip to the outside ankle. Your child will extend their leg at the knee while the ankle is relaxed and held for 5 seconds. The angle will be measured twice for each of your child's legs.

\section{Palpation Meter Measurement}

Measurement will be taken on both sides. Your child will stand with their feet $30 \mathrm{~cm}$ apart and will look at a point ahead of them. Your child will stand with good posture and with both arms folded over their chest. The ASIS (front bony notch) and PSIS (back bony notch) of the pelvis will be found over their clothes and will be marked. The calipers of the PALM device will then be placed at these marked locations. The angle will be directly read from the inclinometer once the device is in place. The angle will measure pelvic tilt (position) and will be measured twice on each side of your child.

\section{Hip Range of Motion Goniometry}

A goniometer will be used to measure the angle of your child's active hip range of motion. Your child will flex their hip (move leg forward) in a supine position (on back).

Your child will extend their hip (move leg backward) in a prone position (on stomach) with their legs off the table.

Your child will abduct their hip (move leg out to side) in a side lying position.

Your child will adduct their hip (move leg toward the body) in a standing position.

Your child will internally rotate their hip (rotate hip joint in) in a short-seated position. 
Your child will externally rotate their hip (rotate hip joint out) in a short-seated position.

The angle will be measured twice for each of your child's legs.

\title{
Risks and Discomforts
}

There are no known or expected risks to your child from participating in this study. A feeling of discomfort and soreness from completing the measurements may be felt and that this will be no more than what is felt when learning a new exercise or skill.

\begin{abstract}
Alternatives
Your child does not have to participate in this study.

\section{Benefits}

Your child may not receive any direct benefit from this study. The knowledge gained from this study may eventually benefit others by providing a preseason screening tool for sacroiliac joint dysfunction (injury to the joint where the tailbone meets the pelvis) and reducing risk of injury by starting prevention programs.
\end{abstract}

\section{Financial Considerations}

No payments will be made for participating in the study.

\section{Confidentiality}

Any information about your child that is obtained as a result of their participation in this research will be kept as confidential as legally possible.

Your child's research records and test results, just like hospital records, may be subpoenaed by court order or may be inspected by the study sponsor or federal regulatory authorities without your additional consent.

In any publications that result from this research, neither your child's name nor any information from which your child might be identified will be published without your consent.

\section{HIPAA}

We know that information about your child and their health is private. We are dedicated to protecting the privacy of that information. Because of this promise, we must get your written authorization (permission) before we may use or disclose your child's protected health information or share it with others for research purposes.

You can decide to sign or not to sign this authorization section. However, if you choose not to sign this authorization, your child will not be able to take part in the research study. Whatever choice you make about this research study will not have an effect on your child's access to athletic training/medical care at University High School.

\section{Persons/Organizations Providing the Information}

Soccer athlete on the University High School soccer teams/University High School injury reports. 


\section{Persons/Organizations Receiving the Information}

- Health care providers who provide services to you as part of this research study: WVU, Michelle A. Sandrey, PhD, ATC, Brian Hanson, ATC, CES. The research site(s) carrying out this study includes WVU.

- The United State Department of Health and Human Services (which includes the National Institutes of Health (NIH), Food and Drug Administration (FDA)) and other groups that have the right to use the information as required by law.

- The members and staff of any Institutional Review Board (IRB) that oversees this research study.

-West Virginia University Office of Research Integrity and Compliance and Office of Sponsored Programs.

\section{The Following Information Will Be Used}

Information from your child's existing medical records and new information about them that is created or collected during the study such as: history and physicals, demographic data, and study forms.

\section{The Information is Being Disclosed for the Following Reasons}

- Review of your child's data for quality assurance purposes

- Publication of study results (without identifying your child)

- Other research purposes such as reviewing the effectiveness of the study screening tool in other populations; developing a better understanding of deficiencies that are related to sacroiliac joint dysfunction.

\section{You May Cancel this Authorization at Any Time by Writing to the Principal Investigator} Michelle A. Sandrey (304) 293-0870 msandrey@ mail.wvu.edu

If you cancel this authorization, any information that was collected already for this study cannot be withdrawn. Once information is disclosed, according to this authorization, the recipient may redisclose it and then the information may no longer be protected by federal regulations.

You have a right to see and make copies of your child's medical records. You will not be able to see or copy your child's records related to the study until the co-PI has completed all work related to the study. At that time you may ask to see the study files related to your child's participation in the study and have the co-PI correct any information about your child that is wrong.

This authorization will expire at the end of the study unless you cancel it before that.

\section{Voluntary Participation}

Refusal to participate or withdrawal will not affect your child's future care at University High School, and will involve no penalty to you. If an injury occurs during the study, Brian Hanson, ATC, CES will provide the necessary first aid and referral if necessary. I understand that there will be no cost for any study related injuries to my child. 
Upon signing this consent, you will receive a copy.

I willingly consent to allow my child to participate in this research.

\section{Signatures}

Signature of Parent or Guardian

\begin{tabular}{lll}
\hline Printed Name & Date
\end{tabular}

Signature of Investigator or Co-Investigator

Printed Name

Date

Time 


\section{Assent Form}

Principal Investigator Dr. Michelle A Sandrey

Department College of Physical Activity and Sport Sciences

Protocol Number 1712880468

Study Title Use of Four Predictive Variables for Determination of Sacroiliac Joint Dysfunction in Adolescent Soccer Athletes

Co-Investigator(s) Brian Hanson, ATC, CES

\section{Contact Persons}

If you are hurt from being in this research, you should contact Dr. Michelle Sandrey at (304) 293-0870. If you have any questions, concerns, or complaints about this research, you can contact Brian Hanson, ATC, CES at (262) 501-3739 or Dr. Michelle A. Sandrey at (304) 2930870 .

For information regarding your rights as a person in research or to talk about the research, call the Office of Research Integrity \& Compliance at (304) 293-7073.

\section{Introduction}

You, , have been asked to participate in this research study, which has been explained to you by

\section{Purpose(s) of the Study}

The purpose of this study is to create an effective screening tool for sacroiliac joint dysfunction (injury to the joint where the tailbone meets the pelvis) in adolescent soccer athletes.

\section{Description of Procedures}

Before the commencement of the study, an orientation meeting will provide you the purpose and methods of this study. At this meeting, risk, discomforts, and confidentiality issues will be explained to you and your consent and you will fill out a questionnaire regarding your demographic information. You do not have to answer all of the questions.

This study involves performing four clinical tests that will measure fundamental movements, hamstring length, pelvic positioning, and hip range of motion. All tests will be completed during scheduled times at University High School unless asked otherwise.

The four clinical tests are the functional movement screen, the active knee extension test, pelvic positioning with a palpation meter (PALM), and hip flexion (moving leg forward), extension (moving leg backward), abduction (moving leg out to side), adduction (moving leg toward the body), internal rotation (rotating the hip joint in), and external rotation(rotating the hip out) with a goniometer. A goniometer has a center circle with degrees revolving $360^{\circ}$, similar to a protractor, and has two arms that extend out to line up with different parts of the body.

Functional Movement Screening 
Functional Movement Screening is an assessment of functional movement completed over seven different fundamental movements. For this screening you will have a demonstration period and a testing period for each section. You will complete each section for a maximum of three trials. There will be approximately ten to twenty seconds of rest between trials. The seven movements you will complete are the Deep Squat, Hurdle Step, Incline Lunge, Shoulder Mobility, Active Straight Leg Raise, Trunk Stability Push Up, and Rotary Stability.

You will perform the deep squat by holding a dowel overhead and attempting to squat parallel while keeping heels on the ground.

You will perform the hurdle step by holding a dowel behind the head resting on your shoulders.

Your will then step over the hurdle touching the heel to the ground and then return the heel to the start position.

You will perform the inline lunge by holding the dowel in line with the spine. While maintaining contact in an upright position your will lunge forward, touching the knee to the ground.

You will perform shoulder mobility by putting one hand overhead and touching the opposite hand that will be touching the back.

You will perform the shoulder clearing test by touching your right hand to the left shoulder without pain and touching your left hand to the right shoulder without pain.

You will perform the active straight leg raise in a supine position. While raising the leg, the opposite leg and back must remain in contact with the ground.

You will perform the trunk stability push-up by lying prone with the hands in line with the chin or forehead, then pushing up.

You will perform the spinal extension clearing test in a prone position. You will place hands under the shoulders and then press the chest off the ground surface trying to extend your elbows.

You will perform the rotary stability test in the quadruped position (hands and knees). The arm and same leg will be extended. Without touching the ground your elbow must touch the knee before returning to the start position.

You will perform the spinal flexion clearing test by starting in the quadruped position and then sitting back on the heels while extending the arms out as far as possible.

\section{Active Knee Extension Test}

The test will be performed on both legs. You will lay supine with the testing leg bent at $90^{\circ}$. The non-testing leg will be held to the table with a strap. The outside knee joint will be marked and a line will be drawn from the hip to the outside ankle. You will extend your leg at the knee while the ankle is relaxed and held for 5 seconds. The angle will be measured twice for each of your legs. 
Palpation Meter Measurement

Measurement will be taken on both sides. You will stand with your feet $30 \mathrm{~cm}$ apart and will look at a point ahead of you. You will stand with good posture and with both arms folded over your chest. The ASIS (front bony notch) and PSIS (back bony notch) of the pelvis will be found over your clothes and will be marked. The calipers of the PALM device will then be placed at these marked locations. The angle will be directly read from the inclinometer once the device is in place. The angle will measure pelvic tilt (position) and will be measured twice on each side.

Hip Range of Motion Goniometry

A goniometer will be used to measure the angle of your active hip range of motion. You will flex your hip (move leg forward) in a supine position (on back).

You will extend your hip (move leg backward) in a prone position (on stomach) with your legs off the table.

You will abduct your hip (move leg out to side) in a side lying position.

You will adduct your hip (move leg toward the body) in a standing position.

You will internally rotate your hip (rotate the hip joint in) in a short-seated position.

You will externally rotate your hip in (rotate the hip joint out) a short-seated position.

The angle will be measured twice for each of your legs.

\section{Risks and Discomforts}

There are no known or expected risks to you from participating in this study. A feeling of discomfort and soreness from completing the measurements may be felt and that this will be no more than what is felt when learning a new exercise or skill.

\section{Benefits}

This study may not help you, but the knowledge gained from this study may eventually benefit others by providing a preseason screening tool for sacroiliac joint dysfunction (injury to the joint where the tailbone meets the pelvis) and reducing risk of injury by starting prevention programs.

\section{Confidentiality}

We promise that anything we learn about you in this study will be kept as secret as possible.

\section{Voluntary Participation}

You do not have to do this. No one will be mad at you if you refuse to do this or if you decide to quit. You have been allowed to ask questions about the research, and all of your questions were answered. If an injury occurs during the study there will be no cost for any study related injuries to your parents. 
I willingly agree to be in this research.

\section{Signatures}

Signature of Subject

Printed Name

Date

Time

The minor has had the opportunity to have questions addressed. The minor willingly agrees to be in the study.

Signature of Investigator or Co-Investigator

Printed Name

Date

Time 


\section{Only Minimal Risk 18 Years or Older Consent Information and HIPAA Form}

Principal Investigator Dr. Michelle A Sandrey

Department College of Physical Activity and Sport Sciences

Protocol Number 1712880468

Study Title Use of Four Predictive Variables for Determination of Sacroiliac Joint Dysfunction in Adolescent Soccer Athletes

Co-Investigator(s) Brian Hanson, ATC, CES

\section{Contact Persons}

In the event you experience any side effects or injury related to this research, you should contact Dr. Michelle A. Sandrey at (304) 293-0870. If you have any questions, concerns, or complaints about this research, you can contact Brian Hanson, ATC, CES at (262) 501-3739 or Dr. Michelle A. Sandrey at (304) 293-0870.

For information regarding your rights as a research subject, to discuss problems, concerns, or suggestions related to the research, to obtain information or offer input about the research, contact the Office of Research Integrity and Compliance (304) 293-7073.

In addition if you would like to discuss problems, concerns, have suggestions related to research, or would like to offer input about the research, contact the Office of Research Integrity and Compliance at 304-293-7073.

\section{Introduction}

You, , have been asked to participate in this research study, which has been explained to you by . This study is being conducted by principle investigator Dr. Michelle Sandrey, PhD, ATC and Co-Investigator Brian Hanson ATC, CES in the college of Physical Activity and Sport Sciences at West Virginia University. This study is being completed for the partial fulfillment of the requirements for the degree of Master of Science in Athletic Training.

\section{Purpose(s) of the Study}

The purpose of this study is to create an effective screening tool for sacroiliac joint dysfunction (injury to the joint where the tailbone meets the pelvis) in adolescent soccer athletes.

\section{Description of Procedures}

Before the commencement of the study, an orientation meeting will provide you the purpose and methods of this study. At this meeting, risk, discomforts, and confidentiality issues will be explained to you and your consent and you will fill out a questionnaire regarding your demographic information. 
This study involves performing four clinical tests that will measure fundamental movements, hamstring length, pelvic positioning, and hip range of motion. All tests will be completed during scheduled times at University High School unless asked otherwise.

The four clinical tests are the functional movement screen, the active knee extension test, pelvic positioning with a palpation meter (PALM), and hip flexion (moving leg forward), extension (moving leg backward), abduction (moving leg out to side), adduction (moving leg toward the body), internal rotation (rotating the hip joint in), and external rotation(rotating the hip out) with a goniometer. A goniometer has a center circle with degrees revolving $360^{\circ}$, similar to a protractor, and has two arms that extend out to line up with different parts of the body.

Functional Movement Screening

Functional Movement Screening is an assessment of functional movement completed over seven different fundamental movements. For this screening you will have a demonstration period and a testing period for each section. You will complete each section for a maximum of three trials. There will be approximately ten to twenty seconds of rest between trials. The seven movements you will complete are the Deep Squat, Hurdle Step, Incline Lunge, Shoulder Mobility, Active Straight Leg Raise, Trunk Stability Push Up, and Rotary Stability.

You will perform the deep squat by holding a dowel overhead and attempting to squat parallel while keeping heels on the ground.

You will perform the hurdle step by holding a dowel behind the head resting on your shoulders.

You will then step over the hurdle touching the heel to the ground and then return the heel to the start position.

You will perform the inline lunge by holding the dowel in line with the spine. While maintaining contact in an upright position you will lunge forward, touching the knee to the ground.

You will perform shoulder mobility by putting one hand overhead and touching the opposite hand that will be touching the back.

You will perform the shoulder clearing test by touching your right hand to the left shoulder without pain and touching your left hand to the right shoulder without pain.

You will perform the active straight leg raise in a supine position (on back). While raising the leg, the opposite leg and back must remain in contact with the ground.

You will perform the trunk stability push-up by lying prone (on stomach) with the hands in line with the chin or forehead, then pushing up.

You will perform the spinal extension clearing test in a prone position. You will place hands under the shoulders and then press the chest off the ground surface trying to extend your elbows. 
You will perform the rotary stability test in the quadruped position (hands and knees). The arm and same leg will be extended. Without touching the ground your elbow must touch the knee before returning to the start position.

You will perform the spinal flexion clearing test by starting in the quadruped position and then sitting back on the heels while extending the arms out as far as possible.

\section{Active Knee Extension Test}

The test will be performed on both legs. You will lay supine with the testing leg bent at $90^{\circ}$. The non-testing leg will be held to the table with a strap. The outside knee joint will be marked and a line will be drawn from the hip to the outside ankle. You will extend your leg at the knee while the ankle is relaxed and held for 5 seconds. The angle will be measured twice for each of your legs.

\section{Palpation Meter Measurement}

Measurement will be taken on both sides. You will stand with your feet $30 \mathrm{~cm}$ apart and will look at a point ahead of you. You will stand with good posture and with both arms folded over your chest. The ASIS (front bony notch) and PSIS (back bony notch) of the pelvis will be found over your clothes and will be marked. The calipers of the PALM device will then be placed at these marked locations. The angle will be directly read from the inclinometer once the device is in place. The angle will measure pelvic tilt (position) and will be measured twice on each side.

Hip Range of Motion Goniometry

A goniometer will be used to measure the angle of your active hip range of motion. You will flex your hip (move leg forward) in a supine position (on back).

You will extend your hip (move leg backward) in a prone position (on stomach) with their legs off the table.

You will abduct your hip (move leg out to side) in a side lying position.

You will adduct your hip (move leg toward the body) in a standing position.

You will internally rotate your hip (rotate the hip joint in) in a short-seated position.

You will externally rotate your hip in (rotate the hip joint out) a short-seated position.

The angle will be measured twice for each of your legs.

\section{Risks and Discomforts}

There are no known or expected risks from participating in this study. A feeling of discomfort and soreness from completing the measurements may be felt and that this will be no more than what is felt when learning a new exercise or skill. 


\section{Alternatives}

You do not have to participate in this study. You may withdraw at any time with no penalty.

\section{Benefits}

This study may not help you, but the knowledge gained from this study may eventually benefit others by providing a preseason screening tool for sacroiliac joint dysfunction (injury to the joint where the tailbone meets the pelvis) and reducing risk of injury by starting prevention programs.

\section{Financial Considerations}

No payments will be made for participating in the study.

\section{Confidentiality}

Any information about you that is obtained as a result of your participation in this research will be kept as confidential as legally possible.

Your research records and test results, just like hospital records, may be subpoenaed by court order or may be inspected by the study sponsor or federal regulatory authorities without your additional consent.

In any publications that result from this research, neither your name nor any information from which you might be identified will be published without your consent.

\section{HIPAA}

We know that information about you and your health is private. We are dedicated to protecting the privacy of that information. Because of this promise, we must get your written authorization (permission) before we may use or disclose your protected health information or share it with others for research purposes.

You can decide to sign or not to sign this authorization section. However, if you choose not to sign this authorization, you will not be able to take part in the research study. Whatever choice you make about this research study will not have an effect on your access to athletic training/medical care at University High School.

\section{Persons/Organizations Providing the Information}

Soccer athlete on the University High School soccer teams/University High School injury reports.

\section{Persons/Organizations Receiving the Information}

- Health care providers who provide services to you as part of this research study: WVU, Michelle A. Sandrey, PhD, ATC, Brian Hanson, ATC, CES. The research site(s) carrying out this study includes WVU.

- The United State Department of Health and Human Services (which includes the National Institutes of Health (NIH), Food and Drug Administration (FDA)) and other groups that have the right to use the information as required by law. 
- The members and staff of any Institutional Review Board (IRB) that oversees this research study.

-West Virginia University Office of Research Integrity and Compliance and Office of Sponsored Programs.

\section{The Following Information Will Be Used}

Information from your existing medical records and new information about them that is created or collected during the study such as: history and physicals, demographic data, and study forms.

\section{The Information is Being Disclosed for the Following Reasons}

- Review of your data for quality assurance purposes

- Publication of study results (without identifying you)

- Other research purposes such as reviewing the effectiveness of the study screening tool in other populations; developing a better understanding of deficiencies that are related to sacroiliac joint dysfunction.

\section{You May Cancel this Authorization at Any Time by Writing to the Principal Investigator}

Michelle A. Sandrey (304) 293-0870 msandrey@ mail.wvu.edu

If you cancel this authorization, any information that was collected already for this study cannot be withdrawn. Once information is disclosed, according to this authorization, the recipient may redisclose it and then the information may no longer be protected by federal regulations.

You have a right to see and make copies of your medical records. You will not be able to see or copy your records related to the study until the co-PI has completed all work related to the study. At that time you may ask to see the study files related to your participation in the study and have the co-PI correct any information about you that is wrong.

This authorization will expire at the end of the study unless you cancel it before that.

\section{Voluntary Participation}

Participation in this study is voluntary. You are free to withdraw your consent to participate in this study at any time.

Refusal to participate or withdrawal will not affect your future care at University High School, and will involve no penalty to you. If an injury occurs during the study, Brian Hanson, ATC, CES will provide the necessary first aid and referral if necessary. I understand that there will be no cost to me for any study related injuries.

In the event new information becomes available that may affect your willingness to participate in this study, this information will be given to you so that you can make an informed decision about whether or not to continue your participation.

You have been given the opportunity to ask questions about the research, and you have received answers concerning areas you did not understand. 
Upon signing this form, you will receive a copy.

I willingly consent to participate in this research.

\section{Signatures}

Signature of Subject

Printed Name

Date

Time

The participant has had the opportunity to have questions addressed. The participant willingly agrees to be in the study.

Signature of Investigator or Co-Investigator

Printed Name

Date

Time 
Subject Number:

Age:

Height:

Weight:

Sex: (circle one) Male / Female

Year in School: (circle one) Freshman / Sophomore / Junior / Senior

How many years have you participated in soccer?

What was the highest level you competed in?

Are you currently participating in any athletics or performance training? Yes / No

If yes, please explain:

Injury History

*Injuries are considered ones that were evaluated by a physician, athletic trainer, or other health care professional

1. Have you had an upper extremity injury (shoulder, neck, upper back, arm) during the past soccer season? Yes / No

If yes, please explain and provide a month and year:

2. Have you ever had a lower extremity injury (hips, legs, ankle) during the past soccer season? Yes / No

If yes, please explain and provide a month and year:

3. Have you had a low back/SI joint injury during the past soccer season? Yes / No If yes, please explain and provide a month and year:

4. Have you had a head injury during the past soccer season? Yes / No If yes, please explain and provide a month and year:

5. Have you undergone any treatment/ rehabilitation for a low back injury during the past soccer season? Yes / No

If yes, please explain and provide a month and year:

6. Are you currently receiving any type of therapy or treatment for any of the above injures?

Yes / No

If yes, please explain and provide a month and year: 


\section{VERBAL INSTRUCTIONS FOR THE FUNCTIONAL MOVEMENT SCREEN}

The following is a script to use while administering the FMS. For consistency throughout all screens, this script should be used during each screen. The bold words represent what you should say to the client.

Please let me know if there is any pain while performing any of the following movements.

\section{DEEP SQUAT}

EQUIPMENT NEEDED: DOWEL, 2X6

\section{INSTRUCTIONS}

- Stand tall with your feet approximately shoulder width apart and toes pointing forward.

- Grasp the dowel in both hands and place it horizontally on top of your head so your shoulders and elbows are at 90 degrees.

- Press the dowel so that it is directly above your head.

- While maintaining an upright torso, and keeping your heels and the dowel in position, descend as deep as possible.

- Hold the descended position for a count of one, then return to the starting position.

- Do you understand the instructions?

Score the movement.

The client can perform the move up to three times total if necessary. If a score of three is not achieved, repeat above instructions using the 2 × 6 under the client's heels.

\section{HURDLE STEP}

\section{EQUIPMENT NEEDED: DOWEL, HURDLE}

\section{INSTRUCTIONS}

- Stand tall with your feet together and toes touching the test kit.

- Grasp the dowel with both hands and place it behind your neck and across the shoulders.

- While maintaining an upright posture, raise the right leg and step over the hurdle, making sure to raise the foot towards the shin and maintaining foot alignment with the ankle, knee and hip.

- Touch the floor with the heel and return to the starting position while maintaining foot alignment with the ankle, knee and hip.

- Do you understand these instructions?

Score the moving leg.

Repeat the test on the other side.

Repeat two times per side if necessary

INLINE LUNGE

EQUIPMENT NEEDED: DOWEL, 2X6 
INSTRUCTIONS

- Place the dowel along the spine so it touches the back of your head, your upper back and the middle of the buttocks.

- While grasping the dowel, your right hand should be against the back of your neck, and the left hand should be against your lower back.

- Step onto the $2 \times 6$ with a flat right foot and your toe on the zero mark.

- The left heel should be placed at mark. This is the tibial measurement marker.

- Both toes must be pointing forward, with feet flat.

- Maintaining an upright posture so the dowel stays in contact with your head, upper back and top of the buttocks, descend into a lunge position so the right knee touches the $2 \times 6$ behind your left heel.

- Return to the starting position.

- Do you understand these instructions?

Score the movement.

Repeat the test on the other side.

Repeat two times per side if necessary

\section{SHOULDER MOBILITY}

\section{EQUIPMENT NEEDED: RULER}

\section{INSTRUCTIONS}

- Stand tall with your feet together and arms hanging comfortably.

- Make a fist so your fingers are around your thumbs.

- In one motion, place the right fist overhead and down your back as far as possible while simultaneously taking your left fist up your back as far as possible.

- Do not "creep" your hands closer after their initial placement.

- Do you understand these instructions?

Measure the distance between the two closest points of each fist.

Score the movement.

Repeat the test on the other side.

\section{ACTIVE SCAPULAR STABILITY (SHOULDER CLEARING)}

\section{INSTRUCTIONS}

- Stand tall with your feet together and arms hanging comfortably. Place your right palm on the front of your left shoulder.

- While maintaining palm placement, raise your right elbow as high as possible.

- Do you feel any pain?

Repeat the test on the other side.

\section{ACTIVE STRAIGHT-LEG RAISE}

EQUIPMENT NEEDED: RULER, DOWEL, 2X6 


\section{INSTRUCTIONS}

- Lay flat with the back of your knees against the $2 \times 6$ with your toes pointing up.

- Place both arms next to your body with the palms facing up.

- Pull the toes of your right foot toward your shin.

- With the right leg remaining straight and the back of your left knee maintaining contact with the $2 \times 6$, raise your right foot as high as possible.

- Do you understand these instructions?

Score the movement.

Repeat the test on the other side.

\section{TRUNK STABILITY PUSH-UP}

\section{EQUIPMENT NEEDED: NONE}

\section{INSTRUCTIONS}

- Lie face down with your arms extended overhead and your hands shoulder width apart.

- Pull your thumbs down in line with the (forehead for men, chin for women).

- With your legs together, pull your toes toward the shins and lift your knees and elbows off the ground.

- While maintaining a rigid torso, push your body as one unit into a pushup position.

- Do you understand these instructions?

Score the movement.

Repeat two times if necessary.

Repeat the instructions with appropriate hand placement if necessary

\section{SPINAL EXTENSION CLEARING}

\section{INSTRUCTIONS}

- While lying on your stomach, place your hands, palms down, under your shoulders.

- With no lower body movement, press your chest off the surface as much as possible by straightening your elbows.

- Do you understand these instructions?

- Do you feel any pain?

\section{ROTARY STABILITY}

EQUIPMENT NEEDED: 2X6

\section{INSTRUCTIONS}

- Get on your hands and knees over the $2 \times 6$ so your hands are under your shoulders and your knees are under your hips.

- The thumbs, knees and toes must contact the sides of the $2 \times 6$, and the toes must be pulled toward the shins.

- At the same time, reach your right hand forward and right leg backward, like you are flying.

- Then without touching down, touch your right elbow to your right knee directly over the $2 \times 6$. 
- Return to the extended position.

- Return to the start position.

- Do you understand these instructions?

Score the movement.

Repeat the test on the other side.

If necessary, instruct the client to use a diagonal pattern of right arm and left leg.

Repeat the diagonal pattern with left arm and right leg.

Score the movement.

\section{SPINAL FLEXION CLEARING}

\section{INSTRUCTIONS}

- Get on all fours, and rock your hips toward your heels.

- Lower your chest to your knees, and reach your hands in front of your body as far as possible.

- Do you understand these instructions?

- Do you feel any pain? 
Table C6. Functional Movement Screen Scoring Procedures ${ }^{25}$

\section{FUNCTIONAL MOVEMENT SCREEN}

\section{Score Criteria}

\section{Deep Squat}

3

2

\section{Hurdle step (test right and left)*}

3

- Foot clears cord (does not touch) and remains dorsiflexed as leg is lifted over hurdle

- Hips, knees, and ankles remain aligned in the sagittal plane

- Minimal to no movement is noted in lumbar spine

- Dowel and hurdle remain parallel

2

- Alignment is lost between hips, knees, and ankles

- Movement is noted in lumbar spine

- Dowel and hurdle do not remain parallel

1

0

\section{ard,} the score is a 1

Pain during test

- Contact between foot and hurdle

- Loss of balance

- Pain during test

\section{Illustration}
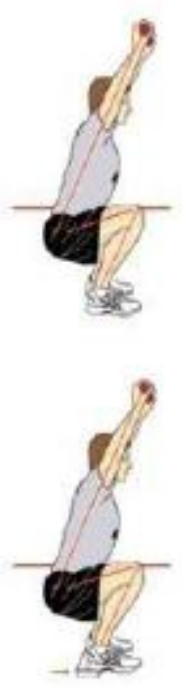

In-line Lunge (test right and left)*

3

- Knee touches board behind heel

- Dowel and feet remain in sagittal plane 
- Dowel contacts remain (head, thoracic spine, sacrum)

- Dowel remains vertical, no torso movement noted

- Knee does not touch behind heel

- Dowel and feet do not remain in sagittal plane

- Dowel contacts do not remain

- Dowel remains vertical

- Movement noted in torso

- Loss of balance

- Inability to achieve start position

- Inability to touch knee to board

- Pain during test

\section{Active Straight Leg Raise (test right and left)*}

3

2

- Malleolus of tested lower extremity located in the region between mid-thigh and anterior superior iliac spine of opposite lower extremity

- Opposite hip remains neutral (hip does not externally rotate), toes remain pointed up

- Opposite knee remains in contact with board

- Malleolus of tested lower extremity located in the region between mid-thigh and knee joint

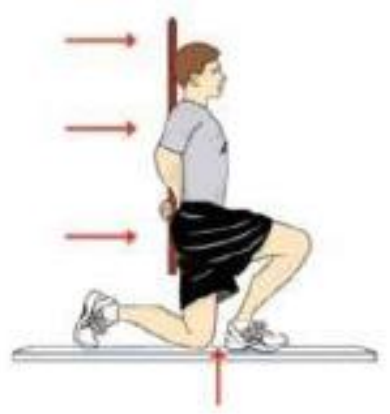
line of opposite lower extremity while other criteria are met

- Malleolus of tested lower extremity located in the region below knee joint line of opposite lower extremity, while other criteria are met

- Pain during test

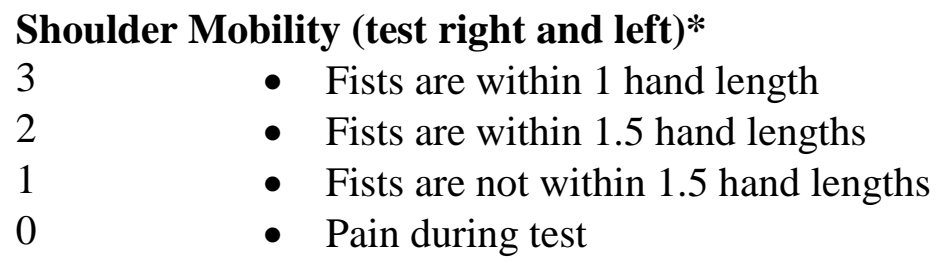

Shoulder Mobility Clearing Test 
If pain is noted as elbow is lifted, shoulder mobility is scored as 0

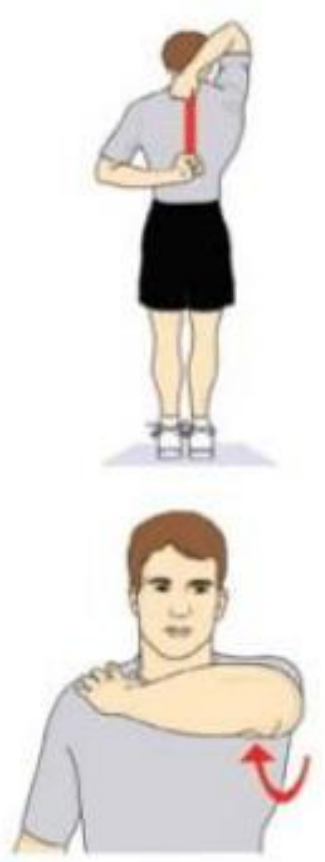

\section{Trunk Stability Push-Up}

3

2

1

0

\section{Extension Clearing Test}

If pain is noted during a prone press-up, push-up is scored as 0 .

- Perform 1 rep: thumbs are aligned with forehead for males and chin for females

- Body is lifted as 1 unit (no sag in lumbar spine)

- Perform 1 rep: thumbs are aligned with chin for males and clavicle for females

- Unable to perform 1 repetition with thumbs aligned with chin for males and clavicle for females

- Pain during test

\section{3}

Quadruped Rotary Stability (test right and left)*

- 1 unilateral repetition (lift arm and left from same side)

- Keep spine parallel to board

- Knee and elbow touch in line over the board and then return to the start position

2
- 1 unilateral repetition (lift arm and leg from opposite side)

- Keep spine parallel to board
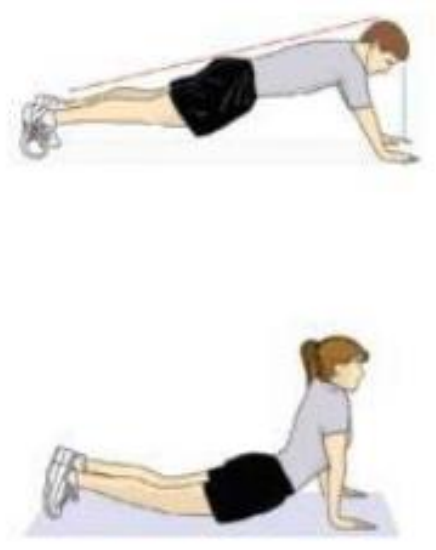
- Knee and elbow touch in line over the board and then return to the start position

1

0

- Inability to perform diagonal repetition

- Pain during test

\section{Flexion Clearing Test}

If pain is noted during quadruped flexion, rotary stability is scored a 0
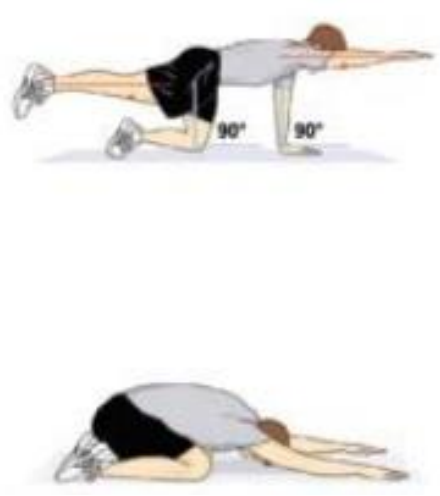

*Tests that are scored for both right and left sides, the lower score is used when calculating FMS composite scores. 
1. Subject will lay supine on the table.

2. The lower extremity not being tested will be secured to the table using a strap across the lower third of the thigh.

3. Subject will actively flex the hip that is being measured to 90 degrees.

4. Subject will then extend the leg at the knee as much as possible while keeping their foot in a relaxed position and hold for approximately five seconds.

5. An angle measurement will be taken by the use of a standard universal goniometer. The axis will be placed over the previously marked joint and the arms will be aligned along the femur and fibula.

6. Repeat test. Record measure then average the two.

7. Repeat on other leg.
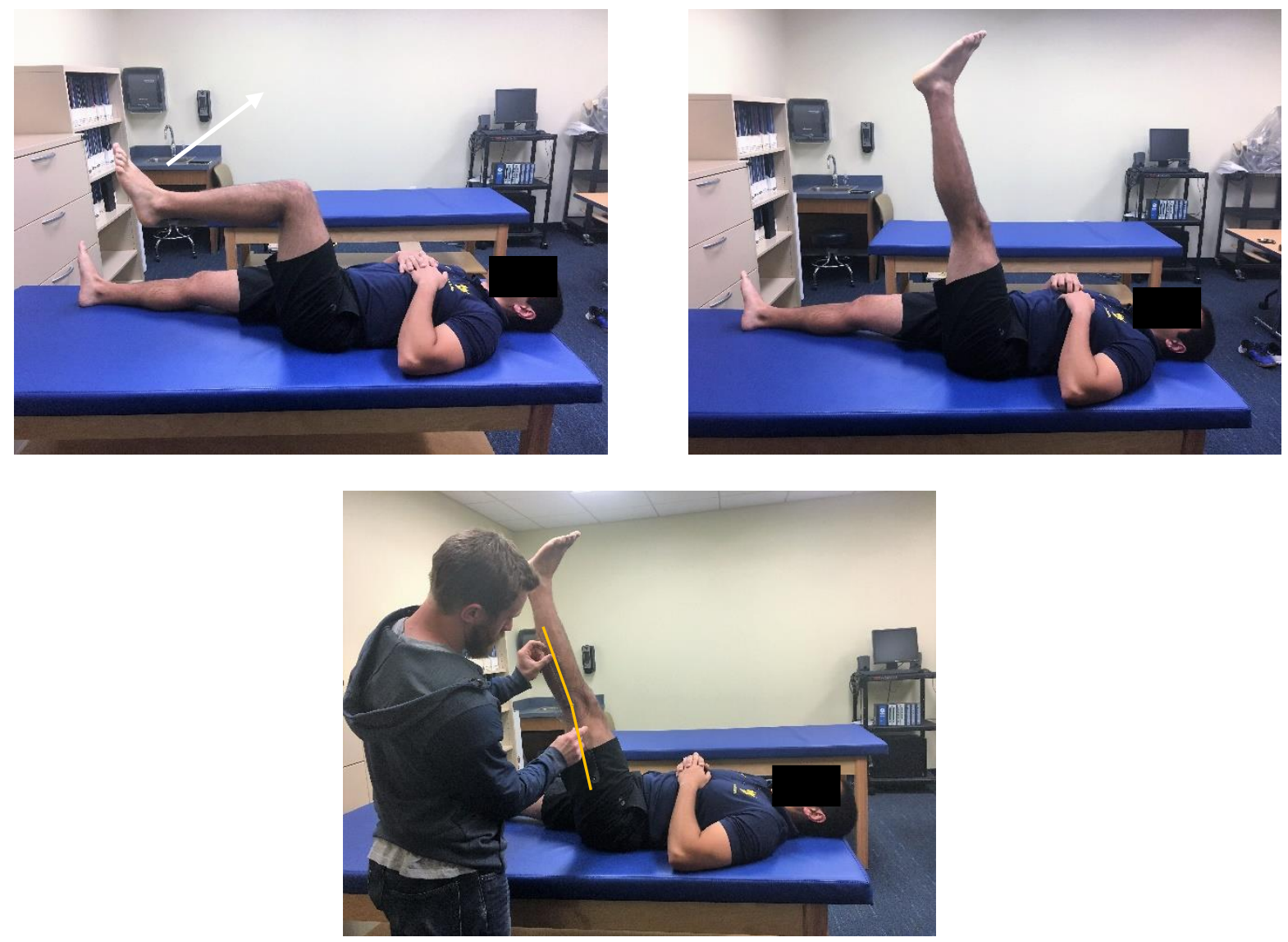


\section{Palpation Meter Pelvic Tilt}

1. Subjects will be in a standing position with the feet placed on marks on the floor that will be $30 \mathrm{~cm}$ apart.

2. Subjects will adopt an erect posture and keep the arms crossed over the chest.

3. The investigator will palpate for the ASIS (bony notch on front of hip) and PSIS (bony notch on back of hip) on each subject and mark them.

4. The palpation of the ASIS will be made by bringing the thumbs inferior to superior and marking the most prominent protrusion. The PSIS will be palpated by tracing the iliac crest posteriorly and then moving the thumbs superiorly and laterally from the sacrum edge to the most prominent protrusion.

5. The caliper tips will then be placed over the marked landmarks on the same side and will be compressed to a firm resistance.

6. The angle of inclination will be read form the inclinometer by the investigator and recorded.

7. Positive degrees will be used to describe anterior innominate tilts and negative degrees will be used to describe posterior innominate tilts.

8. Repeat test. Record measure then average the two.

9. Repeat test on other side of the pelvis.
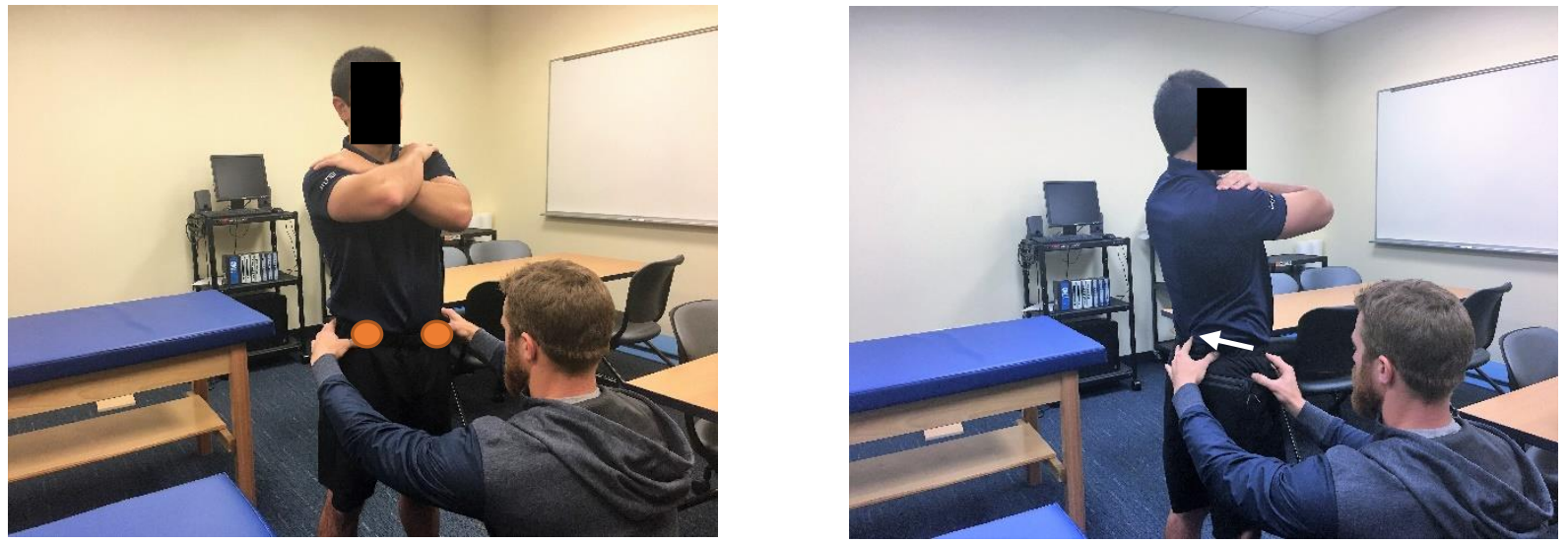

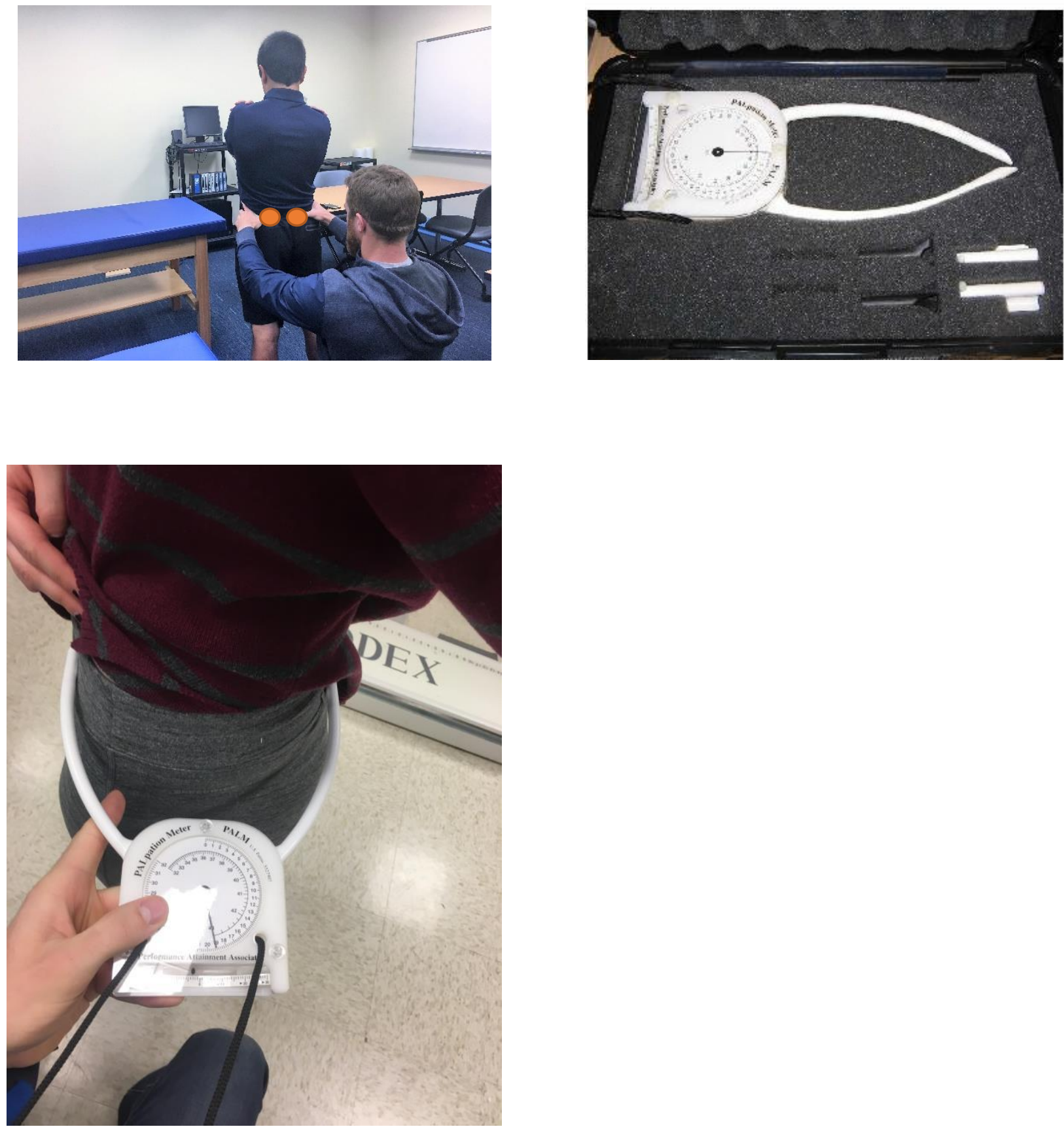


\section{Hip Flexion}

1. The subject will be lying supine.

2. Subject will then actively flex the tested hip as far as possible.

3. A standard universal goniometer will be used with the stationary arm aligned parallel to the table and the movement arm aligned to the femur.

4. Repeat test. Record measure then average the two

5. Repeat test for other leg.
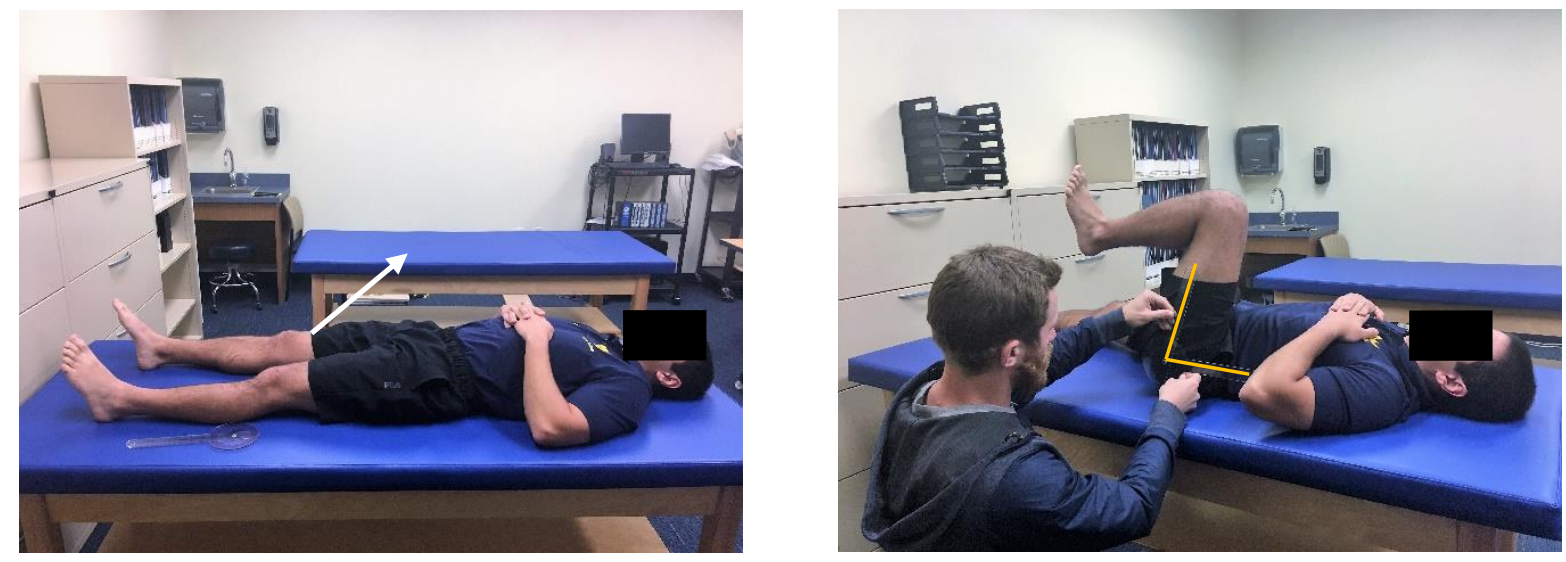

Hip Extension

1. The subject will be lying prone with the extremity extended beyond the table

2. Subject will then actively extend the tested hip as far as possible.

3. A standard universal goniometer will be used with the stationary arm aligned parallel to the table and the movement arm aligned to the femur.

4. Repeat test. Record measure then average the two.

5. Repeat test for other leg. 

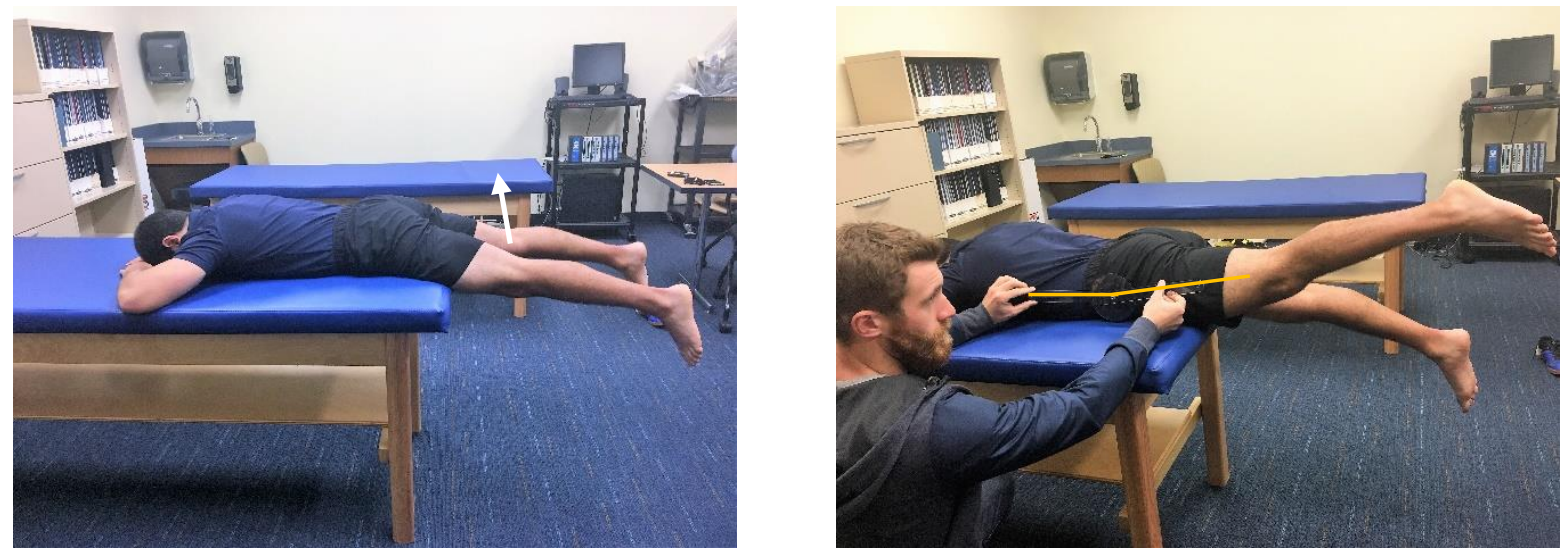

Hip Abduction

1. The subject will be side lying and measurement will be taken on the opposite extremity to the table.

2. Subject will then actively abduct the tested hip as far as possible.

3. A standard universal goniometer will be used with the stationary arm aligned parallel to the table and the movement arm aligned to the femur.

4. Repeat test. Record measure then average the two.

5. Repeat test for other leg.
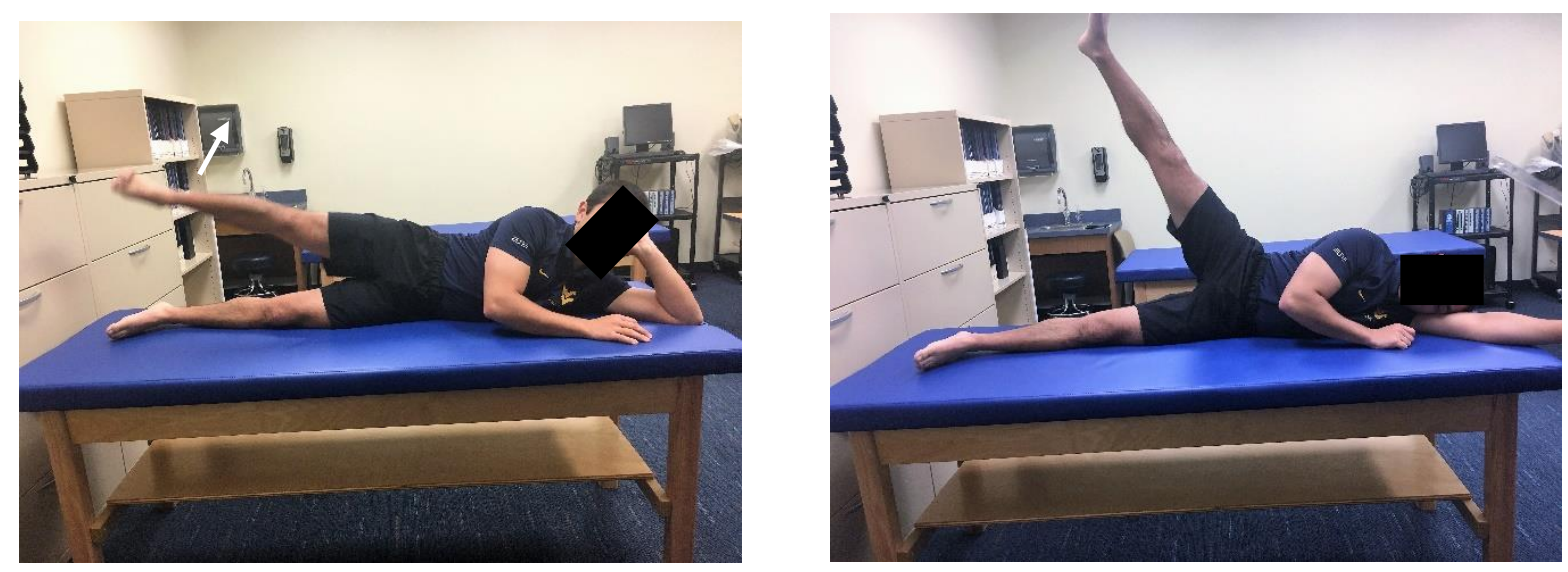

Hip Adduction

1. The subject will be standing. 
2. Subject will then actively adduct the tested hip as far as possible.

3. A standard universal goniometer will be used with the stationary arm aligned parallel to the torso and the movement arm aligned to the femur.

4. Repeat test. Record measure then average the two.

5. Repeat test for other leg.

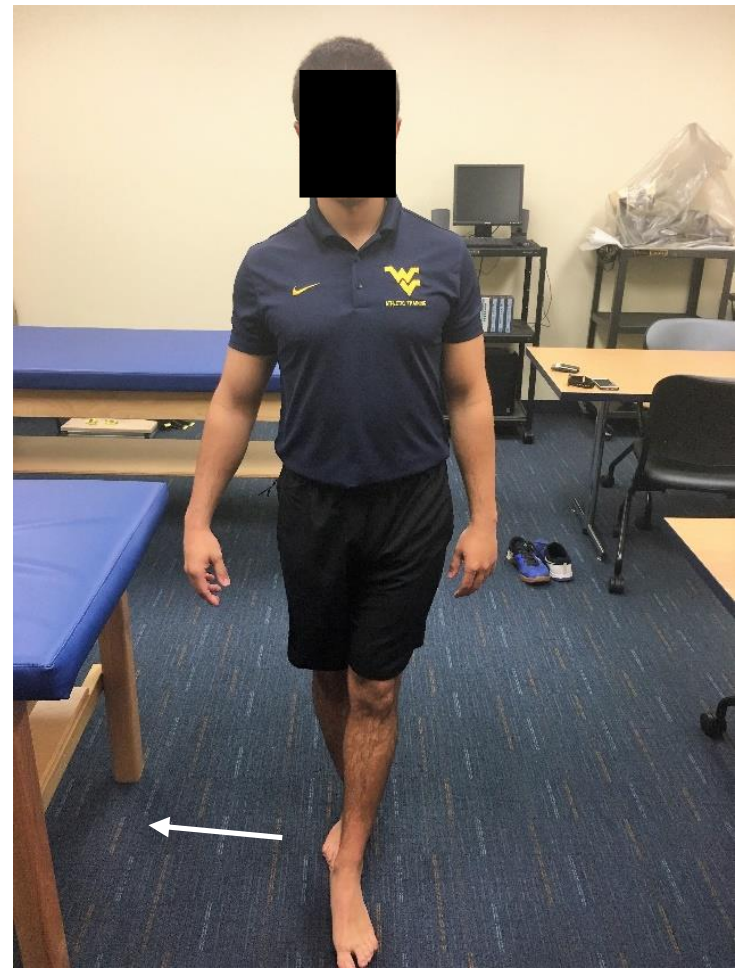

Internal Rotation

1. The subject will be short seated

2. Subject will actively internally rotate as far as possible.

3. A standard goniometer will be used with the stationary arm aligned parallel to the table and the movement arm aligned to the tibia.

4. Repeat test. Record measure then average the two.

5. Repeat test for other leg. 

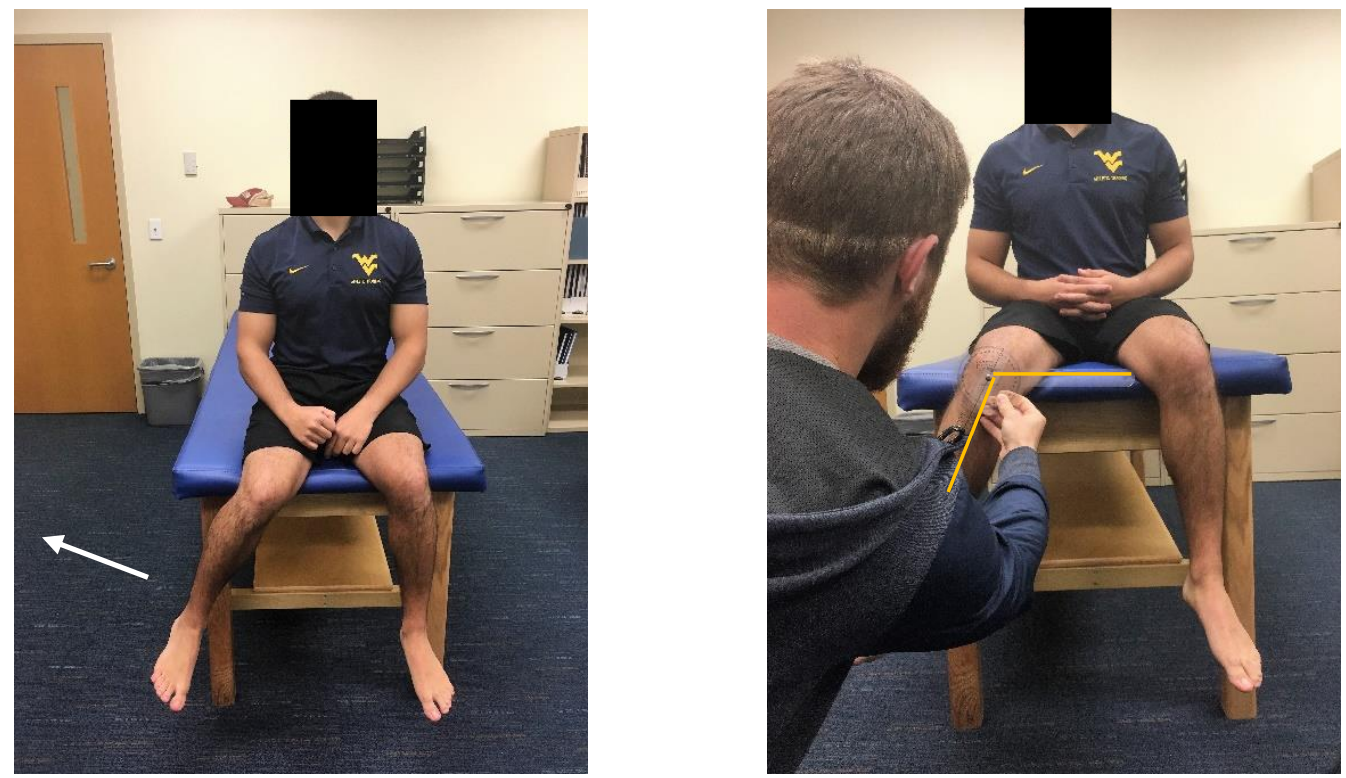

\section{External Rotation}

1. The subject will be short seated

2. Subject will actively externally rotate as far as possible.

3. A standard goniometer will be used with the stationary arm aligned parallel to the table and the movement arm aligned to the tibia.

4. Repeat test. Record measure then average the two.

5. Repeat test for other leg.
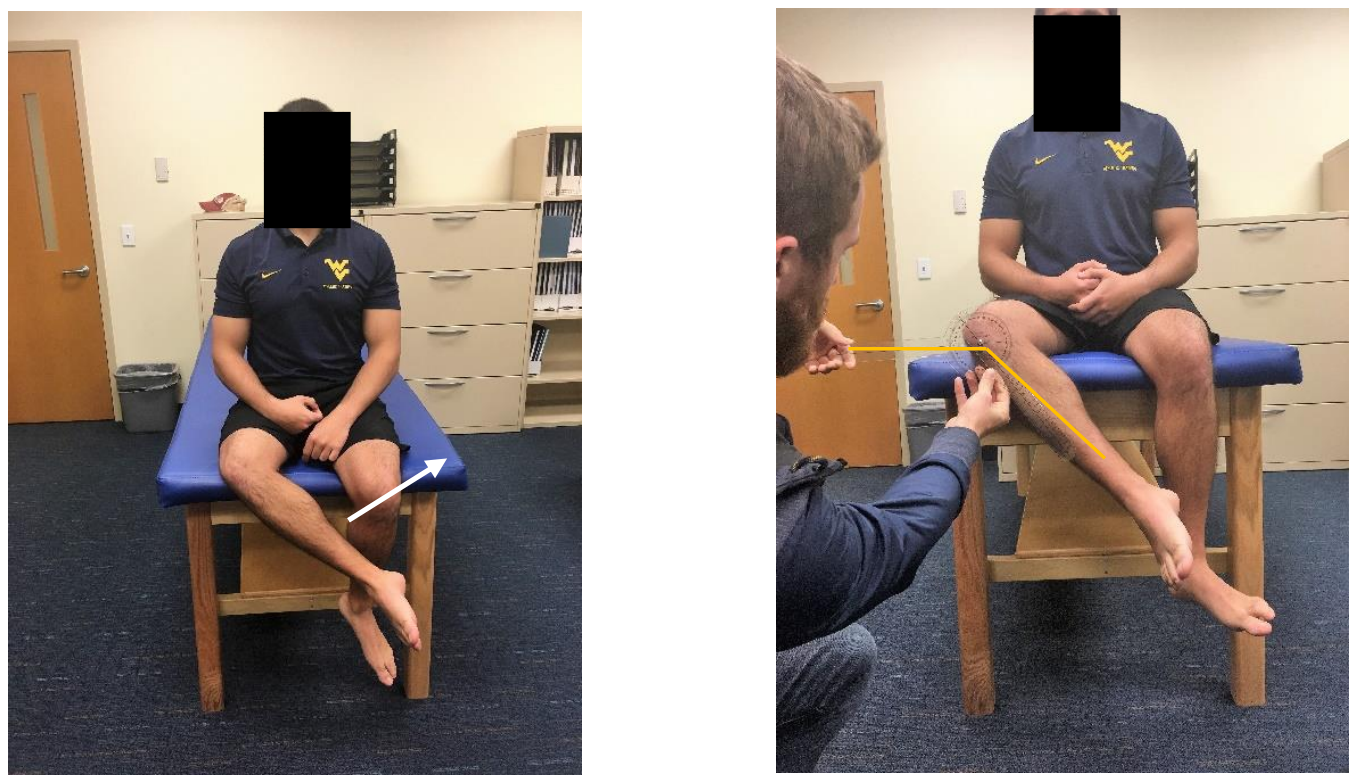
Table C10. Functional Movement Screen Scoring Sheet ${ }^{25}$

THE FUNCTIONAL MOVEMENT SCREEN

SCORING SHEET

Subject Number

Hand/Leg Dominance

Height

SOCCER

Position

Date

Sport SOCCER Position
UNIVERSITY HIGH SCHOOL Age Sex

\begin{tabular}{|l|l|l|l|l|l|l|}
\hline \multicolumn{2}{|c|}{ TEST } & \multicolumn{2}{c|}{ RAW SCORE } & \multicolumn{1}{|c|}{$\begin{array}{c}\text { FINAL } \\
\text { SCORE }\end{array}$} & \multirow{2}{*}{ COMMENTS } \\
\hline Deep Squat & L & & & & & \\
\hline & R & & & & & \\
\hline Inline Lunge & L & & & & & \\
\hline & R & & & & & \\
\hline Shoulder Mobility & L & & & & & \\
\hline & R & & & & & \\
\hline Impingement Clearing Test & L & & & & & \\
\hline & R & & & & & \\
\hline Active Straight Leg Raise & L & & & & & \\
\hline & R & & & & & \\
\hline Trunk Stability Push Up & & & & & & \\
\hline Press Up Clearing Test & & & & & & \\
\hline Rotary Stability & L & & & & & \\
\hline & R & & & & & \\
\hline $\begin{array}{l}\text { Posterior Rocking Clearing } \\
\text { Test }\end{array}$ & & & & & \\
\hline TOTAL & & & & & \\
\hline
\end{tabular}

RAW SCORE: This score is used to denote right and left side scoring. The right and left sides are scored in five of the seven tests and both are documented in this space.

FINAL SCORE: This score is used to denote the overall score for the test. The lowest score for the raw score (each side) is carried over to give a final score for the test. A person who scores a three on the right and a two on the left would receive a score of 2 . The final score is then summarized and uses a total score. 
Table C11. Data Collection Sheet

Hamstring Length/Pelvic Positioning/Hip Range of Motion

Subject Number

Date

Hamstring Length

Active Knee Extension Test

Right Leg

Left Leg

Pelvic Positioning

Thomas Test

Palpation Meter

Right Innominate Pelvic Angle

Trial One

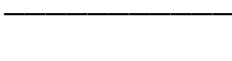

Trial One

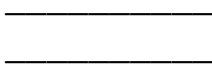

Hip Range of Motion

Goniometer Assessment

Right Hip Flexion

Right Hip Extension

Right Hip Abduction

Right Hip Adduction

Right Hip Internal Rotation

Right hip External Rotation

Left Hip Flexion

Left Hip Extension

Left Hip Abduction

Left Hip Adduction

Left Hip Internal Rotation

Left Hip External Rotation

Trial One

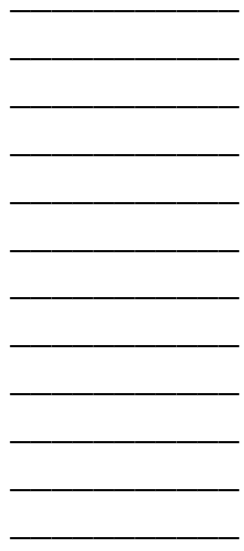

$\operatorname{Right}(+/$ - ) $\quad$ Left ( + / - )

Trial Two

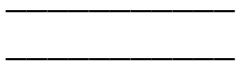

Average

Trial Two

Average
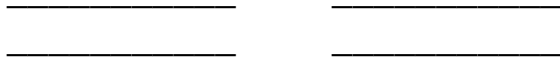

Trial Two

Average
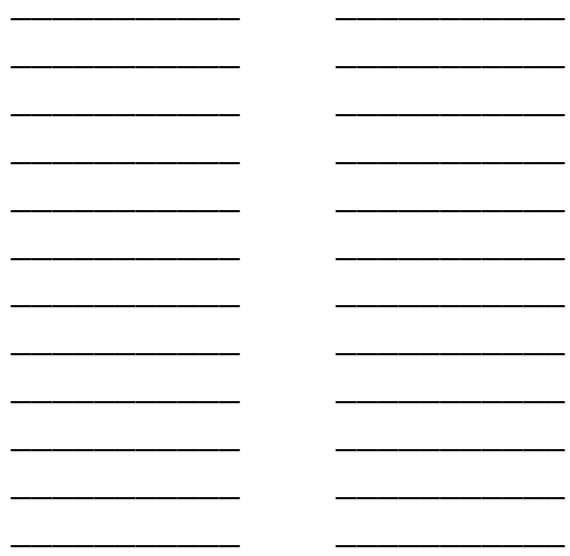


\section{APPENDIX D}

\section{ADDITIONAL RESULTS}

Table D1. Descriptive Statistics (Means \pm SD) for Subject Demographics

\begin{tabular}{cccc}
\hline Demographics & Male & Female & Combined \\
\hline $\mathrm{N}$ & 6 & 14 & 20 \\
Age & $16.33 \pm 1.37$ & $16.00 \pm 1.11$ & $16.10 \pm 1.17$ \\
Height $(\mathrm{cm})$ & $176.50 \pm 6.98$ & $165.93 \pm 6.39$ & $169.1 \pm 8.09$ \\
Weight $(\mathrm{kg})$ & $72.12 \pm 9.92$ & $61.11 \pm 6.92$ & $64.41 \pm 9.25$ \\
Years Playing Soccer & $7.50 \pm 5.01$ & $10.64 \pm 3.34$ & $9.70 \pm 4.05$ \\
Playing Soccer Year- & 4 & 10 & 14 \\
Round & 6 & 12 & 18 \\
Currently Active* & & &
\end{tabular}

Key: $*$ Soccer $=8$, Soccer and weight lifting $=5$, Weight lifting $=4$, Basketball $=1$

Table D2. Descriptive Statistics (Means \pm SD) for All Screening Variables

\begin{tabular}{|c|c|c|c|c|}
\hline Screening Variable & Male & Female & Combined & $\begin{array}{c}\text { Normative } \\
\text { Value }\end{array}$ \\
\hline FMS Comp Score & $18.67 \pm .82$ & $18.29 \pm 1.20$ & $18.4 \pm 1.10$ & $\geq 14^{34-39}$ \\
\hline AKET & $65.92 \pm 10.04$ & $72.16 \pm 11.13$ & $70.29 \pm 10.95$ & $\begin{array}{c}54.4(\mathrm{M})^{44} \\
62.9(\mathrm{~F})^{44}\end{array}$ \\
\hline PALM & $10.21 \pm 4.82$ & $11.43 \pm 3.63$ & $11.06 \pm 3.93$ & $\begin{array}{c}72.3-73.9^{45} \\
6.49(\mathrm{M})^{47} \\
6.78(\mathrm{~F})^{47}\end{array}$ \\
\hline HROM Flex & $126.63 \pm 7.59$ & $128.78 \pm 6.54$ & $128.14 \pm 6.74$ & $\begin{array}{l}113(\mathrm{M})^{52} \\
120(\mathrm{~F})^{52}\end{array}$ \\
\hline HROM Ext & $30.58 \pm 14.14$ & $32.61 \pm 9.81$ & $32.00 \pm 10.92$ & $\begin{array}{l}15(\mathrm{M})^{52} \\
22(\mathrm{~F})^{52}\end{array}$ \\
\hline HROM Abd & $67.88 \pm 10.58$ & $71.59 \pm 17.64$ & $70.48 \pm 15.67$ & $\begin{array}{c}34(\mathrm{M})^{52} \\
44(\mathrm{~F})^{52}\end{array}$ \\
\hline HROM Add & $40.04 \pm 6.68$ & $40.41 \pm 7.16$ & $40.3 \pm 6.85$ & $\begin{array}{l}14(\mathrm{M})^{52} \\
17(\mathrm{~F})^{52}\end{array}$ \\
\hline HROM IR & $43.58 \pm 10.11$ & $43.86 \pm 4.67$ & $43.78 \pm 6.47$ & $\begin{array}{l}35(\mathrm{M})^{52} \\
35(\mathrm{~F})^{52}\end{array}$ \\
\hline HROM ER & $37.25 \pm 4.76$ & $36.57 \pm 3.12$ & $36.78 \pm 3.57$ & $\begin{array}{l}40(\mathrm{M})^{52} \\
46(\mathrm{~F})^{52}\end{array}$ \\
\hline
\end{tabular}

Key: FMS Comp Score $=$ Functional Movement Screen Composite Score; AKET $=$ active knee extension test; PALM = palpation meter(pelvic tilt, Positive degrees = anterior tilt $)$; HROM Flex $=$ hip range of motion flexion; HROM Ext = hip range of motion extension; HROM Abd = hip range of motion abduction; HROM Add = hip range of motion adduction; HROM IR = hip range of motion internal rotation; HROM ER = hip range of motion external rotation; $\mathrm{M}=$ male $; \mathrm{F}=$ female 
Table D3. Descriptive Statistics (Means \pm SD) for Subject Demographics and SIJ Injury

\begin{tabular}{ccc}
\hline Demographics & With SIJ Injury & Without SIJ Injury \\
\hline Male & 5 & 15 \\
Female & 0 & 6 \\
Age & 5 & 9 \\
Height $(\mathrm{cm})$ & $16.00 \pm 1.41$ & $16.13 \pm 1.13$ \\
Weight $(\mathrm{kg})$ & $165.60 \pm 5.60$ & $170.27 \pm 8.61$ \\
Years Playing Soccer & $61.69 \pm 8.38$ & $65.32 \pm 9.62$ \\
Playing Soccer Year-Round & $11.80 \pm 2.77$ & $9.00 \pm 4.24$ \\
Currently Active & 4 & 10 \\
\hline
\end{tabular}

Key: ${ }^{\text {aSoccer }}=8$, Soccer and weight lifting $=5$, Weight lifting $=4$, Basketball $=1$

Table D4. Descriptive Statistics on Means and SD for Screening Variables and SIJ Injury

\begin{tabular}{cccc}
\hline Screening Variables & With SIJ Injury & Without SIJ Injury & Normative Value \\
\hline FMS Comp Score & $17.80 \pm 1.64$ & $18.6 \pm 0.83$ & $\geq 14^{34-39}$ \\
AKET & $68.80 \pm 9.96$ & $70.78 \pm 11.55$ & $54.4(\mathrm{M})^{44}$ \\
& & & $62.9(\mathrm{~F})^{44}$ \\
PALM & $12.35 \pm 2.18$ & $10.63 \pm 4.34$ & $72.3-73.9^{45}$ \\
& & & $6.49(\mathrm{M})^{47}$ \\
HROM Flex & $131.64 \pm 2.60$ & $126.97 \pm 7.34$ & $6.78(\mathrm{~F})^{47}$ \\
HROM Ext & $31.10 \pm 6.03$ & $32.30 \pm 12.29$ & $113(\mathrm{M})^{52}$ \\
& & & $120(\mathrm{~F})^{52}$ \\
HROM Abd & $84.90 \pm 12.49$ & $65.67 \pm 13.77$ & $22(\mathrm{M})^{52}$ \\
& & & $34(\mathrm{M})^{52}$ \\
HROM Add & $41.15 \pm 6.84$ & $40.02 \pm 7.07$ & $44(\mathrm{~F})^{52}$ \\
& $44.15 \pm 6.35$ & $43.65 \pm 6.73$ & $14(\mathrm{M})^{52}$ \\
HROM IR & $37.15 \pm 3.02$ & $36(\mathrm{~F})^{52}$ \\
HROM ER & & $35(\mathrm{~F})^{52}$ \\
& & & $40(\mathrm{M})^{52}$ \\
& & & $46(\mathrm{~F})^{52}$ \\
\hline
\end{tabular}

Key: FMS Comp Score = Functional Movement Screen Composite Score; AKET = active knee extension test; PALM = palpation meter(pelvic tilt, Positive degrees = anterior tilt); HROM Flex = hip range of motion flexion; HROM Ext = hip range of motion extension; HROM Abd = hip range of motion abduction; HROM Add = hip range of motion adduction; HROM IR = hip range of motion internal rotation; HROM ER = hip range of motion external rotation; $\mathrm{M}=$ male; $\mathrm{F}=$ female

Table D5. Pearson Product Correlations of Demographic Data to SIJ Injury

\begin{tabular}{llll}
\hline Variables & SIJ Injury & Years Playing Soccer & $\begin{array}{l}\text { Currently Participating in } \\
\text { Athletics }\end{array}$ \\
\hline SIJ Injury & 1 & & \\
Years Playing Soccer & $0.307 \mathrm{P}=.188$ & 1 & 1 \\
$\begin{array}{l}\text { Currently Participating in } \\
\text { Athletics }\end{array}$ & $-0.256 \mathrm{P}=.276$ & $-0.037 \mathrm{P}=.876$ & \\
\hline
\end{tabular}

Key: No significant correlations were found for demographic data 
Table D6. Pearson Product Correlations of Predictive Variables to SIJ Injury

\begin{tabular}{|c|c|c|c|c|c|c|c|c|c|c|}
\hline Variables & $\begin{array}{l}\text { SIJ } \\
\text { Injury }\end{array}$ & FMS & AKET & PALM & $\begin{array}{l}\text { HROM } \\
\text { Flex }\end{array}$ & $\begin{array}{l}\text { HROM } \\
\text { Ext }\end{array}$ & $\begin{array}{l}\text { HROM } \\
\text { Abd }\end{array}$ & $\begin{array}{l}\text { HROM } \\
\text { Add }\end{array}$ & $\begin{array}{l}\text { HROM } \\
\text { IR }\end{array}$ & $\begin{array}{l}\text { HROM } \\
\text { ER }\end{array}$ \\
\hline $\begin{array}{l}\text { SIJ } \\
\text { Injury }\end{array}$ & 1 & & & & & & & & & \\
\hline FMS & $\begin{array}{l}-0.324 \\
\mathrm{P}=.163\end{array}$ & 1 & & & & & & & & \\
\hline AKET & $\begin{array}{l}-0.80 \\
\mathrm{P}=.736\end{array}$ & $\begin{array}{l}-0.136 \\
\mathrm{P}=.567\end{array}$ & 1 & & & & & & & \\
\hline PALM & $\begin{array}{l}0.194 \\
\mathrm{P}=.413\end{array}$ & $\begin{array}{l}-0.211 \\
\mathrm{P}=.372\end{array}$ & $\begin{array}{l}0.370 \\
\mathrm{P}=.108\end{array}$ & 1 & & & & & & \\
\hline $\begin{array}{l}\text { HROM } \\
\text { Flex }\end{array}$ & $\begin{array}{l}0.380 \\
\mathrm{P}=.186\end{array}$ & $\begin{array}{l}-0.095 \\
\mathrm{P}=.690\end{array}$ & $\begin{array}{l}0.473^{*} \\
\mathrm{P}=.035\end{array}$ & $\begin{array}{l}0.303 \\
\mathrm{P}=.194\end{array}$ & 1 & & & & & \\
\hline $\begin{array}{l}\text { HROM } \\
\text { Ext }\end{array}$ & $\begin{array}{l}-0.049 \\
\mathrm{P}=.838\end{array}$ & $\begin{array}{l}-0.010 \\
\mathrm{P}=.967\end{array}$ & $\begin{array}{l}0.128 \\
\mathrm{P}=.590\end{array}$ & $\begin{array}{l}0.732^{* *} \\
\mathrm{P}<.01\end{array}$ & $\begin{array}{l}0.038 \\
\mathrm{P}=.875\end{array}$ & 1 & & & & \\
\hline $\begin{array}{l}\text { HROM } \\
\text { Abd }\end{array}$ & $\begin{array}{l}0.545^{*} \\
\mathrm{P}=.013\end{array}$ & $\begin{array}{l}0.218 \\
\mathrm{P}=.357\end{array}$ & $\begin{array}{l}0.190 \\
\mathrm{P}=.421\end{array}$ & $\begin{array}{l}0.119 \\
\mathrm{P}=.617\end{array}$ & $\begin{array}{l}0.359 \\
\mathrm{P}=.120\end{array}$ & $\begin{array}{l}0.118 \\
\mathrm{P}=.621\end{array}$ & 1 & & & \\
\hline $\begin{array}{l}\text { HROM } \\
\text { Add }\end{array}$ & $\begin{array}{l}0.074 \\
\mathrm{P}=.758\end{array}$ & $\begin{array}{l}0.027 \\
\mathrm{P}=.910\end{array}$ & $\begin{array}{l}0.238 \\
\mathrm{P}=.312\end{array}$ & $\begin{array}{l}-0.072 \\
\mathrm{P}=.764\end{array}$ & $\begin{array}{l}0.248 \\
\mathrm{P}=.291\end{array}$ & $\begin{array}{l}0.106 \\
P=.658\end{array}$ & $\begin{array}{l}0.352 \\
\mathrm{P}=.127\end{array}$ & 1 & & \\
\hline $\begin{array}{l}\text { HROM } \\
\text { IR }\end{array}$ & $\begin{array}{l}0.034 \\
\mathrm{P}=.886\end{array}$ & $\begin{array}{l}0.032 \\
\mathrm{P}=.894\end{array}$ & $\begin{array}{l}0.345 \\
\mathrm{P}=.137\end{array}$ & $\begin{array}{l}0.410 \\
\mathrm{P}=.073\end{array}$ & $\begin{array}{l}0.362 \\
\mathrm{P}=.117\end{array}$ & $\begin{array}{l}0.245 \\
\mathrm{P}=.298\end{array}$ & $\begin{array}{l}0.205 \\
\mathrm{P}=.385\end{array}$ & $\begin{array}{l}0.101 \\
\mathrm{P}=.673\end{array}$ & 1 & \\
\hline $\begin{array}{l}\text { HROM } \\
\text { ER }\end{array}$ & $\begin{array}{l}0.062 \\
P=.794\end{array}$ & $\begin{array}{l}0.155 \\
\mathrm{P}=.513\end{array}$ & $\begin{array}{l}0.244 \\
\mathrm{P}=.300\end{array}$ & $\begin{array}{l}-0.255 \\
\mathrm{P}=.278\end{array}$ & $\begin{array}{l}0.122 \\
P=.607\end{array}$ & $\begin{array}{l}-0.218 \\
\mathrm{P}=.356\end{array}$ & $\begin{array}{l}0.437 \\
\mathrm{P}=.054\end{array}$ & $\begin{array}{l}0.324 \\
\mathrm{P}=.163\end{array}$ & $\begin{array}{l}0.398 \\
\mathrm{P}=.062\end{array}$ & 1 \\
\hline
\end{tabular}

Key: FMS Comp Score $=$ Functional Movement Screen Composite Score; AKET = active knee extension test;

PALM = palpation meter(pelvic tilt, Positive degrees $=$ anterior tilt $)$; HROM Flex $=$ hip range of motion flexion; HROM Ext = hip range of motion extension; HROM Abd = hip range of motion abduction; HROM Add = hip range of motion adduction; HROM IR = hip range of motion internal rotation; HROM ER = hip range of motion external rotation; *Correlation is significant at .05 level (2-tailed); **Correlation is significant at .01 level (2-tailed)

Table D7. Crosstab of Lower Extremity (DS, IL, HS) Movements from the FMS

\begin{tabular}{lccc} 
& Movement Scored 2 & Movement Scored 3 & Total \\
\hline Deep Squat & - & - & - \\
SIJ injury occurred & 2 & 3 & 5 \\
No SIJ injury & 8 & 7 & 15 \\
Inline Lunge & - & - & - \\
SIJ injury occurred & 3 & 2 & 5 \\
No SIJ injury & 0 & 15 & 15 \\
Hurdle Step & - & - & - \\
SIJ injury occurred & 3 & 2 & 5 \\
No SIJ injury & 5 & 10 & 15 \\
\hline
\end{tabular}

Key: DS = deep squat; IL = inline lunge; HS = hurdle step; FMS = Functional Movement Screen. No subjects scored below a 2 out of 3 on these three lower extremity based movements. 
Table D8. Binary Logistic Regression Model for Screening Variables Associated with the Occurrence of a SIJ Injury

\begin{tabular}{|c|c|c|c|c|c|}
\hline Predictor Variable & Cox \& Snell R ${ }^{2}$ & Nagelkerke $\mathrm{R}^{2}$ & $\begin{array}{c}\text { Hosmer } \\
\text { Lemeshow } \\
\text { Test }^{\mathrm{a}}\end{array}$ & $\begin{array}{l}\text { Odds Ratio } \\
\text { (95\% } \\
\text { Confidence } \\
\text { Interval) }\end{array}$ & P Value \\
\hline $\mathrm{FMS}^{\mathrm{b}}$ & .095 & .140 & .697 & $\begin{array}{c}.505(.179, \\
1.435)\end{array}$ & .197 \\
\hline AKET & .006 & .009 & .691 & $\begin{array}{c}.983(.896, \\
1.079)\end{array}$ & .720 \\
\hline PALM & .040 & .059 & .199 & $\begin{array}{c}1.141(.841, \\
1.547)\end{array}$ & .397 \\
\hline HROM Flex & .104 & .154 & .285 & $\begin{array}{c}1.151(.932, \\
1.422)\end{array}$ & .192 \\
\hline HROM Ext & .002 & .004 & .571 & $\begin{array}{c}.990(.900, \\
1.087)\end{array}$ & .827 \\
\hline HROM Abd & .282 & .418 & .935 & $\begin{array}{c}1.115(1.003 \\
1.239)\end{array}$ & $.044^{*}$ \\
\hline HROM Add & .005 & .008 & .583 & $\begin{array}{c}1.025(.884 \\
1.188)\end{array}$ & .743 \\
\hline HROM IR & .001 & .002 & .673 & $\begin{array}{c}1.012(.866, \\
1.184)\end{array}$ & .878 \\
\hline HROM ER & .004 & .006 & .156 & $\begin{array}{c}1.043(.776, \\
1.402)\end{array}$ & .781 \\
\hline Years Playing ${ }^{\mathrm{b}}$ & .113 & .167 & .381 & $\begin{array}{c}1.319(.854 \\
2.036)\end{array}$ & .212 \\
\hline Currently Active & .059 & .088 & $<0.001$ & $\begin{array}{c}621336498.800 \\
(.000, .000)\end{array}$ & $>0.999$ \\
\hline
\end{tabular}

Key: aHosmer and Lemeshow Test must be insignificant in value for the regression model to be analyzed by SPSS. . ${ }^{b}$ Regression model correctly predicted one case for the FMS and Years playing variables. *Statistically significant finding

Table D9. Stepwise Binary Logistic Regression Model for Screening Variables Associated with SIJ Injury

\begin{tabular}{cccccc}
\hline Model Number & Cox \& Snell R $\mathrm{R}^{2}$ & Nagelkerke R & $\begin{array}{c}\text { Hosmer } \\
\text { Lemeshow Test }^{\mathrm{a}}\end{array}$ & $\begin{array}{c}\text { Odds Ratio } \\
(95 \% \\
\text { Confidence } \\
\text { Interval) }\end{array}$ & P Value \\
\hline 1: HROM Abd & .282 & .418 & .935 & $\begin{array}{c}1.115(1.003, \\
1.239)\end{array}$ & $.044^{*}$ \\
$\begin{array}{c}\text { 2: HROM Abd } \\
\text { and FMS }\end{array}$ & .426 & .631 & .873 & $\begin{array}{c}1.168(1.004, \\
1.359)\end{array}$ & $.045^{*}$ \\
\hline
\end{tabular}

Key: ${ }^{a}$ Hosmer and Lemeshow Test must be insignificant in value for the regression model to be analyzed my SPSS.

*Statistically significant finding. The interaction term between HROM Abd and FMS was not significant. 


\section{APPENDIX E}

\section{RECOMMENDATIONS FOR FUTURE RESEARCH}

1. Increase sample size to include more healthy controls as well as those who sustained SIJ injury by recruiting from multiple high schools to expand the data collection window.

2. Determine normative values for screening variables for the adolescent athletic population and compare those to the normative values established in the literature for the 18 years or older athletic population by increasing sample size.

3. Use other sport's teams such as football, basketball, and lacrosse to evaluate prevalence of SIJ by using a screening tool.

4. Conduct study with the adolescent recreational, adolescent club, and youth athlete populations within the region and may expand to the United States.

5. Conduct screening measurements utilized in this study (FMS, AKET, PALM, active HROM) before the beginning of season to control for post season / out of season training fatigue.

6. Analyze unilateral differences in AKET, pelvic tilt, and active HROM data collection compared to the side of SIJ injury.

7. Conduct study using other screening variables such as passive hip range of motion, muscle activity and symmetry (ie. max force production) using a handheld dynamometer, and ultrasound imaging for measuring hamstring muscle lengths.

8. Implement a preventative intervention program that includes lumbopelvic control, postural restoration, and transverse abdominis exercises over the duration of the season. 


\section{ADDITIONAL REFERENCES}

83. Walker J. The sacroiliac joint: a critical review. Phys Ther. 1992;72:903-16.

84. Cibulka MT, Rose SJ, Delitto A, Sinacore DR. Hamstring muscle strain treated by mobilizing the sacroiliac joint. Phys Ther. 1986;66(8):1220-3.

85. Boyle KL. Clinical application of the right sidelying respiratory left adductor pull back exercise. Int J Sports Phys Ther. 2013;8(3):349-58.

86. Chaudhari AM, Mckenzie CS, Borchers JR, Best TM. Lumbopelvic control and pitching performance of professional baseball pitchers. J Strength Cond Res. 2011;25(8):21272132.

87. Schwarzer AC, Aprill CN, Bogduk N. The sacroiliac joint in chronic low back pain. Spine. 1995;20(1):31-7.

88. Bray TJ, Vendhan K, Roberts J, et al. Association of the apparent diffusion coefficient with maturity in adolescent sacroiliac joints. J Magn Reson Imaging. 2016;44(3):556-64.

89. Bollow M, Braun J, Kannenberg J, et al. Normal morphology of sacroiliac joints in children: magnetic resonance studies related to age and sex. Skeletal Radiol. 1997;26(12):697-704.

90. Willard FH, Vleeming A, Schuenke MD, Danneels L, Schleip R. The thoracolumbar fascia: anatomy, function and clinical considerations. J Anat. 2012;221(6):507-36.

91. Barr KP, Griggs M, Cadby T. Lumbar stabilization: a review of core concepts and current literature, part 1. Am J Phys Med Rehabil. 2005;84(6):473-80.

92. Panjabi MM. The stabilizing system of the spine. Part I. Function dysfunction, adaptation, and enhancement. J Spinal Disord. 1992;5(4):383-389.

93. Panjabi MM. The stabilizing system of the spine. part II. neutral zone and instability hypothesis. J Spinal Disord. 1992;5(4):390-396.

94. Colachis SC, Worden RE, Bechtol CO, Strohm BR. Movements of the sacroiliac joint in the adult male. Arch Phys Med Rehabil. 1963;44:490-8.

95. Egund N, Olsson TH, Schmid H, et al. Movements in the sacroiliac joints demonstrated with roentgen stereophotogrammetry. Acta Radiol 1978;19:833-46.

96. Kellis E, Katis A. Biomechanical characteristics and determinants of instep soccer kick. $J$ Sports Sci Med. 2007;6(2):154-65.

97. Nunome H, Asai T, Ikegami Y, Sakurai S. Three dimensional kinetic analysis of side foot and instep soccer kicks. Med Sci Sports Exerc. 2002;34:2028-2036. 
98. Dorge H, Bull-Andersen T, Sorensen H, Simonsen E, Aagaard H, Dyhre Poulsen P, Klausen K. EMG activity of the iliopsoas muscle and leg kinetics during the soccer place kick. Scand J Med Sci Sports. 1999;9:155-200.

99. Schmidt-Olsen S, Jørgensen U, Kaalund S, Sørensen J. Injuries among young soccer players. Am J Sports Med. 1991;19(3):273-5.

100. Choi HS, Shin WS. Validity of the lower extremity functional movement screen in patients with chronic ankle instability. J Phys Ther Sci. 2015;27(6):1923-7.

101. Koehle MS, Saffer BY, Sinnen NM, Macinnis MJ. Factor structure and internal validity of the Functional Movement Screen in adults. J Strength Cond Res. 2016;30(2):540-6.

102. Cook EG, Burton L, Hoogenboom BJ. Pre-participation screening: The use of fundamental movements as an assessment of function-Part 2. N AM J Sports Phys Ther. 2006;1(3):132139.

103. Cook EG, Burton L, Hoogenboom BJ. Functional movement screeing: The use of fundamental movements as an assessment of function-Part 2. Int J Sports Phys Ther. 2014;9(4):549-562.

104. Teyhen DS, Shaffer SW, Lorenson CL, Halfpap JP, Donofry DF, Walker MJ, Dugan JL, Childs JD. The functional movement screen: a reliability study. J Orthop Sports Phys Ther. 2012;42(6):530-540.

105. Onate JA, Dewey T, Kollock RO, et al. Real-time intersession and interrater reliability of the functional movement screen. J Strength Cond Res. 2012;26(2):408-415.

106. Gulgin H, Hoogenboom B. The functional movement screening (FMS): an inter-rater reliability study between raters of varied experience. Int J Sports Phys Ther. 2014;9(1):1420 .

107. Smith LJ, Creps JR, Bean R, Rodda B, Alsalaheen B. Performance of high school male athletes on the Functional Movement Screen ${ }^{\mathrm{TM}}$. Phys Ther Sport. 2017;27:17-23.

108. Bierma-Zeinstra SM, Van gool JJ, Bernsen RM, Njoo KH. Measuring the sacral inclination angle in clinical practice: is there an alternative to radiographs. J Manipulative Physiol Ther. 2001;24(8):505-8.

109. Chaudhari AM, Mckenzie CS, Pan X, Oñate JA. Lumbopelvic control and days missed because of injury in professional baseball pitchers. Am J Sports Med. 2014;42(11):273440 . 
110. Yedimenko J, Jamison ST, McNally MP, McKenzie CS, Onate JA, Chaudhari, AM. Intraand inter-rater reliability of a single-leg raise test of pelvic sagittal control. Paper presented at: American College of Sports Medicine Annual Meeting; May 29, 2013; Indianapolis, IN

111. Charlton PC, Mentiplay BF, Pua YH, Clark RA. Reliability and concurrent validity of a Smartphone, bubble inclinometer and motion analysis system for measurement of hip joint range of motion. J Sci Med Sport. 2015;18(3):262-7. 